Florida International University FIU Digital Commons

$11-15-2010$

\title{
Immigrant High School Students's In-depth Understanding of the Value of Heritage Language and Bilingualism
}

Edwin D. Arrieta

Florida International University, edwinarrieta9@yahoo.com

DOI: $10.25148 /$ etd.FI11050310

Follow this and additional works at: https://digitalcommons.fiu.edu/etd

\section{Recommended Citation}

Arrieta, Edwin D., "Immigrant High School Students's In-depth Understanding of the Value of Heritage Language and Bilingualism" (2010). FIU Electronic Theses and Dissertations. 376.

https://digitalcommons.fiu.edu/etd/376 


\title{
FLORIDA INTERNATIONAL UNIVERSITY
}

Miami, Florida

\section{IMMIGRANT HIGH SCHOOL STUDENTS’ IN-DEPTH UNDERSTANDINGS OF THE VALUE OF HERITAGE LANGUAGE AND BILINGUALISM}

\author{
A dissertation submitted in partial fulfillment of the \\ requirements for the degree of \\ DOCTOR IN EDUCATION
}

in

CURRICULUM AND INSTRUCTION

by

Edwin David Arrieta

2011 
To: Dean Delia C. García

College of Education

This dissertation, written by Edwin David Arrieta, and entitled Immigrant High School Students' In-depth Understandings of the Value of Heritage Language and Bilingualism, having been approved in respect to style and intellectual content, is referred to you for judgment.

We have read this dissertation and recommend that it be approved.

Benjamin Baez

Mohammed Farouk

Hilary Landorf

Eric Dwyer, Major Professor

Date of Defense: November 15, 2010

The dissertation of Edwin David Arrieta is approved.

Dean Delia C. García

College of Education

Interim Dean Kevin O’Shea

University Graduate School

Florida International University, 2011 


\section{DEDICATION}

Dedico este esfuerzo de muchos años a mi hermano Jesús, a quien extraño intensamente. Siempre celebramos nuestros triunfos juntos, y esa tradición que siempre ha existido, la llevare siempre en mi corazón. Tus gozos y alegrías, también eran las mías. Siempre estarás en mi corazón y en mi mente. Hubiese deseado que estuvieses aquí para celebrar juntos, pero lo celebraré con tus hijos, quienes reflejarán siempre parte de ti. En ellos me refugio para tenerte cerca y saber que te ríes y celebras con todos nosotros.

Muchos sacrificios hemos tomado en la vida para estar cada uno en esta realidad, sin embargo querido hermano si alguna recompensa de Dios he de tener, la comparto con tus hijos quienes reciben el fruto de todas las semillas que tu sembraste en la vida. Que Jehová, quien tiene piedad y gran amor por todos nosotros, bendiga todos lo que hiciste en esta tierra.

Aunque he pasado mucho tiempo en las aulas...las mejores enseñanzas vinieron de ti querido hermano....amar intensamente a los que están a tu alrededor. Hay que disfrutar intensamente y vivir cada día como si fuera el último día de nuestro existir. Te llevo siempre en mi corazón. 


\section{ACKNOWLEDGMENTS}

I wish to express my sincere gratitude to the entire committee, Dr. Mohammed

Farouk, Dr. Benjamin Baez, Dr. Hilary Landorf, and Dr. Eric Dwyer. My deepest appreciation is extended to my major professor, Dr. Eric Dwyer, for his guidance, patience and encouragement throughout the years.

I also want to express a special thank you to all the faculty and staff from the College of Education for their commitment to help students achieve their academic aspirations. I also would like to extend my gratitude and recognition to Dr. Barbetta and all of the wonderful staff from the Office of Graduate Studies. 
ABSTRACT OF THE DISSERTATION

IMMIGRANT HIGH SCHOOL STUDENTS’ IN-DEPTH UNDERSTANDINGS OF

\author{
HERITAGE LANGUAGE AND BILINGUALISM
}

by

Edwin David Arrieta

Florida International University, 2011

Miami, Florida

Professor Eric Dwyer, Major Professor

The purpose of this research was to explore perceptions among $9^{\text {th }}$ through $12^{\text {th }}$ grade students from Brazil, Haiti and Jamaica, with respect to their heritage languages: Portuguese, Haitian Creole, and Jamaican Patois. An additional purpose was to understand in greater detail possible variations of perception with respect to heritage language maintenance (or loss) in relation to one's gender, first language, and place of birth. The research implemented semi-structured interviews with male and female adolescents with these heritage language backgrounds. Participants' responses were recorded and transcribed. The transcriptions were analyzed via a categorizing of themes emerging from the data.

Data were analyzed using inductive analysis. Three categories emerged from the inductive analysis of the data: (a) heritage language, (b) bilingualism, and (c) English as a second language. The analysis reveals that as participants learn English, they continue to 
value their heritage language and feel positively toward bilingualism, but differ in their preference regarding use of native language and English in a variety of contexts. There seems to be a mismatch between a positive attitude and an interest in learning their heritage language. Families and teachers, as agents, may not be helping students fully understand the advantages of bilingualism. Students seem to have a lack of understanding of bilingualism's cognitive and bi-literacy benefits. Instead, employment seems to be perceived as the number one reason for becoming bilingual. Also, the students have a desire to add culture to the heritage language curriculum.

The study was conducted at one of the most diverse and largest high schools in Palm Beach, in Palm Beach County, Florida. The results of this study imply that given the positive attitude toward heritage language and bilingualism, students need to be guided in exploring their understanding of heritage language and bilingualism. Implications for teaching and learning, as well as recommendations for further research, are included. 


\section{TABLE OF CONTENTS}

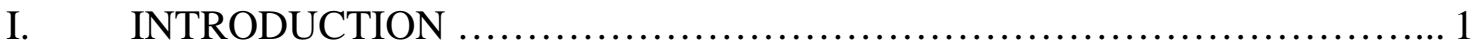

Factors Affecting Heritage Language Maintenance.............................. 4

Advantages of Bilingualism and Heritage Language Maintenance................6

Impediments to Bilingualism........................................... 7

Statement of the Research Problem.......................................... 7

Theoretical Framework..................................................... 8

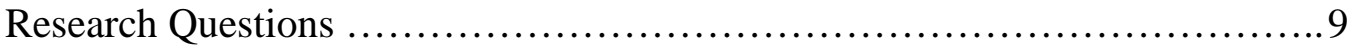

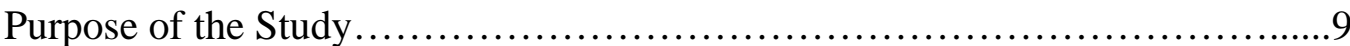

Definitions and Terms ........................................................ 10

Significance to Theory and Practice........................................ 13

Assumptions........................................................... 14

Delimitations of the Study................................................... 14

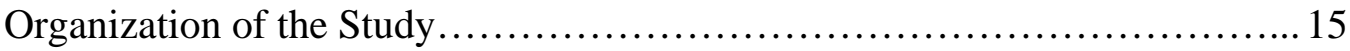

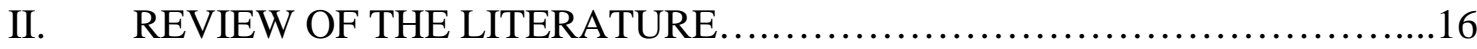

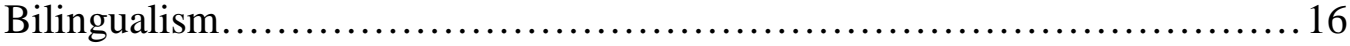

Additive Bilingualism ............................................... 18

Promoting Heritage Language and Bilingualism ............................19

Maintenance and Attrition of Heritage Language..............................22

Language Maintenance..................................................... 23

Possible Factors of Policy Contributing to Heritage Language Attrition..........24

Attrition................................................................. 29

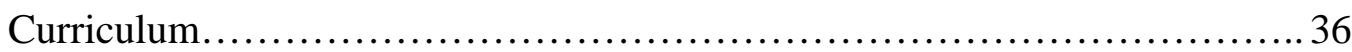

High School Students and Heritage Language .................................37

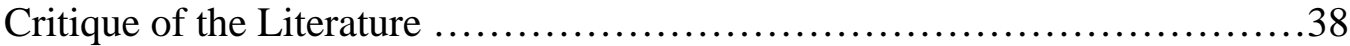

III. METHODS ................................................................ 41

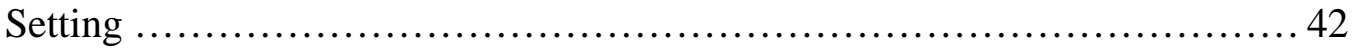

Methodological Approach ............................................. 45

Coding Data............................................................... 48

Data Analysis............................................................... 49

Participant Selection .................................................. 51

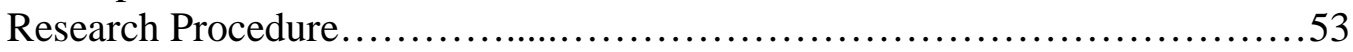

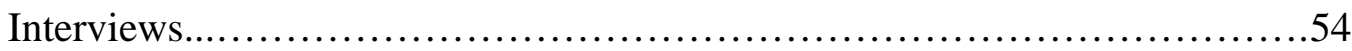

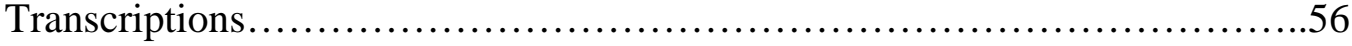

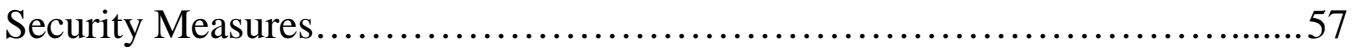

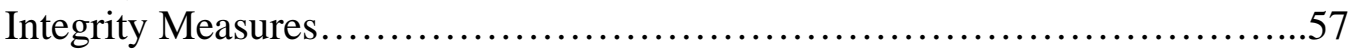

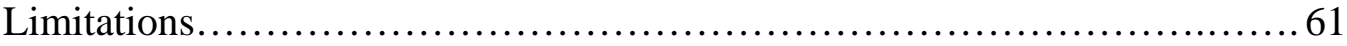


Researcher's Role..................................................... 62

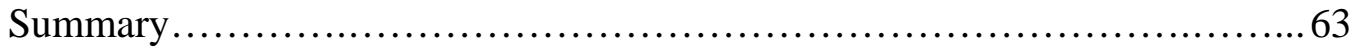

IV. ANALYSIS OF DATA..............................................65

Answers to Research Questions..........................................65

Inductive Analysis................................................... 66

Country Comparison.................................................... 71

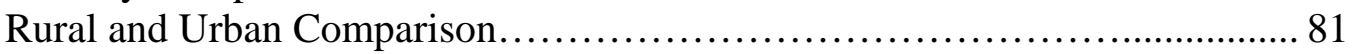

Further Analysis........................................................83

Summary............................................................... 103

V. CONCLUSIONS AND DISCUSSION ....................................

Findings.......................................................106

A Reconsideration of the Meaning of Heritage Language Learner..............111

Implications of the Findings......................................... 114

Heritage Language and Future Considerations............................117

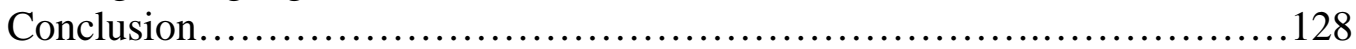

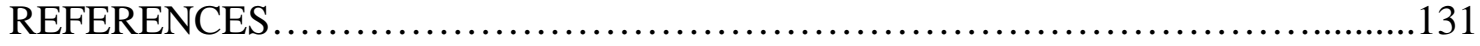

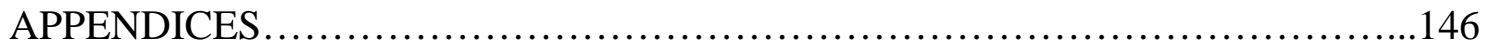

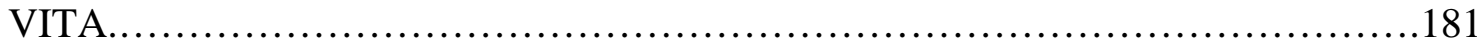




\section{CHAPTER I \\ INTRODUCTION}

The United States has always been a multilingual society, in which thousands of people from Latin America, Southeast Asia, Eastern Europe and other non-English speaking countries have been [constantly migrating]” (Carrasquillo \& Rodriguez, 2002, p. 2). However, most children will lose their predecessors' heritage language within three generations of their family's arrival in the country (Hinton, 1999; Wiley \& Valdes, 2001). Immigrants often offer overt statements regarding the necessity of learning English and their desire to utilize "the wealth of information, culture, and resources with[in] them" (Pappamihiel, 2003, p. 2). New residents along with citizens born in the United States also seem interested in maintaining their heritage language (Hae-Young, 2003; Veltman, 1990) and report a positive disposition toward their heritage language (Veltman, 1990). In fact, many immigrants and new residents maintain their heritage language and interact with relatives and friends who use that language at home (Hinton, 1999; Wiley \& Valdes, 2001).

Currently, learning English seems to be a national priority, although there is also recent impetus for students to maintain or develop their heritage language. As a consequence, many educators are now recognizing that fluency in English and a heritage language, at academically advanced proficiencies, can be advantageous for the student and the nation (Cummins, 2005; Hakuta et al., 2000; Krashen, 1996; Thomas \& Collier, 1997). 
In fact, many legal decisions have been favorable toward bilingualism. ${ }^{1}$ In the cases of Lau vs. Nichols and Plyler vs. Doe, the United States Supreme Court held that all children merit access to school content regardless of their language background or immigration status (Banks \& McGee, 2006; Epstein, 2001). These decisions imply a compliance factor as well as a perspective in which students are no longer forced to disconnect from their cultural and linguistic communities (Crawford, 1996) as previously established by policies that were imposed at the beginning of the $20^{\text {th }}$ century.

This study similarly applies Lewis (1980), Omaggio-Hadley (1993), and Carrasquillo and Rodriguez's (2002) concept of an additive approach to education in which students build upon any language they bring into the classroom. Here, immigrant heritage language students optimally work through their education in one dominant language —in this case, English — without risking the loss of their heritage language. For example, a member of a Mayan community outside of Guatemala, may be considered a heritage language learner should they be studying and acquiring their heritage language.

It is important to note the complexities of language and how these complexities intertwine with the heritage language. In the case of the students from Jamaica, it is important to recognize that students reflect a more complex linguistic representation from a variation of their languages. Throughout this study, the term Jamaican Patois will be used, a term often popularly implemented by Jamaicans when referring to the language spoken by the low social class in Jamaica (Pryce, 1997). Nevertheless, this study also recognizes the terms Jamaica Creole, which some linguists use

\footnotetext{
${ }^{1}$ Grosjean (1989) defines bilingualism as a person with communicative skills in two or more languages in daily life. Throughout this dissertation, the term bilingual will be used; however, such does not imply a limitation of two languages. For example, students who speak Haitian-Creole and French may also be engaging in a form of bilingualism in the addition of a third language, English.
} 
interchangeably with Patois (Pryce, 1997), and Jamaican Standard English, which refers to a dialect used more in academic settings (Alleyne, 1989). This study also recognizes that students are not necessarily choosing either version of the language, using rather a mixture of both versions (Shields, 1989).

In such cases all learners are part of the community and are heritage language learners regardless of their proficiency level and mastery of that language (Fishman, 2001; McCarty, 2002). In addition, students who come from homes where they have had some exposure to the language are also considered heritage language learners. In general, a heritage language student is a person studying a language to which that student has a cultural connection. Valdes (2001) defines heritage language as a language learned at home that is different from the dominant language of the new or hosting community.

A principal challenge of this study was to understand the extent to which any additive approach may foster a student's re-affirmation (or lack thereof) of both the dominant language and the heritage language. An additional goal of this study was to understand how to merge the dominant and heritage languages into an emerging bilingualism.

According to Valdés (2001), bilingualism is the ability to communicate effectively in two languages with similar degrees of proficiency in both languages. Contrastively, Wong-Fillmore (1991) indicates that language attrition occurs when people of the language minority shift to the dominant language and, at the same time, replace and lose their heritage language.

This study examines these tethered phenomena — bilingualism, heritage language maintenance, and attrition - with respect to language use in immigrant high school 
students. High school students were asked about their in-depth understanding of their heritage language to determine to what extent they believe they are maintaining or desire maintaining their heritage language. The purpose of this study was to examine what students think about heritage language. This study was limited to immigrant high school students primarily because heritage language studies have focused on elementary school students, and research reports that as age increases, heritage language decreases.

\section{Factors Affecting Heritage Language Maintenance}

In reviewing contributing factors with respect to heritage language maintenance, gender, place of birth and residence seem to be determining factors in people’s in-depth understanding of their heritage language. Dewaele (2005) concluded that "[gender] was significantly linked to attitudes toward [heritage language], with female participants being much more positive than male participants” (p. 128). Potowski (2004) similarly revealed that immigrant females used $18.5 \%$ more Spanish than males, regardless of the variety of language used. Veltman (1990) also indicated that Hispanic immigrant women were more likely than Hispanic immigrant men to remain Spanish monolinguals.

In reviewing contributing factors with respect to heritage language maintenance, gender, place of birth, and residence seem to be determining factors in people's in-depth understanding towards their heritage language. Dewaele (2005) concluded that "[gender] was significantly linked to attitudes toward [heritage language], with female participants being much more positive than male participants” (p. 128). Potowski (2004) similarly revealed that immigrant females used 18.5\% more Spanish than males, regardless of the 
variety of language used. Veltman (1990) also indicated that Hispanic immigrant women were more likely than Hispanic immigrant men to remain Spanish monolinguals.

The location of one's residence also appears to be a contributing factor in heritage language maintenance and attrition. Dewaele (2005) indicated that students living in rural areas are less likely to maintain their heritage language as compared to those living in urban areas, suggesting that, partly because of the size of enclaves of speakers who support heritage language maintenance, students may encounter fewer opportunities to engage in the heritage language, thus depleting their disposition toward maintaining that language. Indeed, Ramirez (2000) found that Hispanic high school students living in urban areas in Miami and Los Angeles demonstrated different dispositions toward heritage language, and exhibited a tendency to value Spanish more than students living in rural areas.

Additionally, there may be a relationship between place of birth and the perception of heritage language. In a pilot study of $9^{\text {th }}$ through $12^{\text {th }}$ grade students in South Florida, Arrieta and Dwyer (2003) found inconsistencies—both positive and negative-in students' in-depth understanding of their heritage language. In that study, males and females reported different in-depth understanding, depending on where they were born. For example, the responses of female adolescents from South America were more favorable toward heritage language when compared to the responses of the female adolescents from Central America. 


\section{Advantages of Bilingualism and Heritage Language Maintenance}

By promoting self-identity, self-esteem, and self confidence, bilingualism promotes cognitive abilities, increases academic achievements, and assists students in becoming more employable in the job market (Bialystock, 2001; Diaz, 1983; Peal \& Lambert, 1962). For example, bilingual students try to solve problems in one language but are able to switch to the other if needed. Mouw and Xie (1999) concluded that bilingual students have an advantage because they possess two codes for each concept, leading to greater cognitive flexibility and abstract reasoning. Furthermore, research reveals that bilingualism has a positive effect on children's academic achievement because the student may feel positive about their desired linguistic identity, as expressed by Bourdieu (1997). These reports support the premise that bilingual students posses a social advantage in a world where the majority of the population is multilingual, including the job market. Additionally, the bilingual student contributes to society's cultural richness and resources as they hold skills that are valued and are becoming more essential in the current global market place (Snyder, 2008).

Similarly, heritage language development is a major step toward bilingualism, and as such, it is considered an existing and essential resource. A clear advantage is the capability of the heritage language student of tapping into their existing linguistic and cultural knowledge. In this respect, heritage language is an asset that serves as an intellectual instrument to be used at the convenience and the necessity imposed by the student in becoming bilingual (Cummins, 1994; Skutnabb-Kangas, 1995; and TokuhamaEspinoza, 2003). 


\section{Impediments to Bilingualism}

Extrinsically, a lack of cultural and linguistic resources, English-only policies, and anti-bilingual education policies serve as impediments toward bilingualism (Crawford, 2006). Intrinsically, the lack of interest and conscious or unconscious misinformation about the benefits of bilingualism can be barriers toward bilingualism. Perhaps, a major ablution may be the students' lack of intensity, enthusiasm, and motivation to continue learning the heritage language (Cummins, 1994; SkutnabbKangas, 1995; and Tokuhama-Espinoza, 2003). In this case, if the advantages outweigh the impediments, the students seem able to foster cognitive capabilities, communicate with people of their heritage language and background, and strengthen their employment opportunities.

\section{Statement of the Research Problem}

An obvious question remains: Why is there a decline in heritage language use when there are so many positive reasons for students to maintain and develop their heritage language? As will be discussed further in Chapter 2, there are numerous possibilities that may explain this phenomenon. However, a predominant possibility is that speakers of these languages — in many cases, language immigrant students—rather than being seen as untapped and strategic resources benefiting their communities, are often perceived by other students as having a communicative impediment. As a result of such negativity and despite the theoretical benefits of additive bilingualism, heritage language speakers are seemingly not inclined to maintain their heritage language, displaying an overwhelming preference toward English (Portes \& Hao, 2002). 
Students whose first language is not English regularly report a positive disposition toward their heritage language and report an intention to maintain it (Beaudrie \& Ducar, 2005). Similarly, researchers report that bilingualism is often an advantage for students (Cummins, 2005; Krashen, 1996; Thomas \& Collier, 1997). If students consider both (a) wanting to learn their heritage language and (b) the positive aspects of bilingualism, then students would be expected to continue actively pursuing learning their heritage language. However, language attrition is still a dominant phenomenon with communities losing their heritage language within three generations (Hinton, 1999; Wiley \& Valdes, 2001). Furthermore, there is evidence that high school may be a critical time in people's lives when decisions are made with respect to maintaining one's heritage language (Krosnick \& Wittenbrink, 2005). Finally, those decisions seem to be made differently depending on the decision-maker's gender and place of birth (Arrieta \& Dwyer, 2003). As a result of these considerations, the problem addressed in this study is the continuing decline of bilingualism regardless of students' positive attitude toward heritage language.

\section{Theoretical Framework}

This study is based on the premise that heritage language students are able to develop equal language competence and proficiency in their heritage language and English through Carrasquillo and Rodriguez’s (2002) notion of an additive approach. Some benefits coming as a result of bilingual language education—e.g., self-identity, self-esteem, self-confidence, cognitive abilities, increase academic achievement, and increased opportunities in the job market—could lead one to ask why bilingualism is not more widely promoted. Nevertheless, subtractive forces-i.e., the replacing of one 
language at the expense of one already existing by elements, often political or societal that suggest that bilingualism is more problematic than advantageous—can create forces and environments where bilingualism is hindered rather than fostered (Hinton, 1999; Agbo, 2004). Of principal intrigue in this study is how a tug-of-war between additive and subtractive notions is manifested in a population of students at an age where decisions to advance into bilingualism could be most critical. In other words, if adolescents actively endeavor toward bilingualism with their heritage language during their teenage years, prospects for bilingualism and cognitive benefits associated with it—may propel students toward some sort of academic prowess. However, if subtractive forces are stronger, we should ask these same students why they are not pursuing bilingualism and to what extent these forces may be outweighing the additive ones.

\section{Research Questions}

The following research questions were explored in this study:

1. What in-depth understanding of the value of heritage language do students have about their own heritage language?

2. What is their in-depth understanding of the value of bilingualism?

3. Are there any differences in the answers associated with (a) gender, (b) place of birth, or (c) first language?

\section{Purpose of the Study}

The goal of this study was to explore immigrant high school students' in-depth understanding of heritage language as it pertains to their own bilingualism (or lack 
thereof) through their heritage language. This study sought to examine pressures high school students may experience with respect to either maintaining or losing their heritage language. Student responses could provide insight for both teachers and their students regarding language maintenance and additive bilingualism, or indeed a lack thereof. In addition, such close encounters with immigrant students could provide a more detailed examination of the evolution of language policies such as Lau vs. Nichols and Plyler vs. Doe, which originally exhibited apparent contradictions and discouraged bilingualism.

Another purpose of this study was to further examine immigrant high school students' in-depth understanding of their heritage language, which in turn may provide a foundation for creating mechanisms to foster heritage language maintenance.

A final purpose of this research was to engage politicians, as well as private and public entities, to attend to the interests of heritage language maintenance. The objective was to engage policy makers and community advocates in an active discussion with respect to creating mechanisms that foster heritage language maintenance and to address heritage language-hindering policies and practices.

\section{Definitions and Terms}

In order to foster more definitive comprehension of this research study, the following operational definitions were employed:

Additive bilingualism. Carrasquillo and Rodriguez (2002) define additive bilingualism as

"a linguistic instructional context in which learners who have attained the expected level of proficiency in their first language add a second language to their existing linguistic repertoire” (p. 67). 
Agents. Lane (2003) refers to agents as people who have the power or authority to represent and act on behalf others.

Attrition. Wong-Fillmore (1991) defines language attrition as the loss of language skills within an individual over time.

Balanced bilinguals. Carrasquillo and Rodriguez (2002) define balanced bilinguals to individuals who have developed equal competence and proficiency in both languages.

Bilingual. Valdés (2001) refers to bilingualism for those speakers with native or nativelike proficiency in two languages.

Bilingualism. Grosjean (1989) defines bilingualism as a person with communicative skills in two or more languages in daily life.

Credibility. Trochim (2006) states that credibility criteria involve establishing the results of the investigation to be credible or believable from the perspective of the participants in the research.

Curricularist. Hayes (1991) refers to a curricularist as a curriculum theorist.

Generalizability. Rubin and Rubin (1995) define generalizability as "extend[ing] what you learned beyond the original setting and the original interviewees by logic of comparison” (p. 76).

Heritage language. Valdés (2001) denotes heritage language as a language learned at home that is different from the dominant language of the community.

Heritage language student. Valdés (2001) defines a heritage language student as a one who speaks or merely understands the heritage language and is to some degree proficient in both the dominant language and the heritage language. 
Intention. Rummel (1976) defines intention as a particular disposition in the process of realization, an active need to reach some future goal through a specific behavior in a particular situation.

Jamaican Creole. Pryce (1997) refers to Jamaican Creole as the definition used by linguists to refer to Jamaican Patois.

Jamaican Patois. Pryce (1997) defines Jamaican Patois as the popular term used by Jamaicans when referring to the language spoken by lower social classes in Jamaica.

Jamaican Standard English. Alleyne (1989) defines Jamaican Standard English as the language spoken by upper and middle social classes in Jamaica.

Language maintenance. Brandt and Youngman (1989) define language maintenance as a collective decision to continue using the language or languages traditionally used at home or in the community.

Language minority student. Anstrom (1996) defines a language minority student as an individual living in a household in which a language other than English is spoken.

Semi-structured interviews. Rubin and Rubin (1995) refer to semi-structured interviews as "introduc[ing] a topic, then guid[ing] the discussion by asking specific questions” (p. 5).

Subtractive bilingualism. Wong-Fillmore (1991) defines subtractive bilingualism as the replacement of one language at the expense of another.

Title III. Title III is a grant funded by the United States Department of Education for English language learners and immigrant students. 


\section{Significance to Theory and Practice}

This research is important because the findings might have wider implications in terms of curricular design and instructional models that foster realistic means for students to maintain their heritage language. Chevalier (2004) and Douglas (2005) argued for developing a heritage language curriculum that includes the uniqueness of the heritage language student, envisioning a specific curriculum that recognizes the needs of the heritage language learner as a vehicle towards bilingualism. These authors suggested that a principal task for curriculum writers should be to initiate a process of developing a curriculum in cooperation with heritage language students. Specifically, findings from this study may hold implications for attitudinal research in heritage language by

- providing a basis for understanding specific activities to be adopted by students in order to maintain their heritage language;

- addressing differences in attitudes among young men and women from different geographical regions where a language other than English is spoken;

- assisting students, teachers and parents in understanding and learning about the emotions associated with maintaining or losing a heritage language; and

- acknowledging variables such as gender and place of birth with respect to future study of heritage language, and learning of other world languages. 


\section{Assumptions}

Lai (2005) and Taylor (1994) concluded that monolingual immigrants living in the United States may be able to speak English and their heritage language. On the other hand, bilingual immigrants living in the United States may not equally coexist in both linguistic and social environments. Many immigrants recognize the need to live in harmony with both linguistic environments. The underlying assumption for the immigrant is the desirability to achieve competence in several languages, not just the heritage language. Consequently, bilingualism is assumed to be the most desirable cooperative goal among all heritage language speakers. Heritage language maintenance and development, as well as the increase of bilingualism, are related to other underlying issues in language policy, language choice, and heritage language instruction as a vehicle toward bilingualism.

\section{Delimitations of the Study}

The study focused on immigrant high school students for two fundamental reasons: First, Lucas (1993) and Norrid-Lacey and Spencer (1999) indicate that research in the area of bilingualism and heritage language education has focused primarily on the elementary age students; thus, we know little about older students. Next, Crystal (2000) reports that as age increases heritage language decreases. With respect to these reasons, immigrant high school students may face difficult decisions regarding bilingualism and language attrition because of the high academic language demands of their classes as well as the social language demands in and out of the home (Ovando \& Collier, 1998). 
It is also important to consider the critical nature of the high school students' age and its potential effect on important decisions, such as language choices. This seems to be an age when students make decisions, either consciously or unconsciously, about whether to pursue heritage language study, an endeavor necessitating extra time and energy. In turn, both perception and adaptation may affect students' need to maintain the heritage language and how immigrants ultimately value their own bilingualism (Anderson, 1981; Gibbons et al., 2002).

A greater understanding of individuals whose high school experiences could drive the sustenance or the loss of heritage language while they face an unequivocal opportunity to be bilingual or monolingual can become a tool to support these students in their decision-making process.

\section{Organization of the Study}

The second chapter contains a review of the literature from the fields of bilingualism, linguistics, sociolinguistics, culture, and psychology, as they relate to understanding attitudes and in-depth understanding associated with language development. The review of the literature provides a foundation that helps relate the research questions to the existing research. The research design and methods are described in the third chapter. In the fourth chapter an analysis of the data and its findings is presented. Lastly, in the fifth chapter, implications of the findings and recommendations for future research are proposed. 


\section{CHAPTER II \\ REVIEW OF THE LITERATURE}

This literature review provides background justifying this inquiry, specifically revealing a lack of understanding of how in-depth understanding is constantly changing and how students adapt to new roles within the immediate social context.

Promoting heritage language use in the United States denotes equal value to both one’s heritage language, as well as English. Encouraging students may facilitate recognition of bilingualism as equally comprehensive and satisfying in both languagesan additive approach — without risking a replacement of one language at the expense of another-a subtractive approach. In history as well as current times, the subtractive approach has dominated. Heritage language continues to decline despite heritage language communities’ positive perception of heritage language and the value of bilingualism. Such linguistic repression dates from the early 1800s (and likely much earlier), when Native American children were forced to learn English, to the present with mandates such as Proposition 227 in California, demonstrating the unvalued position of heritage languages in the United States (Crawford, 2006).

\section{Bilingualism}

Bilingualism is the ability to communicate effectively in two languages with similar degree in both languages (Valdés, 2001). In contrast to the historical policies of the United States, research by several authors, including Bialystock (2001), as well as 
Peal and Lambert (1962), has shown bilingual people outperforming their monolingual counterparts during cognitive experiments. ${ }^{2}$ Peal and Lambert indicated bilingual children significantly outperform monolingual children in most cognitive tests and subtests, even when groups were controlled for gender, age, and socio-economic status. Diaz (1983) noted that bilingual children have been found to have a more "diversified pattern of abilities than their monolingual peers” (p. 32). Diaz (1983) and Landry (1974) suggested the presence of flexibility in terms of language switching, where the bilingual students try to solve problems in one language but switch to the other if needed. Mouw and Xie (1999) concluded that bilingual students have an advantage over monolingual students because they possess two codes for each concept, leading to greater cognitive flexibility and abstract reasoning. Research reveals that bilingualism has a positive effect on children’s academic achievement because it increases a desired identity and, as expressed by Bourdieu (1997) and Hooghe (2007), provides access to cultural capital. These reports support the premise that additive bilingualism promotes a heightened development of the heritage language speaker's cultural, economic, and social opportunities in a world where the majority of the population is multilingual.

Furthermore, research indicates that bilinguals may hold some advantages over monolinguals in their ability to form concepts. In fact, such advantages of bilingualism in young people have long been acknowledged. Peal and Lambert (1962) summarized their research supporting the positive advantages of bilingualism as follows:

\footnotetext{
2 The term cognitive was first used by Peal \& Lambert (1962) to describe the performance of bilinguals on measures of general intelligence. Also, see Diaz (1983).
} 
Two language systems seems [sic] to have left [children] with a mental flexibility, a superiority in concept formation, and a more diversified set of mental abilities, in the sense that the pattern of abilities developed by bilinguals was more heterogeneous...In contrast the monolingual appears to have a more unitary structure of intelligence, which he must use for all types of intellectual tasks. (p. 112)

In addition, Diaz (1983) indicated that bilinguals show a greater grasp of linear measurement concepts and greater natural ease for discovering additive rules than their monolingual peers.

Magiste (1986) explained that achieving equal proficiency in both languages is a slow process, even if the formal and informal training conditions are optimal: "If the language task is suited to the students’ cognitive capability, elementary school students will generally acquire that task with greater ease than high school students due to their greater spontaneity, flexibility, and imitative ability” (p. 117). Lambert and Klineberg (1967) found that children at age 10 also experienced a positive shift in interest toward other cultures and languages, recognizing that children at this age may be at a pinnacle in maximizing their willingness to maintain other languages.

\section{Additive Bilingualism}

Additive bilingualism "is a linguistic...context in which learners who have attained the expected level of proficiency in their first language add a second language to their existing linguistic repertoire” (Carrasquillo \& Rodriguez, 2002, p. 67). In other words, “the second language and culture are unlikely to replace the first language and culture” (Carrasquillo \& Rodriguez, 2002, p. 67). Furthermore, there is a recognized distinction between balanced and dominant bilinguals. Carrasquillo and Rodriguez (2002) 
clarify that balanced bilinguals refers to all the students who may develop reasonably equal competence and proficiency ${ }^{3}$ in both languages, ${ }^{4}$ while dominant bilinguals are students who demonstrate greater proficiency and competence in one language than in the second language. Collier (1992), as well as Slavin and Cheung (2005), support the idea of additive bilingualism by advocating the promotion of language minority students' first language development, and English, with high degrees of contextual support and active cognitive task involvement, in order to achieve high levels of competence in both languages.

Research has found negative consequences of not promoting additive bilingualism. Veltman (2000) indicates that an inverse phenomenon occurs when students learn a second language and replace their first language with it, an act referred to as subtractive bilingualism. According to Wong-Fillmore (1991), when acquisition of the first language is interrupted and insufficient, or unstructured language input follows from the second language, the speaker may become partially proficient in the second language, but often below the monolingual standards.

\section{Promoting Heritage Language and Bilingualism}

According to Lewis (1980), continuance of heritage language is an ideal way to promote bilingualism among children. To support this idea, Lambert (1985), though not explicitly addressing heritage language, explained that "Spanish-American children and adolescents can learn English better and adjust more comfortably to [the United States] if

\footnotetext{
${ }^{3}$ Omaggio-Hadley (1993) explains that proficiency "is the actual production and comprehension of language used in specific instances of language use" and competence "refers to one's implicit or explicit knowledge of the systems of language” (p. 3).

${ }^{4}$ This is a conceptualization of a so-called "perfect" construct. Thus, the absolute equal use of two languages where one doesn't show dominance over another may not be realistic.
} 
their linguistic and cultural ties with the Spanish speaking world are kept alive and active from infancy on” (p. 128).

Bronwyn (2003) indicated that in many parts of the world heritage language is utilized to promote bilingualism and that many societies consider being bilingual or multilingual the norm, rather than the exception, for children. Research reveals that an equal promotion of a heritage language and English is an asset and an intellectual tool for the second language learner's academic achievement (Birch, 1998). The "knowledge gained in one language serves as a foundation and facilitates learning in the second language” (Gort, 2006, p. 5). Heritage language learners are able to gain wide access to other languages and are also capable of tapping into their preexisting knowledge, thus promoting literacy in English as well as their heritage language (Crawford, 1995; Thomas \& Collier, 1997).

In spite of these results, achieving balanced bilingualism using one's heritage language is not easy. Clyne (2004) proposes goals for additive bilingualism programs to facilitate the development of high levels of bilingual proficiency. These goals would be cooperatively developed with the government and include

1. developing a consistent language policy around language maintenance, second language acquisition, and provision of services in immigrant languages; 
2. cooperating with other countries to make their languages more accessible (for example, the International Spanish Academy in the United States founded by Spain’s Ministry of Education of Science ${ }^{5}$ );

3. collecting data and financial support for the use and maintenance of heritage languages within their nations;

4. promoting heritage language awareness with respect to the importance of languages and cross-cultural communication at all levels;

5. monitoring the implementation of the heritage language policies; and

6. coordinating the development of schemes to join resources for curriculum development and teacher training.

The heritage language community is essential to the maintenance of heritage language. The community serves as a link between generations and facilitates the transmission of heritage language from one generation to the next. The role of the community includes trying to create new uses of the language that will be useful to the next generation, providing heritage language and culture classes outside the mainstream school system, facilitating links between heritage language speakers and the country of origin, and acquainting young people with parents and grandparents with shared ethnolinguistic roots so they may inculcate bilingualism and “dispel negative myths and misconceptions about [bilingualism]” (Clyne, 2004, p. 20). Additionally, Clyne proposes that any commitment to bilingualism must create critical conditions for the maintenance of both languages. In line with Clyne's framework, Lewis (1980) explained that heritage

\footnotetext{
${ }^{5}$ For more information please visit http://www.mec.es/exterior/usa/en/programs/isas/concept.shtml
} 
language programs must be attractive and offer optimal conditions to develop the linguistic skills students bring to school.

Cummins (1994), Skutnabb-Kangas (1995), and Tokuhama-Espinoza (2003) encouraged additive bilingualism in which the nonnative English-speaking students' cultures and languages are as equally valid and valued as the cultures and language of native English speaking students. In order to accomplish this, students must be encouraged to explore and incorporate their diverse linguistic and cultural backgrounds into their daily lives. August and Hakuta (1997) and Baker (2001) propose placing the emphasis on the native language to achieve bilingual proficiency through heritage language. Their recommendations also include placing an emphasis on native language skills while simultaneously developing and maintaining high standards of proficiency in English, and developing constant interactive opportunities through an environment that supports and encourages bilingualism.

\section{Maintenance and Attrition of Heritage Language}

Despite positive benefits of maintaining one's heritage language, research continues to demonstrate a steady decrease in the number of heritage language learners. As evidence of this phenomenon, studies indicate that language shift to English, as it is the dominant language of the country, is powerful and rapid (Agbo, 2004). In general, language minority individuals are shifting to the dominant language and, at the same

time, losing their heritage language with remarkable speed. Krashen (1996) and Veltman (1983) have observed that total transition to English is generally complete within three generations. 


\section{Language Maintenance}

According to Siegel (2004), language maintenance is a primordial issue for heritage language learners in the United States, requiring that children maintain their linguistic and socio-cultural knowledge through routine interactions with members of the heritage language community. Crystal (2000) found that "the lower the average language population age, the more successful the parents are in getting young people to speak [the heritage language]” (p. 17). Ochs and Shieffelin (1984) similarly stated that building parental and community support is also essential to heritage language maintenance.

Rivera-Mills (2001) found that second and third generation immigrants continued to demonstrate a keen desire to maintain their heritage language, despite a clear preference for the dominant language. Lee (2002) conducted a study of United States born Chinese-Americans and Korean-Americans and found that individuals have a strong desire to maintain their heritage language and culture. Arriagada (2005) concurred, stating that relationships with parents and affirmations of heritage language use at home positively influenced children’s heritage language maintenance over generations.

Within the United States, several Native American communities have been successful in maintaining their heritage language. Graymorning (1997) applauded the tribal language movement as heritage language maintenance in the United States because it "emphasiz[ed] an intergenerational language transmission at home” (p. 14) and through public classes for mothers with children between 16 and 24 months old. Some Native Americans have encouraged the preservation and maintenance of American Indian languages by modeling and encouraging their use in schools, as well as in their communities. Reyhner (1999) reported the success of the Rock Point Community School 
in the Navajo Nation, "which has had a maintenance (developmental bilingual) program for almost thirty years [and] is a good example of what can be done in schools to build on home and community language preservation efforts” (p. 6). In 1996, the American Indian Higher Education Consortium (AIHEC) listed more than 30 colleges where required courses in tribal language and culture were integral parts of curricula. Crystal (2000) pointed out that Native Americans often understand the role of the school in the development of the heritage language, noting that the school is seen as a setting that provides an "increasingly widening range of opportunities for children...as they learn to cope with the demands of the curriculum” (p. 136). Overall, the success of heritage language maintenance in these communities can partly be attributed to careful preparation in providing the heritage language a status parallel to the language of the majority.

\section{Possible Factors of Policy Contributing to Heritage Language Attrition}

As mentioned in Chapter 1, historically, heritage language has not been viewed in the United States as a beneficial resource. In the 1800s, Native American children were removed from their tribes and land to be placed in boarding schools. During that era, instruction in such institutions rigorously abided by English-only policy by prohibiting other languages (Crawford, 1992). Also, citizens of German ancestry suppressed their language use during and after the $20^{\text {th }}$ century World Wars, due to anti-German sentiment in the United States. As a result, anti-foreign language attitudes developed, and the teaching of heritage languages was impeded by public policy (Lantolf \& Sunderman, 2001; Kloss, 1998). 
During the late 1990s, similar anti-immigrant policies and xenoglossophobia were revived by the Proposition 227 in California, Proposition 203 in Arizona, and the English for the Children Proposition in Massachusetts, in which voters approved a mandate for English-only instruction and the elimination of bilingual education in the states' public schools. In 2002, a similar plan was created with Amendment 31 to the Constitution of Colorado and in 2008 with Measure 58 in Oregon, but voters did not adopt these propositions. Nevertheless, as Crawford (2006) indicated, these public initiatives created a new wave of anti-bilingual programs and policies, which rapidly extended throughout the United States and persist today.

Another example of anti-bilingualism surfaced in 2007 with Florida’s Senate Bill 2512. In this instance, the policy authors were not fully informed of established language acquisition principles. ${ }^{6}$ In Florida, any teachers with an English language learner (ELL) in their class must be trained to work with such students. However, the proposed Senate Bill $2512^{7}$ reduced the number of ELL in-service training hours for reading teachers by $80 \%$. As a result, established required courses in cross-cultural communication, curriculum development, assessment, and teaching methods would no longer be requirements. ${ }^{8}$ In spite of statewide support for this bill, Florida Governor Charlie Christ vetoed it, but numerous responses to newspaper web logs across the state on the subject of this bill indicated anti-immigrant and anti-bilingual sentiment.

\footnotetext{
${ }^{6}$ See http://www.flsenate.gov/data/session/2007/Senate/bills/billtext/pdf/s2512.pdf

${ }^{7}$ See http://www.fldoe.org/aala/cdpage2.asp

${ }^{8}$ Please note that Governor Charlie Chris vetoed Bill 2512; see letter dated June 28, 2007 | http://www.elladvocates.org/documents/legislation_litigation/SB2512_Veto.pdf
} 
For the past few years, legislators in Oklahoma have proposed an English-only language amendment, House Bill 1020, requesting English become the official language of the state, despite the 37 Native American tribes living in the region. In 2007, Georgia also introduced the English-only amendment House Resolution 413 proposing the exclusive use of English in all official transactions of government business. ${ }^{9}$ In South Carolina ${ }^{10}$ proposition bill S.857 adopted English as the language of official business of the state, joining the English-only movement adopted by eight other states. ${ }^{11}$

In 2002, with the introduction of the No Child Left Behind Act (NCLB), policies emphasized the need for educational institutions to focus on the development of English language proficiency and English-only language classrooms. Referring to federal language education policy and its effects on heritage language, Evans and Hornberger (2005) concluded:

In the No Child Left Behind Act, ${ }^{12}$ English Language development is taken as the sine qua non of academic achievement and a child's heritage language is assigned less of a facilitative role in promoting English language development. Indeed, it may be viewed as a crutch in subject area study that prevents children from making adequate progress toward English language proficiency. (p. 89)

Careful consideration of the discourse of Title III reveals that it does not mention "the value of multiculturalism to the nation or to the child's English language development and academic achievement” (Evans \& Hornberger, 2005, p. 92). An additional problem

\footnotetext{
${ }^{9}$ Please see the entire document at http://www.georgialegislativewatch.com/hr413-english-onlyamendment-fails/

${ }^{10}$ Please see the entire document at http://scsenategop.com/senate-passes-english-only-bill.htm

${ }^{11}$ To see a complete list of all English-only states, please see http://en.wikipedia.org/wiki/Englishonly_movement

${ }^{12}$ Title III of the No Child Left Behind Act of 2001 provides federal financial support to state and local educational agencies for (ELL) English Language Learners and Immigrant students in the Unites States.
} 
encountered by the heritage language learners is the approach of Title III, because it accentuates the acquisition of English as a second language, but makes no mention in favor of a child's native language (see The No Child Left Behind Act of 2001, 7 U.S.C $\S 3115) .^{13}$

In addition, Cummins (2005) pointed out that policies need to be understood in a more contextual and broader term "to include the underlying assumptions held by various actors who influence the opportunities made available to children to use and maintain their heritage language and the attitudes that children develop in relation to the status of language” (pp. 89-90). The language community in the United States, as noted by Bransford, Brown, and Cocking (2000), as well as Cummins (2005), realizes that policy makers often ignore the linguistic assets language minority students bring into the classroom, while simultaneously dismissing additive strategies that tap in to the pupils' language as an effective catalyst for engaging in multiculturalism and bi-literacy.

To address the aforementioned issues, Campbell (1998) suggested building on the bilingual skills of heritage language students. Campbell describes the optimal conditions for heritage language education as the following:

There must be agreement on the part of parents, school officials, and the larger community [to] conserv[e] the...heritage language. The school system must make a long-term commitment to the program and, from the beginning, be assured that there are teachers available, or recruitable, who are competent to teach [K-12] school in the target language. There must be means for the acquisition or development of instructional and library materials in the heritage language. And

\footnotetext{
${ }^{13}$ In a May 2008 email to the LEP partnership listserv, the United States Department of Education sent out a Notice of Proposed Interpretations regarding Title III. In the notice, Secretary of Education Margaret Spellings proposed interpretations of several provisions of Title III related to the administration of English language proficiency assessments to ELL students served by Title III, the establishment and implementation of annual measurable achievement objectives (AMAOs) for states and districts receiving Title III funds, and state and local implementation of Title III accountability provisions.
} 
there must be a plan in place for the administration and interpretation of evaluation instruments and procedures. (p. 87)

After spending time in US classrooms, it becomes clear that these suggestions have not been carried out to any great extent. Kondo-Brown (2005) suggested placing less proficient heritage language students in foreign language classes in order for them to study the language, but also suggested that doing so is actually counterproductive. In fact, Valdés (1995) and Valdés and Figueroa (1994) critiqued such decisions, noting that students continue to be placed in foreign language classes where learning is occurring without heritage language connections. They argued that heritage language learners enrolled in traditional foreign language classes create an ambiance unsupportive of heritage language, thereby resulting in even further heritage language attrition among the heritage language students who attend these classes. For Roca and Marcos (1999), previous quantitative facts about heritage language are equally as important as the selfperception of heritage language speakers and the self-perception of the larger community to which they belong. ${ }^{14}$

Hence, there is a need for those who support heritage language to engage with politicians, as well as private and public entities to defend its importance. The objectives of this effort are (a) to engage in an active discussion about language policies and practices that hinder the maintenance of heritage languages, (b) to create mechanisms that foster heritage language maintenance, and (c) to discuss how policies were informed by, but not based on, principles not fully understood by the decision maker.

\footnotetext{
${ }^{14}$ For further analysis see the works of Collison (1994), Lewelling and Peyton (1999), and McQuillan (1996).
} 


\section{Attrition}

As stated previously, regardless of one's positive disposition toward their heritage language, the use of the heritage language among heritage language learners, as well as learners’ exhibiting any motivation toward daily learning and use of a heritage language, continues to decline at an alarmingly fast rate. Research conducted by Luo and Wiseman (2000), Pease-Alvarez (2002), and Schecter and Bayley (2004) indicated the relative importance of English and the perception of heritage language varied at different times of one's life, a variation which may indicate a possible fluctuation in the disposition of heritage speakers toward their heritage language, bilingualism and English.

For Hinton (1999), a primary factor contributing to language attrition is tough assimilative pressure at school. Commonly, Hinton reports, students develop a sense of shame toward their heritage language and culture for fear of being criticized. NorridLacey and Spencer's (1999) study of immigrant students in urban schools indicated that students were often labeled and ridiculed by the majority group, causing the minority group to feel a sense of resentment toward their heritage language and a need for linguistic and cultural assimilation. In addition to the peer pressure, this study indicated that English-only zone initiatives also discouraged the study of heritage language as students were rapidly placed in English-only classrooms regardless of their heritage language or English ability.

Recent studies agreed that, even with a positive disposition toward their heritage language, heritage language learners easily depart from the mother language a few years after their arrival to the United States. In many cases, by the third generation, immigrants will have lost their heritage language (Hinton, 1999). In fact, Veltman (1990) noted that 
younger Spanish speaking immigrants make English their preferred language, and only 4\% prefer Spanish to English as the principal language of use when they become adults. As noted in Table 1, the "younger the immigrant upon arrival to the United States, the greater degree of movement to the English group” (Veltman, 1990, p. 114). According to research conducted by Veltman (1990), the percentage of individuals 0-19 years old speaking Spanish as a heritage language declined from 41.3\% in 1976 to 29.4\% in 2001. This follows the fact that language shift, particularly the development of English monolinguals, is more common in younger age groups.

Portes and Hao's (2002) research of 5,000 heritage language students of different language backgrounds also concluded that over two-thirds of the sample expressed a preference for English over the heritage language. Similarly, Portes and Shauffler (1994) identified an overwhelming preference for English in their subjects' daily routines and conversations. Concurrent with the aforementioned studies, Pease-Alvarez (2002) concluded that English is preferred, even among second generation speakers who value bilingualism. In a seven-year study of Mexican-descent immigrants and U.S.-born parents and their U.S.-born children, participants reported positive opinions about English, mainly because of its perceived higher value. Paradoxically, the same participants were also highly positive about bilingualism and maintenance of Spanish as the heritage language.

Despite the social and academic benefits of additive bilingualism, heritage language speakers are not inclined to maintain their heritage language and culture equally as they display an overwhelming preference toward English. Rivera-Mills (2001) indicated that second and third generation speakers continue to demonstrate a keen desire 
to maintain their heritage language, despite their clear preference for the dominant language. Studies conducted by Lee (2005), as well as Imbens-Bailey (1996), ${ }^{15}$ indicated that students revealed variations in the desire to maintain their heritage language.

Tse (2000) mentioned that heritage language learners experience a language metamorphosis as they become more integrated with the target language. In other words, a simultaneous approximation to two languages may create a sense of deliberate linguistic apathy and in some cases a complete rejection of one of the languages. Cho et al. (2004) and Tse (2000) concluded that one could actively reject their heritage language while completely submersing in the dominant language — due in part to the simultaneous creation of an ethnic, linguistic ambivalence.

In addition, Agbo (2004) further explained the importance of recognizing that immigrants are often absorbed in the majorities’ culture and language, and as a result, they are constantly and gradually defining the boundaries that could "minimize [total] assimilation or acculturation” (p. 18). Delgado-Gaitan (1994) and Fishman (1991) recognized the uniqueness of heritage language speakers and their desire to keep the heritage language for economical, political, social, cultural and linguistic reasons. ${ }^{16}$ However, for immigrants attempting to realize an ideal personal life, in the United States, holding onto the language is not an easy task because doing so represents adopting at least two countries, two distinctive cultures, and two languages.

\footnotetext{
${ }^{15}$ See also Pease-Alvarez (2002), as well as Portes and Shauffler (1994).

${ }^{16}$ For further reference see Gonzalez (2001a), Ochs \& Schiefellin (1984), Ogbu (1982), and Shatz (1991).
} 
Table 1

Projected Language Characteristics of Immigrants by Length of Residence in the United States, Persons of Spanish Mother Tongue

High Conservation Hypothesis

\begin{tabular}{|c|c|c|c|c|}
\hline $\begin{array}{l}\text { Length of } \\
\text { Residence }\end{array}$ & $\begin{array}{l}\text { English } \\
\text { Monolingual }\end{array}$ & $\begin{array}{l}\text { English } \\
\text { Bilingual }\end{array}$ & $\begin{array}{l}\text { Spanish } \\
\text { Bilingual }\end{array}$ & $\begin{array}{l}\text { Spanish } \\
\text { Monolingual }\end{array}$ \\
\hline
\end{tabular}

\begin{tabular}{lllll}
\hline 2.5 Years & $0.6 \%$ & $9.3 \%$ & $29.0 \%$ & $61.1 \%$ \\
7.5 Years & $1.3 \%$ & 14.2 & $37.3 \%$ & $47.2 \%$ \\
12.5 Years & $2.5 \%$ & $20.2 \%$ & $41.3 \%$ & $36.0 \%$ \\
17.5 Years & $4.4 \%$ & $24.4 \%$ & 46.9 & $24.3 \%$ \\
22.5 Years & $6.6 \%$ & $23.0 \%$ & $47.3 \%$ & $23.1 \%$ \\
& & & & \\
\hline
\end{tabular}

Middle Conservation Hypothesis

$\begin{array}{lllll}2.5 \text { Years } & 0.7 \% & 10.3 \% & 33.2 \% & 55.8 \% \\ 7.5 \text { Years } & 1.4 \% & 15.8 \% & 39.8 \% & 43.0 \% \\ 12.5 \text { Years } & 2.8 \% & 22.2 \% & 42.3 \% & 32.7 \% \\ 17.5 \text { Years } & 4.8 \% & 26.9 \% & 46.2 \% & 22.1 \% \\ 22.5 \text { Years } & 7.2 \% & 25.3 \% & 46.5 \% & 21.0 \%\end{array}$

Low Conservation Hypothesis

$\begin{array}{lllll}0.5 \text { Years } & 0.8 \% & 11.3 \% & 37.1 \% & 50.8 \% \\ 7.5 \text { Years } & 1.5 \% & 17.3 \% & 42.0 \% & 39.2 \% \\ 12.5 \text { Years } & 3.1 \% & 24.4 \% & 42.8 \% & 29.7 \% \\ 17.5 \text { Years } & 5.3 \% & 29.6 \% & 45.0 \% & 20.1 \% \\ 22.5 \text { Years } & 7.9 \% & 27.8 \% & 45.1 \% & 19.1 \%\end{array}$

Note. From "The status of the Spanish Language in the United States at the beginning of the 21st century," by C. Veltman, 1990, International Migration Review, 21(1), p. 115.

The individual's conflict and challenge lies in desiring to maintain one's culture and language, while being faced with diametrically opposed challenges in maintaining the 
native language, as well as accepting a new host in face of competing and contradicting historical events and national policies. ${ }^{17}$

A contrasting view, presented by Carrigo (2000) and Fortune (2001), suggested that heritage language resistance among speakers may be the result of a lack of interest. For example, in a study conducted by Potowski (2004) of an English-Spanish two-way immersion program, students used English to cover a wider range of topics and functions in the classroom as compared to Spanish. Hence, Potowski (2004) concluded:

The challenge is that many bilingual Latino students, in an attempt to conform to mainstream society's language expectations and to their classmates' language use, assert their English competence by using it as often as possible. Some teachers commented that even recent arrivals from Latin America with low English proficiency preferred to speak whatever English they knew and were often the most difficult students to get to use Spanish in class. (p. 86)

However, Fishman, (1964); Cho, Shin, and Krashen (2004); and Valdés (2000) found that heritage language resistance is not due to general disinterest or minimal participation.

Rather, they found that students' lack of interest is the result of a mismatch between their intention of taking the language classes and the intention of the instructors. Veltman's (1990) early research suggested an intergenerational pattern of progressive tendencies as a frequently noted behavior, rather than a total language rejection and disinterest (see Table 1). Other research findings suggest additional factors that may be associated with the decreasing rate of heritage language use and an increase in English, including the following:

- $\quad$ the presence of grandparents in the household (Ishizawa, 2004; Kondo Brown, 2005);

\footnotetext{
${ }^{17}$ For further information please see TESOL's (2004) position paper on English-only legislation in the United States available at http://www.tesol.org/s tesol/bin.asp?CID=922\&DID=4162\&DOC=FILE.PDF
} 
- $\quad$ gender, females being more likely to maintain the heritage language

(Portes \& Hao, 2002);

- $\quad$ parental commitment to maintenance (Zhang, 2004); and

- $\quad$ higher levels of parental education and socio-economic status (Portes \& Shauffler, 1994).

Research by Guardado (2002) noted that families supported learning Spanish as a heritage language when they perceived such as promoting future economic opportunities for their children. Gonzalez (2001) concluded that superimposition of a language creates a conflict of interest in the heritage language learner. In other words, a child may demonstrate a positive attitude toward the heritage language and may be interested in maintaining the language; however, as Gonzalez (2001) explains, the heritage language learner child may also navigate a complex affective situation. In addressing the affective needs of the heritage language speakers, Guardado (2002) suggests speaking positively with children about heritage language in order to encourage them to use it and maintain it.

In many instances, children find expressing opinions difficult as they receive mixed messages about their heritage language use. For example, in the Hispanic community in general, parents often help children improve vocabulary and language use (Gonzalez, 2001). However, these children are also often asked to leave if they interrupt an adult conversation, ultimately resulting in children missing an opportunity to engage and use their heritage language. In other words,

the child's willingness to express his opinion and ideas may not be penalized but would not be encouraged either. This socially unacceptable behavior from the Hispanic cultural perspective of family interactions would result in a parent 
request for the child to show respect towards [their] elders and [demand] not to interrupt the conversation. (Gonzalez, 2001, p. 20)

Although heritage language maintenance declines "only after one generation, the traditional Hispanic values survive across intergenerational socialization practices even when using English, but only in relation to the context of interpersonal family relations” (Gonzalez, 2001, p. 20). As a result, cultural imposition in relation to language and culture could reveal a negative situation in attitude formation. First, it seemingly provides a mixed message about the heritage language. On one hand, it encourages the use of the language in informal conversations; on the other hand, it minimizes an intrinsic value in the use of the language in other contexts, including school and other formal settings.

According to Veltman (1990), immigrants experience a decline toward heritage language as they learn moderate levels of English as a second language. In fact, the length of residence in the United States seems to be a factor in the shifting between heritage language and English. First, while moderate levels of English proficiency are on the rise, these levels overlap with declining use of the heritage language. A second language shift follows when the languages become more independent of each other. Finally, during the third shift, individuals often replace the native language with the language used outside the home (see Table 1, Veltman, 1990).

According to Chevalier (2004) and Dressler (1991), as a result of constant linguistic shifts in the heritage language community, one's knowledge of the heritage language becomes characterized by an informal, conversational speech style, used with known interlocutors with a constrained collection of topics focused on daily events. In other words, even if the daily use of the heritage language is maintained, the formal and 
academic use of this language may be gradually lost. As a result of this constant shift toward informal language, heritage speakers tend to develop a limited linguistic pattern and limited interactions with the heritage language community.

Chevalier (2004) and Van Dijk (1985) explained that linguistic shifting complexities in heritage language include an ongoing carving away of morphology, phonology, lexicon, and syntax. In other words, second and third generations often display a limited learning of the heritage language with respect to more sophisticated and complicated linguistic constructions. These minimal linguistic limitations are not necessarily restrictive, but they represent a challenge to the continual learning of a heritage language.

\section{Curriculum}

For Chevalier (2004) and Douglas (2005), legitimization of the heritage language student occurs when the curriculum recognizes and validates the individuals' needs. In other words, when the curriculum incorporates and inculcates pragmatic approaches to learning that are within the cultural and linguistic realities of the learner. To recognize the real needs of the heritage language student, curricularists must consider the need for multilevel planning that focuses on academic specificity, as well as the unfolding of a curriculum best designed to appropriately support the student throughout the heritage language learning experience. According to Lasagabaster (2005), legitimizing the needs of the heritage language learner turns out to be "the most [complex] socio-linguistic concept when it comes to setting up particular strategic options in the process of teaching and learning languages” (p. 298). 
For Wiley and Valdés (2001), the curriculum must serve the linguistic and cultural requests of the heritage language speaker, which may be beyond the traditional academic format, and it must adapt new teaching strategies. Douglas (2005), Kagan and Dillon (2001), and Valdés (1995) propose and prioritize a curriculum that considers the heterogeneity of the students' language proficiency in both languages and recognizes the heritage language learner as a legitimate student through a pedagogical approach that provides a personal and meaningful incentive to gain similar language proficiency and status of a native speaker.

\section{High School Students and Heritage Language}

Understanding high school students' viewpoints on heritage language

maintenance is important because high school students compose a group with substantial risk of heritage language loss. Van Hook, Bean, and Passel (2005) indicated that high school students face difficulties specific to their age group, for example, lack of social acceptance, racial labeling, and categorization (James, 1997; Perkins, 2000). Rong and Preissle (1998) stated that newly arrived high school immigrants must also endure the academic pressures in order to advance. For heritage language learners, this may mean focusing their attention on mastering English. Jay (2000) concluded that developing verbal and written competence in English can be a life changing event for the newly arrived immigrant student. At the very least, students view English competence as primordial in order to understand what is happening in the classroom. In turn, English language competence allows the students to excel academically and also show their ability to perform, just as they had in their home countries and in their native languages. 
A second difficulty high school heritage language learners face is the notion of age. Research confirmed an old theory that young individuals are more likely to be persuaded than adults. A closer look at age analyses (Alwing et al., 1991) revealed two important conclusions: (a) children have the greatest propensity toward accepting any new suggestion and (b) their attitudes are less stable. Briñol and Petty (2005) emphasized the findings of Visser and Krosnick (1998), claiming that "attitude change [is] greater during early adulthood,” suggesting a difficult period for high school students to maintain their heritage language (p. 601).

\section{Critique of the Literature}

Findings from the literature review indicated that heritage language maintenance is a preferred form of achieving bilingualism. The literature review provided insight into several aspects of the research, as noted in Table 2, which delineates the research questions and the relevant reviewed literature. As evidenced by research, heritage language is the perfect candidate that parents, communities, and educational institutions should further explore when considering bilingualism. Although there are counterproductive policies and tough assimilation pressures for the heritage language speakers, students continue to express a strong desire to maintain their heritage language. 
Table 2

Research Questions and Corresponding Literature

Question

Literature review

Page reference contributing authors

What in-depth understanding

Lucas (1993), Norrid-Lacey and

15,24

of the value of heritage

Spencer (1999), Crystal (2000)

language do students have

about their own heritage

language?

What is their in-depth

Hinton (1999), Wiley \& Valdes

$1,8,24,30$

understanding of the value of

(2001), Siegel (2004)

bilingualism?

Are there any differences in the answers associated with

Crystal (2000), Dewaele (2005),

Ramirez (2000)

4, 5, 25

(a) gender, (b) place of birth, or (c) first language?

Research also indicated that additive bilingualism may represent economic, social, and cognitive advantages to heritage language speakers; furthermore, the heritage language speaker is, by far, the best candidate for promoting bilingualism. However, bilingualism is not easily achievable, especially for vulnerable groups such as high school students, as they may encounter many barriers at home, the school, the community, and the government. From weak affirmative support at home to anti-bilingual policies, the heritage language speakers experience difficult assimilation pressures that create certain 
levels of ambivalence and mismatch between their intention to maintain and learn the heritage language.

As an attempt to counter heritage language loss, researchers and educators are providing alternatives to tentatively address this phenomenon. For example, Ada and Campoy (2004) suggest teachers empower students by providing opportunities to express their views and reaffirm their heritage language and culture. One of their major suggestions is honoring students' direct participation "as a starting point for reflection” and "freeing the spirit, unlocking the fears that have stopped too many [students] from exploring their own [language] experiences” (p. 3). This idea is presented as a way to reorient heritage language speakers toward "discover[ing] the power that those voices can bring to our educational discourse” (p. 3). 


\section{CHAPTER III}

\section{METHODS}

The goal of this study was to explore immigrant high school non-Spanishspeaking students' in-depth understanding of the value of their heritage language. This chapter describes the methods employed in answering the following questions:

1. What in-depth understanding of the value of heritage language do students have about their own heritage language?

2. What is their in-depth understanding of the value of bilingualism?

3. Are there any differences in the answers associated with (a) gender, (b) place of birth, or (c) first language?

To answer these questions, I selected a qualitative approach because I was seeking to understand students’ in-depth understanding. Previous investigations of the experiences of heritage language learners from this age group have not been conducted. Furthermore, previous research results were largely obtained through quantitative means, thereby leaving out questions regarding details of students' experiences with respect to their heritage languages. Merriam (1998) indicated that qualitative researchers “are interested in understanding the meaning people have constructed” (p. 6). To Rubin and Rubin (1995), interviewing provides an opportunity to uncover new information and by accessing life experiences. The general intent is to "captur[e] the richness and complexity of the subject matter and explain it in a comprehensible way” (p. 76). Therefore, I conducted two semi-structured interviews with each participant to determine their indepth understanding of the value of their heritage language. 


\section{Setting}

Understanding the community is vital because doing so provides an opportunity to understand the students in the context of their environment (see Miles \& Huberman, 1994). For the purpose of this study, I followed Erickson’s (1994) suggestions of "working [describing] from the outside to the core of the setting” (p. 28).

Palm Beach County, a region comprised of all levels of socio-economic classes, is located approximately 77 miles north of Miami. Henry Flagler was a major character in founding Palm Beach County in 1909. He was also known as the founding father of Miami and was considered a major figure in developing the East Coast Railway. He was a business partner of Rockefeller in the Standard Oil Company, which specialized in the production, transportation, refinement and marketing of oil (Palm Beach, 2006).

The School District of Palm Beach County is the $11^{\text {th }}$ largest school district in the United States, and the $5^{\text {th }}$ largest school district in the State of Florida, with 123 elementary schools, 40 middle schools, 59 high schools, 12 combination schools, and 25 adult schools and a total of 259 schools. In the 2007-2008 academic year 170,582 students were enrolled, of whom 19,290 students were recognized as English Language Learners. There are 78,774 students enrolled in elementary school: 30,986 (39\%) are White; 22,022 (28\%) are Black; and 19,035 (24\%) are Hispanic. At the elementary school level, 40,856 (52\%) are male, and 37,916 (48\%) are female (School District of Palm Beach County, 2008).

In addition, there are approximately 39,795 students enrolled in middle school: 16,903 (42\%) are White, 11,322 (28\%) are Black, and 8,854 (22\%) are Hispanic. Overall, 20,455 students (51\%) are male and 19,340 (49\%) are female. 
At the high school level, there are 51,239 enrolled students: 23,566 (46\%) are White; 14,625 (29\%) are Black; and 10,094 (20\%) are Hispanic. Approximately 25,898 (51\%) of the students are male, and 25,341 (49\%) are female.

The School District of Palm Beach County has a diverse student population; it reports that students attending schools throughout the district currently speak approximately 149 languages, from many regions of the world. Of the students born abroad 1,706 students are from Brazil, 2,615 are from Colombia, 2,016 are from Cuba, 2,091 are from Guatemala, 12,445 are from Haiti, and 1,216 are from Jamaica (School District of Palm Beach County, 2008).

According to the 2006 United States Census Bureau, Palm Beach registered 474,175 households and 303,946 families residing in the county. Of the aforementioned households, $24.90 \%$ had children under the age of 18 living with parents, 50.80\% were married couples living together, 9.70\% reported a female as the head of the household with no husband present, and 35.90\% reported living with non-relatives. The population ages also varied: $21.30 \%$ of the residents were under the age of 18 , and $6.60 \%$ of its population was between the ages of 18 to 24 years old. The same report indicated that individuals between the ages 25 and 44 years old represented $27 \%$ of the total population. Also, 22\% were between the ages of 45 and 65 years old. The median age was 42 years old (United States Census Bureau, 2006).

In 2003, the United States Census Bureau reported a total population of 1,268,548 in Palm Beach County. From the general population: 10.6\% reported living below the poverty level and $89.4 \%$ at or above the poverty line, $78 \%$ are U.S.-born, $21 \%$ are immigrants, $8.2 \%$ are naturalized United States citizens, and $13.4 \%$ are not United States 
citizens. According to the Census Bureau 925,983 people are White; 192,084 are Black or African-American; 201,633 are Hispanic or Latino; 26,392 are Asian; and 3,119 are American Indian.

The largest Hispanic group in Palm Beach County is from South America with a total population of 41,792. In addition, there are 37,377 people from Mexico, 36,109 from Puerto Rico, 33,325 from Cuba, 5,877 from the Dominican Republic, 13,678 from Jamaica, 2,698 from Brazil, and 30,958 from Haiti.

The educational attainment for the population age 25 and over is as follows: less than high school graduate: $10.9 \%$; high school graduate: $25.2 \%$; some college or an associate degree: 30.8\%; and bachelor’s degree or higher: 33.1\%.

According to the Census Bureau (2006), the median income in Palm Beach County is approximately $\$ 31,780$. Those in the workforce with only a high school diploma earned approximately $\$ 25,757$, with a college or associate degree approximately $\$ 32,122$, with a bachelor’s degree approximately $\$ 45,191$, and with graduate and professional degrees approximately \$56,039. However, in Palm Beach County the median is higher for males when separated by gender. For example, males with a high school diploma earn approximately $\$ 30,501$; with a college degree or associate degree approximately $\$ 36,774$; a bachelor’s degree, approximately $\$ 53,893$; and a graduate or professional degree, approximately $\$ 76,137$. On the other hand, females with a high school diploma earned approximately $\$ 20,498$, with a college degree approximately $\$ 28,795$, with a bachelor's degree approximately $\$ 36,934$, and graduate and professional degrees approximately $\$ 42,435$. 


\section{Methodological Approach}

The study design followed Schram’s (2003) and Seidman’s (2006) advice that qualitative inquiry provides opportunities to gain in-depth understanding of meaningful life experiences of participants. Moreover, these scholars both suggest semi-structured interviews because subjects’ answers can provide discrete explanations of their experiences, whereupon the compiling of these explanations can ultimately describe and illuminate social phenomena, perhaps even uncovering facets seldom elicited from quantitative inquiry.

\section{Semi-Structured Interview}

According to Alsop (2002), Denzin (1997), and Eisner (1981), interviewing provides a frame of reference to express the realities that people describe regarding their experiences. To Rubin and Rubin (1995), “one of the goals of interview design is to ensure that results are deep, detailed, vivid, and nuanced” (p. 76). In the words of Furman, Lietz, and Langer (2006), such an approach will "penetrate the essence of human experience and [reveals itself] fully to an engaged audience” (p. 2). Rubin and Rubin (1995) determined that when using a semi-structured interview, "the interviewer introduces a topic, then guides the discussion by asking specific questions” (p. 5). For Kvale (1996), Patton (1989), and Scharam (2003), one benefit of semi-structured interviews is that they allow for attentiveness to particulars, acknowledging that meaningful life experiences provide an opportunity to gain understanding of the social 
world. ${ }^{18}$ Rubin and Rubin (1995) found this format of interviewing to be helpful in obtaining specific information from the interviewee.

In keeping with the flexible nature of a semi-structured interview, Bogdan and Biklen (1998), Lofland and Lofland (1984), and Patton (1990) have recommended its use and the implementation of modifications during the interview to focus attention on areas of particular interest. As suggested by Leech (2002) and Weinberg (1996), the questions from a semi-structured interview can be arranged from general to specific in order to provide a comfortable atmosphere for the interviewee. In addition, semi-structured interviews provide extensive opportunities to gather in-depth and detailed descriptions of information about students’ understandings concerning their heritage language before and after arriving in the United States (see appendix D).

Leech (2002) and Schram (2003) suggested that semi-structured interviews are appropriate, as they provide opportunities for participants to clarify each response, provide detailed explanations, and help emphasize depth and richness. Concurrent with previous research, Krosnick, Judd and Wittenbrink (2005) also encouraged the use of probing questions in the interview as a way to further explore and capture the various responses from the interviewee (p. 35). Alcoff (1991), Bartholomew, Henderson and Marcia (2000), and Gluck and Patai (1991) propose a semi-structured interview technique because it is more interactive and provides more autonomy for the participants. Similarly, semi-structured interviews offer greater flexibility "of stimulus presentation to match the

\footnotetext{
${ }^{18}$ For further discussion with respect to semi-structured interviews, please also see Schultz (1967), Seidman (2006), and Van Manen, (1990).
} 
flow of the situation and yield rich source of information” (Bartholomew, Henderson, \& Marcia, p. 288).

\section{Research Questions}

The semi-structured interviews were based on the following research questions:

1. What in-depth understanding of the value of heritage language do students have about their own heritage language?

2. What is their in-depth understanding of the value of bilingualism?

3. Are there any differences in the answers associated with (a) gender, (b) place of birth, or (c) first language?

The research questions are seeking insight for both teachers and students regarding language maintenance and additive bilingualism, or indeed a lack thereof. A set of 18 guiding questions was developed to be employed during the interview, to answer the research questions. Previous research conducted by Crystal (2000), Dewaele (2005), and Ramirez (2000) noted differences in attitudes toward heritage language associated with gender, place of birth and first language. Consequently, the interview questions offer appropriate guidelines to the qualitative scope of the research and offer some flexibility to explore emerging and related narrative. In this case, the interview questions incite a subjective narrative of students' experiences with their heritage language. They also provide an opportunity to gather information about each individual student—something that has not been qualitatively investigated in previous research. 


\section{Coding Data}

First, Bryant and Hoon (2006) suggest that intersections of qualitative data be divided into categories and themes. Morse and Field (1995) indicated that such thematic analysis included the identification of possible categories and emergent themes that may surface during the interview. I followed the following steps to code and arrange the data (See Table 3). I read the field notes and the transcript. The next step consisted of reviewing the research questions for guidance in terms of developing the concrete questions. I coded the data based on the identification of main categories and themes that emerged with all themes falling under a main category. The categories and themes were assigned to the appropriate question by using index cards that denoted gender and place of birth. After dividing the index cards by gender and place of birth, I proceeded by comparing the responses as groups and individually.

Three categories emerged from the data: (a) heritage language, (b) bilingualism, and (c) English as a second language. In turn, the following themes emerged from each category. First, five themes emerged from the heritage language category: (a) language difficulty, (b) motivators, (c) language attrition, (d) language preference, and (e) discouraging factors. Second, four themes emerged from the bilingualism category: (a) awareness, (b) importance, (c) perception, and (d) employment. Third, four themes emerged from the English as a second language category: (a) comfort, (b) preference, (c) difficulty, (d) proficiency upon arrival, and (e) language choice at school. The main question was also written on the index card to be used as a reference. All of the themes were analyzed to determine relevance to the research questions. 
Table 3

Coding Data Process

\begin{tabular}{|c|c|}
\hline Step & Process \\
\hline 1 & read field notes and transcript \\
\hline 2 & review research questions \\
\hline 3 & identify emergent categories \\
\hline 4 & $\begin{array}{l}\text { identify emergent themes } \\
\text { from categories }\end{array}$ \\
\hline 5 & $\begin{array}{l}\text { separate data according to gender and } \\
\text { place of birth }\end{array}$ \\
\hline 6 & $\begin{array}{l}\text { identify research questions with } \\
\text { respect to categories and themes }\end{array}$ \\
\hline 7 & compare among groups \\
\hline 8 & review original interview \\
\hline 9 & $\begin{array}{l}\text { group students by gender and place } \\
\text { of birth to examine as a group }\end{array}$ \\
\hline 10 & $\begin{array}{l}\text { compare responses among individual } \\
\text { students }\end{array}$ \\
\hline
\end{tabular}

\section{Data Analysis}

Data were analyzed using inductive analysis. The inductive analysis involved identifying categories and themes in the emergent data to extract meaning from the data. All of the data were mined from the semi-structured interview. For the purpose of this research, and as advocated by Glaser and Strauss (1967), an inductive method was 
utilized in building codes after data collection. Griffee (2005) indicated that all categories are grounded in the data: "grounded means they emerge from the data and reflect the data” (p. 36). For Miles and Huberman (1994), such an approach allows data to "get well molded to the codes that represent them, and we get more of a code-in-use flavor than the generic-code-for-many-uses generated by a pre-fabricated start list” (p. 58).

Bartholomew, Henderson, and Marcia (2000) explained that this approach prevents the researcher from predetermining what it is to be derived or coded from the data. Rather, "the findings emerge more inductively from an intense study of the records" (p. 288). Ultimately, all of the information provided in the course of the interview was coherently organized into themes. A categorization of emerging themes avoids looking at data to fit a code that was pre-determined before the transcription and analysis of the data. Instead, it calls to understand and coherently organize emergent data and code it accordingly. Butler (1990), Jackson (1996), Witz, Halford, and Savage (1996) argue that the aim is for themes and categories to integrate and interrelate through analysis. That is, a researcher finds connections without giving precedence to one category or retiring one category over another. For Anthias, (2001), Hoepft (1997), Strauss and Corbin (1990), and Reay (1997), this distinction represents a methodological approach that allows an empirical exploration of emergent themes. In this study, the categorization of the emergent themes was developed after the collection of the data. Such categorization avoids looking at data to fit a particular code, or a code to fit the data. Instead, it requires understanding and coherent organization of the emergent data. The inductive approach allowed me to efficiently examine the research problems within their own context. For the purpose of this research, any specific conclusion concerning heritage language loss among heritage 
language learners, despite their positive attitude, was only possible through the inductive approach that began with an examination of the specifics and grew to include more general examination.

\section{Participant Selection}

Students participating in this study were enrolled in the School District of Palm Beach County as English Language Learners. All participants were immigrant adolescents attending high school—that is, in $9^{\text {th }}$ through $12^{\text {th }}$ grade in the 2008-2009 academic school year. Participants included Portuguese speaking students from Brazil, Haitian-Creole speaking students from Haiti, and Jamaican Patois speaking students from Jamaica. The sample for the present investigation included a total of six students. The six students selected included were: one high school male adolescent and one high school female adolescent from Brazil who speak Portuguese; one high school male adolescent and one school female adolescent from Haiti who speak Haitian-Creole; and one high school male adolescent and one high school female adolescent from Jamaica who speak Jamaican Patois. The contact person at Dwyer High School used the school district database to randomly select potential participants based on the following procedure: first, a list of potential students who speak Haitian-Creole, Portuguese, and Jamaican Patois were selected as follows:

1. Five female adolescents and five male adolescents born in Haiti were selected.

2. Five adolescent females and five adolescent males born in Brazil were selected. 
3. Five adolescent females and five adolescent males born in Jamaica were selected.

Second, the names of the students were placed inside a bag and were selected at random. Each name was written on a separate piece of paper and placed in a bag with the names of the other adolescents of the same gender and from the same country. Third, the pieces of paper were pulled from the bag to reveal the name of each participant who was then contacted and invited to participate in the study. All students were contacted in person.

A letter explaining the purpose of the study was provided to each participant. Due to the ages of the participants, a letter was also provided to their parents or legal guardians to explain the purpose of the study and request signed consent for their son/daughter to voluntarily participate in the study. Upon receiving parental consent, students were contacted to set up a time to meet outside of their class schedules. A second letter was provided to each student to assent to participate in research. All interviews were conducted in the school's library. The original copies of the signed consent forms were submitted to the school's principal so that compliance as established by the School District of Palm Beach County could be maintained.

The sample size was appropriate for the project because of its potential to generate sufficient data. The number of participants is congruent with the assumptions of qualitative research in emphasizing context rather than numbers (see Seidman, 2006). The rationale behind student selection is as follows: Students from Haiti, Brazil, and Jamaica who speak Haitian-Creole, Portuguese, and Jamaican Patois were selected because of their continued immigration influx to South Florida; students from Haiti, 
Brazil, and Jamaica are graduating in public schools, which assume a level of language proficiency in English as second language; furthermore, there is no evidence in the existing body of literature that mentions these three groups in previous studies.

\section{Research Procedure}

The following documentation procedure was followed in order to carry out the study. A letter of intent to conduct research was mailed to the Office of Research and Evaluation in the School District of Palm Beach County. Once approval was obtained from the School District of Palm Beach County, a letter requesting to conduct research was provided to the Office of Evaluation and Research. Dwyer High School was selected as the research site based on their enrollment of English Language Learners (ELLs). Upon receiving approval from the School District of Palm Beach County, the principal of the school was notified for an initial meeting to explain my research.

Copies of the letter of approval from Dwyer High School and the letter from FIU were provided to briefly explain the research. After approval from the principal, a contact person was selected within the school to initiate communication with the potential participants. Students were selected and contacted (an explanation of the selection process was previously explained; please see page 51). Two letters were provided to each participant. The first letter (see Appendix A) informed the parents about the study and requested their parental consent for their daughter or son to participate in the research. The second letter (see Appendix B) was provided to each student to give assent to participate in research. I scheduled a follow-up meeting with the students to collect forms 
A and B. All copies of the forms were submitted to the administration of the school before the interviews.

\section{Interviews}

\section{First Semi-Structured Interview}

During the first interviews, I met individually with the students for approximately one hour. The interview started with an explanation of my intent to learn about their experiences and make contributions to research of heritage language and bilingualism. The interviews started with all the research questions. The available times for the interview were between 8:00 am and 3:00 pm during the course of one week and students were able to select the best day and time to meet for the interview. I prepared 18 semi-structured questions, and I met with the students in their school's media center. I placed a digital tape recorder on top of the table (70 inches wide x 30 inches long), but slightly to the side, in an effort to minimize student discomfort during the interview. The students were sitting across from the table. All of the students seemed relaxed and ready for the interview. Bottles of water were available on top of the desk and were offered to each participant at the beginning of the interview. All questions were printed and readily available in my folder. Also, a writing pad was available to take field notes. I started the interview process by reminding students that a digital tape recorder was recording the conversation and then proceeded with the semi-structured interview questions. Students elaborated each response for approximately three to four minutes. As suggested by Reis and Judd (2000), I took notes of emphasized or keywords in students' responses during the interview session. This was intended to reflect my interest in the interviewee and to 
soften the intensity of face-to-face contact throughout the interview session. These notes also provided an opportunity to note non-verbal cues and key words that could potentially reveal imperative information or serve as a base for follow up questions and exploration. ${ }^{19}$ The aforementioned approach allowed me to review questions I had with respect to a particular answer that needed additional clarification. Additionally, I was able to also maintain an information flow with the interview questions.

\section{Second Semi-Structured Interview}

The second interview was scheduled two-and-a-half-weeks after the first interview. The second interview occurred in the school's media center and lasted approximately 30 minutes with each student. During the second interview, I had an opportunity to clarify questions from the first interview. The questions for the second interview consisted of any questions from the initial interview questions needing clarification. These questions were identified after the completion of the first transcription. The second interview was not uniform, as it provided a personalized opportunity for interviewees to clarify their previous responses when needed. Also, I asked students to clarify their previous answers from the first interview when there was a question regarding their narrative (i.e., student meant country of birth when referring to their home). The second interview was valuable as the transcripts faithfully reflected the exact narrative of the students. After the completion of the interviews, I reviewed the original transcription and added any missing words and added notes that students felt

\footnotetext{
${ }^{19}$ For further information please see Rubin \& Rubin (1995).
} 
were important. The final transcript reflected all of the answers and additions as a result of the second interview.

\section{Transcriptions}

\section{First Post-Interview Transcription}

After the first interview, I transcribed the collected data (see Cassel \& Symon, 2004). I listened to the tape and noted questions for which the answers were not clear either due to the student's accent or the quality of the recording. Most of the transcription occurred without any unexpected delays as a result of the student's accents or the quality of the voice. However, during the transcription, I encountered a few unexpected problems with some words students used. A space was highlighted in the transcript and a note was written in my field notes to verify with the student during the second interview. The original field notes were in folder in a file cabinet. I added notes to my original field notes when I was transcribing the recordings from the interview. Also, I used the original digital tape recorder to transcribe each interview. For each interview, I played, rewound, and fast forwarded the interview when such was needed. I did not request any additional assistance to transcribe the interviews.

\section{Second Post-Interview Transcription}

The fully transcribed transcript was reviewed and analyzed by an outside reader in an effort to assert credibility of the document. 


\section{Security Measures}

A file with a copy of the transcripts was maintained on a USB memory stick protected with a password. A second file was maintained on a personal computer. A password was required to access the main frame and a second password was required to access the file containing the transcript. All of the names in the transcripts were coded to pseudonyms. For example; JM was used for Jamaican-male and JF was used for Jamaicafemale. Also, HM was used for Haitian-male and HF was used for Haitian female. In addition, I used BM to refer to Brazilian-male and BF for Brazilian-female. The collected data were recorded on a cassette tape. These data were stored in a locked file cabinet until all the data were transcribed. All coded cassette tapes were stored in a locked file cabinet to be kept for 5 years.

\section{Integrity Measures}

The integrity of qualitative research is determined by its trustworthiness. The criteria I used for evaluating the trustworthiness of my present study are: (a) credibility, (b) validity, (c) reliability, and (d) generalizability.

\section{Credibility}

According to Trochim (2006), the credibility criteria involve establishing the results of the investigation to be credible or believable from the perspective of the participants in the research. A foremost consideration to establishing credibility was maintaining field notes and self-memos that would serve to monitor feelings, personal bias, and other emotional responses of the interviewer. Another intricate function of writing memos was explained by Sherman and Webb (1988), who considered memos “a 
vital part of this process [where] the researcher quickly and spontaneously records his ideas in order to capture the initially elusive and shifting connections within the data” (p. 136).

As Schram (2003) postulated, there are three key considerations in establishing the trustworthiness of qualitative research: (a) posturing and role presentation, (b) disclosing and exchange, and (c) making public the private. In considering Schram's recommendations, I followed seven practical and ethical questions that served as a guide to the research and the accounts to be trusted:

1. What is the relationship between my presence in a setting and how I establish the credibility of my work?

2. How do I address the necessity of attending to some things but not others?

3. How do I engage and monitor the subjectivity that influences my research?

4. How do I balance my research commitments with the desire to engage authentically those who are participating in the study?

5. How much and what types of information do I share with participants, and for what reasons?

6. How do I address the potential of betraying the trust of the study participants?

7. How do I deal with things that I did not intend and possibly did not want to learn? (pp. 96-101).

The aforementioned inquiries served as a guide in reflecting on my presumptions and disclosing them, and allowing committee members to make suggestions at each stage 
of the research process. The questions guided my reflections and decisions because they served as a constant reminder to continuously adhere to qualitative principles. The adherence to these questions allowed me to acknowledge my biased deductions and presuppositions in order to maintain my subjectivity as a researcher. Cassell and Symon (2004) indicated that to be reflexive "refers to the recognition that the researcher as an active participant in the research process shapes the nature of the process and the knowledge produced through it” (p. 20). Keeping field note memos to record my personal feelings about the process was a way in which my reflections were communicated to the committee. Merriam (2002) suggests the researcher "[be] the primary instrument for data collection and data analysis;" rather than eliminating biases or subjectivity, it is more important to "monitor [biases with respect to] how they may be shaping the collection and interpretation of data” (p. 5). In an effort to monitor personal bias, a copy of a fully coded transcript was provided to an outside reader for analysis and review in order to assert that interview protocols contained sufficient and important information. It also served to "assess constructs of interests, [where biases] or ambiguities [were] brought to light” (Reis \& Judd, 2000, p. 299).

I also asked an independent reader to participate in the verification of the transcript. First, the independent reader confirmed that all of the primary and research questions were present in the transcript. Second, the independent reader corroborated that the entire interview was transcribed and maintained according to the data collection procedures. After the verification, the independent reader indicated that several sentences had spaces as some of the words used in the original recording were not decipherable. 
The independent reader indicated that some missing words needed to be clarified or restated by the interviewee during the second interview (Merriam, 2002).

\section{Validity}

According to Golafshani (2003) "the concept of validity is described by a wide range of terms in qualitative studies” (p. 602). To Kirk and Miller (1986), validity is the degree to which the findings are interpreted with accuracy. Davies and Dodd (2002) defined validity in terms of quality and rigor. In other words, validity is replaced by the idea of establishing "confidence in the findings” (Johnson, 1997, p. 282). For the purpose of this study, a copy of the analysis and interpretation was submitted to the committee for review in order to determine the accuracy of revealing the complexity of the issue and guard against any personal bias.

\section{Reliability}

In qualitative research, reliability refers to the replications of the research methods at a different time and place. However, there are few or no expectations that identical or similar results would occur. To Trochim (2006), reliability is "essentially concerned with whether we would obtain the same results if we could observe the same thing twice” (p. 34). In this study, the context and the assumptions that are central to the research were explained in detail. In addition, the same semi-structured interview was utilized on two different occasions with the same interviewee, and the data collection was guided by the procedures and protocols utilized in qualitative research.

\section{Generalizability}

To Rubin and Rubin (1995), generalizability is appropriate "when what you want to generalize are numbers of categorical responses and people can be treated as if they 
were alike” (p. 72). However, in the qualitative interview that was employed in the present study "we want to make broader statements about more complex responses than yes or no [answers]” (p. 72). In the present study, a total of six students were interviewed twice. According to Seidman (2006), researchers are able to "set a goal for a certain number of participants in the study” (p. 56). Glaser and Strauss (1967) explained that to make a broader statement it is necessary to reach completeness. Rubin and Rubin (1995) indicated that completeness is ultimately reached when the data provide a sense of meaning about a concept. In terms of generalization, through completeness the researcher is able to "extend what was learned beyond the original setting and the original interviewees by a logic of comparison” (p. 76). Equally important, Seidman (2006) and Rubin and Rubin (1995), concluded that completeness does not imply a pre-determined quantity of participants or a set number of emergent themes.

\section{Limitations}

This section describes the limitations of my role as a researcher. A general goal of this study was to inquire about specific in-depth understanding, assuming that an individual had already established a particular position on heritage language and bilingualism. Zaller and Feldman (1992) indicated that without a decision about a relevant belief, substantial data may be overlooked unless the participant explores and reflects about unfamiliar questions about a specific attitude. Fabrigar, McDonald, and Wegener (2005) therefore suggested: "whether based on a preexisting judgment or a newly formulated one, responses presumably reflect the individual orientation toward the object” (p. 47, emphasis added). 


\section{Researcher's Role}

Within the framework of the aforementioned qualitative theoretical stance (Rubin \& Rubin, 1995), my role as a researcher was to explore the in-depth understanding of heritage language among $9^{\text {th }}$ through $12^{\text {th }}$ grade non-Spanish-speaking bilingual students from different language backgrounds and who spoke English and their heritage language. My qualifications as a researcher included being a former immigrant student, English language learner, and world language teacher. When I first arrived to the United States, I was very interested in learning English as a second language and did not realize, at the time, the importance of continuing to learn my heritage language. As an English language learner, I understood that bilingualism was positive to me. Soon after I came to the United States, I lived and studied in Pennsylvania for almost 10 years. During this time, I traveled only a few times to my native country, Costa Rica. Perhaps such was the root of the decline in my use of my own native language. During my studies, I was concentrated on learning English. In fact, 2 years after I arrived in the United States my English improved significantly, but I also started to lose Spanish as my heritage language. At this point, my focus was on learning English as fast as possible, fitting in with the rest of the students and assimilating into the culture. Furthermore, I felt that English was more important to learn and that it presented more opportunities in my academic and personal life.

The assumptions I made based on my personal experiences with heritage language were confirmed during my teaching career. I taught high school for 8 years, and it was during this phase that I noticed Spanish immigrant students studying their native language for only for a year or two. Most of the time, they only took the number of 
courses required by the school to graduate. In fact, many students enrolled because they considered their language to be easier to study, since they already had some knowledge of the language. I realized that students were also interested in learning English at the expense of their own language, just as I had experienced when I came to the United States.

This interest in and personal involvement with heritage languages helped me become passionate about the issues surrounding heritage language and bilingualism. I believe that learning heritage languages is positive for students and good for our communities. I believe that students need to recognize that continuing to study their heritage language while learning English is a viable way to become bilingual. These personal experiences have offered me some basic skills needed to query students, elicit meaningful responses from them, observe their non-verbal responses, and glean significant information.

\section{Summary}

This chapter described the research design and the reason for studying high school students' in-depth understanding of heritage language as a vehicle toward being bilingual. As a fundamental underpinning, the design offers a qualitative approach and an argument for its use. In addition, it also outlined the procedures used in selecting the participants. Semi-structured interviews were used as the primary instrument for the initial and subsequent research questions. In the analysis of the transcription, explanation of the data collection was included in order to create a consistency of emerging themes and terminology across the multiple interviews. Finally, in recognizing considerations of 
credibility of qualitative inquiry and the inductive analysis, a series of steps was delineated to serve as a guide to establish trustworthiness in the research. 


\section{CHAPTER IV}

\section{ANALYSIS OF DATA}

The purpose of this study was to explore high school students’ in-depth understanding of the value of heritage language as such may pertain to their own bilingualism; more specifically, the study addresses experiences of first generation students who immigrated to the U.S. This chapter describes the results of this study through an analysis of the data collected through semi-structured interviews. Analysis of the data includes results from the items pertaining to the subjects' self-exploration in the areas of heritage language and bilingualism. The following section of the analysis entails an examination of the items of the semi-structured interview. The students' responses were analyzed as a whole, and then the items were classified with respect to gender, place of birth, and first language. Finally, a holistic analysis was conducted with respect to the responses of the students from Brazil, Haiti, and Jamaica. The students’ responses were compared among the groups to determine if there were any differences between their responses. The chapter concludes with a summary of the main research questions and related findings pertaining to heritage language and bilingualism.

\section{Answers to Research Questions}

The following research questions were explored in this study: With respect to high school students from families who have recently immigrated to the United States, (a) what are their in-depth understandings of the value of their heritage language? 
(b) what are their in-depth understandings of the value of bilingualism? and (c) are there any differences in the answers associated with gender differences, place of birth, and first language.

\section{Inductive Analysis}

Thematic analysis was utilized to analyze inductively the data from the transcripts. There were three categories that emerged from the data: (a) heritage language, (b) bilingualism, and (c) English as a second language. Subsequently, themes emerged from each category. All the findings emerged from the data through an analysis of the data. The following five themes emerged from the heritage language category:

(a) language difficulty, (b) motivators, (c) language attrition, (d) language preference, and (e) discouraging factors. Also, four themes emerged from the bilingualism category:

(a) awareness, (b) importance, (c) perception, and (d) employment. Lastly, five themes emerged from the English language category: (a) comfort, (b) preference, (c) difficulty, (d) proficiency upon arrival, and (e) language choice at school.

\section{Heritage Language}

Heritage language refers to the language learned at home that is different from the dominant language of the community (Valdés, 2001). Five concepts related to heritage language were described by interviewees: (a) heritage language was not difficult to learn; (b) family and friends were a major motivator to learn the heritage language; (c) students were not concerned about losing the heritage language; (d) students preferred to use their heritage with family and friends; and (e) students were discouraged by people deriding their language and making fun of their accents. 
All the participants agreed that their heritage language was not difficult to acquire as their primary language. BM concluded, "My [heritage] language was natural and easy to learn.” JF also said, "Patois was easy.” All the participants also agreed that family and friends were major motivators to continue learning the language. When asked why he wanted to continue learning his heritage language, HM explained, "For me, my friends and family.” And JM also indicated, "My friends and family motivate[s] me to know Patois.” For the participants, heritage language attrition, or losing their heritage language did not represent a concern. For example, HF said, “I don’t worry about [losing] Creole; I speak it with my family all the time.” And JF said, “I will always speak Patois; I won’t forget.”

Additionally, students also agree that behaviors of others have had a negative impact on the maintenance of their heritage language. In fact, all the students in this study were discouraged from learning their heritage language when others derided their language or their accent. JM explained, “I don’t like when my classmates or my friends make fun of my accent; it makes me feel bad and don't want to learn it.” When confronted with the question about what discourages learning their heritage language, HF explained, "When they make fun of my language.” These sentiments were also corroborated by BM, who stated that he is discouraged when "people make fun of [his] accent.”

\section{Bilingualism}

For Valdés (2001) bilingualism is the ability to communicate fluently in more than one language. Four themes emerged from the bilingual category. The interviewees indicated that (a) they know how to become bilingual, (b) bilingualism was more 
important than monolingualism, (c) bilingualism is positive in their lives, and (d) bilingualism was important for employment. Students agreed on how to become bilingual. BF concluded, "I need to read the newspaper and visit the country.” HM further explained, “Going to Haiti was nice and help me know two languages. I also like listening to music.” JF similarly referred to "watching movies and listen[ing] to the music.”

Students further showed a positive view of bilingualism and they indicated that bilingualism was more important than monolingualism. JM stated, "I like to know two languages more than one.” Also, BF stated, “Two languages is better than one language; I like knowing two languages.” The interviewees also viewed bilingualism to be an important factor in their lives. BM said, "Portuguese and English are good for me.” Also, HM concluded that "knowing two languages is a good thing.” JF added: "I know two languages, and it is nice.” Finally, students also concluded that being bilingual was important for future employment. JM explained that "all the jobs want you to speak more languages.” BF said, "You need to know two languages to get a good job.” HF also said, "I think it is important if you are applying for jobs."

\section{English as a Second Language}

Five themes emerged from the English language as a category. The interviewees noted (a) their comfort level around English speakers, (b) being comfortable using English around family and friends, (c) lack of difficulty in learning English, (d) a low proficiency level upon their arrival to the U.S. and (e) that English was their language of preference at school. Heritage language students seemed to feel comfortable with other English speakers. For example, JF said, “I feel fine around English... when I am talking 
to people.” In addition, BM said, “I like to be around people who speak English. I speak English.” When I asked whether she felt comfortable around people who spoke English, HF replied: “[It] is ok for me; I am fine.” More specifically, heritage language learners seem to be comfortable using English with family and friends. BF stated, "I use English with my friends and my family.” HM said, "I like to speak English with my grandma and my brother... and my friends.” Also JM said, "I speak English with my friends,...so...I can talk to my uncle and friends".

Some students reported that English was easy to learn. JF said, "English was easy; my aunt used to teach me. She is [in] Jamaica. I used to live with her. Because of her job, she had to speak proper English.” HF concurred: "I had to watch it from TV...English was not that hard.” HM added, "It is [was] easy."

Perhaps even more remarkably, most of the heritage language learners in this study viewed English as easy to learn despite their low proficiency of the language upon their arrival to the U.S. When asked about their English proficiency when they arrived in the U.S., BF said, “[My] English was so bad; I couldn’t speak any English.” Also, JM said, "Not good.” And, HF concluded, “Uh! Not so good.” Contrastively, however, students reported a strong preference for using English at school, suggesting that low proficiency levels, at least in the minds of these students, may not have persisted too long. In response to a question about which language they prefer in school, BF said, “No, not there! I don’t speak Portuguese at school.” JM explained, “At school I don’t [speak Patois], only English.” HF simply stated, "English at school.” 
Overall, the comments heritage language students have about bilingualism and heritage language reflected their perceptions and experiences as immigrant students in the U.S. All the students demonstrated a lack of in-depth understanding about the benefits of maintaining their heritage language as a means toward bilingualism.

\section{The Composite Group}

The six students ranged in age from 15 to 18 . There was variety among the six students in terms of length of time in the U.S., ranging from 3 months to 8 years, thus reflecting wide variety of international experiences present in a single class. However, in spite of these differences, all students noted that they speak their heritage language at home with their families: JF said he speaks with "the whole entire family." Only two of the six students stated that they also use English at home. BM said very simply, "[I speak] English...with my family at home.” Four of the six reiterated that they found English rather easy to learn in the realm that HF noted that, "English was not that hard." On the other hand, two said it was difficult. BF was firm, saying, "It is really hard to speak English; it is really hard for me because I don't like speaking English.” Interestingly, no students reported spending any academic time learning their heritage language. In spite of this, no student seemed to sense that they were losing any ability to speak their heritage language.

There was variety in the answers with respect to appreciating one language over the other. Five of the six had a preference. Of those five, three preferred English over the heritage language and two preferred the heritage language. 


\section{Country Comparison}

Answers to interview questions are presented according to each country’s cumulative perspective.

\section{(a) What are their In-Depth Understandings of the Value of their Heritage}

\section{Language?}

Students from Brazil indicated their preference and interest in studying their culture over their language to maintain Portuguese. When asked specifically about the best way to maintain heritage language, BF stated: "My culture, for me. I think [it] is good to learn a little bit about the people, the food, and everything.” However, the Brazilian students preferred English to communicate with friends in school and Portuguese to communicate with family and others in their country of origin. BF explained that this is "because in here my friends speak English....and most of my family speaks Portuguese...I rather speak English with my friends.” Their responses also revealed a lack of concern about losing Portuguese as a heritage language. For example, BF said, “I don’t think I am going to forget Portuguese though because I have family here...so... How I am going to forget my own language?” Students also reported that family and friends are considered a major motivator to maintain Portuguese. However, students pointed out that comments deriding their Portuguese language discourage its use. BF was particularly candid in saying, "My friends are so mean...because I have the accent. I know it is not really good, but they laugh.”

Students from Haiti recommended studying and speaking with parents to maintain Haitian Creole as a heritage language. However, the students from Haiti seemed to have a 
clear preference for Haitian-Creole when communicating with their friends outside of school, but preferred English for conversing with their friends at school. HM noted, "speaking with [my] family...[because] people may forget it ... but this way [I] do not forget.” Similarly, the students were discouraged from using Haitian-Creole when people associated Haitian-Creole with the political situation in Haiti. HM iterated that, "The political situation at home, people think that I am as bad like my situation in my country.” In spite of this, Haitian students revealed that they are not concerned about losing Haitian-Creole as a heritage language. In fact, HM proclaimed, “I like both...I don’t know which one is the best, but I think that Haitian Creole is easier to learn that English. I know 'cause is my native language...But when I go on vacation, I love it...You learn new words, you know.”

Students from Jamaica also concluded that they preferred to speak in Patois to communicate with their friends, as well as their immediate and extended families, even preferring Patois over English. JM said, “At home I speak Patois, and in class I speak Patois.” In addition, they recommended visiting Jamaica as a way to maintain their heritage language. When asked how they can maintain their heritage language JM offered, “To go back and visit Jamaica! [We] have to reconnect.” Moreover, students from Jamaica were not concerned about losing Patois as a heritage language, though they did not offer much detail about their perspectives on this issue. JM responded to a question about losing his heritage language, stating, "No, not yet, maybe someday, but not now.” Still, both Jamaican students felt discouraged from using Patois when people derided Patois or when they were misunderstood. JM expressed such discouragement by saying, "Sometimes I get mad when they make fun of my language...or make fun the way 
we talk, like I get mad they ask me to repeat myself, because I feel they are making fun of me."

\section{(b) What are the Students' In-Depth Understandings about the Value of}

\section{Bilingualism?}

A close analysis revealed that students from Brazil considered bilingualism to be important. For example, BM said, "The whole world speaks English, [but] knowing two languages is important.” BF also added, "I think [it] is important to speak both.” However, the students' responses varied in terms of the importance of bilingualism for a) personal opportunities for employment as in BF's comment, "I think that for you to get a job, you have to speak more than one language,” and b) as a tool to communicate in the world's economic language, as revealed in BM's declaration "Knowing two languages is important to work.” In addition, students emphasized studying the culture and subsequently the language as a way to bilingualism. BF asserted, "My culture, for me...I think is good to learn a little bit about the people, the food, and everything.” BF, additionally indicated her interest in being bilingual through saying, "Read[ing], watch[ing] movies, not worry[ing] about my accent, express[ing] myself, [and] not worry[ing] about what people [have to] say.”

Students from Haiti indicated the positive benefits of being bilingual and had a clear preference for studying the language and the culture as a way to attain bilingualism. HF professed, "You need to learn both, because you can deny it." She also said, "Stick to the language, I guess, [and] focus on the language.” HM added, “I like both languages because I could mix [them] up, because I could say something in Creole and at the same 
time say something in English. He also added, "[I like] culture, because it is different down there than it is here. That is probably the only reason I want to learn [the language] and [also] the music.”

On the other hand, the students from Jamaica considered English and Patois to be equally important, but preferred only to study the culture of Jamaica as a way to bilingualism. JF said, “I like to study the culture.” When confronted with a question about whether he would prefer to study the language or the culture, JM concluded very simply, “culture.”

\section{(c) Are there any Differences in the Answers Associated with Gender Differences, Place of Birth, or First Language?}

Gender comparison. The sample was divided into three groups according to the students' gender, place of birth, and first language. The responses were first analyzed within the group and subsequently compared among the three groups. The findings are based on the three female participants from Brazil, Haiti, and Jamaica.

All females. Overall, an analysis of the qualitative data revealed certain similarities among females from Brazil, Haiti, and Jamaica. For example, the students preferred Portuguese, Haitian-Creole, and Jamaican Patois to communicate with family. In addition, they were not concerned about losing their heritage language and agreed that people deriding their heritage language discouraged its use. An analysis of the qualitative data also revealed certain differences between females from Brazil, Haiti, and Jamaica. BF preferred English over Portuguese: "I think for me now English. I rather speak English with my friends...most of the time.” Nevertheless, she wouldn't ascribe a label of 
one language as more important than another, instead considering English and Portuguese to be equally important: "I think it is important to speak both.” She also considered family and friends to be a motivator to learn Portuguese. When asked what motivates her to speak Portuguese, she replied, "Because in here my friends speak English so....and most of my family speaks Portuguese.” On the other hand, HF preferred Haitian-Creole over English and preferred to study the language and culture as a way to bilingualism. Her comments lacked specificity: "Stick to the language... I guess...to focus on the language.” Nevertheless, HF also preferred English to communicate with friends, stating, "If they speak English, then I speak English.” She also showed concern about the negative association people make between the Haitian-Creole language and the political situation in Haiti, "I like the language, but it is really bad in Haiti." In the meantime, she also considered family a major motivator to learn Haitian-Creole; when asked why she wanted to learn Haitian-Creole, she replied, "I think my mom.”

Finally, JF recommended visiting Jamaica, each year, to maintain Patois as a heritage language. She stated enthusiastically, “And I go there every year. I will go to Jamaica and go to my family and talk it...I don't think I am going to lose it.” She also preferred Patois over English: "Well, Patois is important to me because that is where I come from and that is what I know, my language...and I love speaking my language.” JF also preferred Patois to communicate with friends; however, unlike other students in this study, she cited people's positive disposition toward her native language, thus contributing her motivation to learn Patois: "I like the way I speak it...sometimes people do not understand it....everybody likes my accent. They love to hear me talk.” 
All males. Overall, an analysis of the qualitative data revealed certain similitude between males from Brazil, Haiti, and Jamaica. For example, the males preferred to use their heritage language with friends, use English at school, and would rather study than language as a way to bilingualism. Overall, male students were not concerned about losing their heritage language. Qualitative data also revealed certain differences among the male students. For example, BM recommended reading and watching movies to maintain Portuguese, preferred English to Portuguese, and studied the language and the culture as a way to bilingualism. He stated, "To read, watch movies, do not worry about accent express themselves, do not worry about what people say.” However, BM stated that he prefers to speak Portuguese with family and friends who are major motivators toward learning the heritage language.

On the other hand, HM recommended studying the language and culture to communicate with immediate family and to maintain Haitian-Creole but preferred to study both Haitian-Creole and English combined as a way to bilingualism. HM considered English and Haitian-Creole to be equally important. For HM, studying the culture was considered a major motivator to maintain Haitian-Creole; and, as with his female counterpart, a negative association of the Haitian-Creole language and the political situation in Haiti discouraged learning their language, emphasizing in this context, "Speaking with my family, I use Creole, but English with my friends.”

JM recommended visiting Jamaica to maintain Patois. He said he preferred Patois to English, studying the culture as a way toward bilingualism and speaking Patois with friends. He noted self-identity and being able to speak with the family as major motivators to learn Patois, explaining, "Because when you come here you don't have an 
idea of how to speak it, beside it is really hard to read Patois.” JM also indicated, "The fact that I am Jamaican, I have my own motivation. I use it whenever I feel like it.” Furthermore, unlike his female compatriot, he explained that derision of Patois by others and not being understood by peers discouraged his use of the native language; however, he also noted contrastingly how Jamaican peers provide a positive outlook on Patois: "When I am with a one to one they ask me how to say things, but they don't make fun of me.”

Male and females from Brazil. Analyses of the qualitative data revealed certain similitude between the male and female subjects from Brazil with respect to their responses. For example, both students recommended studying the culture to maintain Portuguese, but recommended using English more than Portuguese. BF referred again to culture and food: "My culture. I think is good to learn a little bit about the people, the food, and everything,” while MB stated, “[I] am interest[ed] in culture.”

They also indicated an inclination to study the language, and not the culture, as a way to maintain their heritage language. MB indicated, "To read, watch movies, do not worry about accent express themselves, do not worry about what people say.”

The two Brazilian students also preferred Portuguese to communicate with family and people in the native country. They also preferred to study English to communicate with friends during class, considered English to be more important than Portuguese, and associated bilingualism with employment opportunities. BF said, "I rather speak English with my friends.” She added, "Because in here my friends speak English and most of my family speaks Portuguese.” Meanwhile, BM indicated, “Speaking with family, I speak Portuguese all the time.” 
Neither student was concerned about losing Portuguese as a heritage language and they both considered family and friends as major motivators to maintain Portuguese. BM rejected the thought of losing the Portuguese, stating, "Speaking with my family [is a major motivator].” Finally, both BF and BM pointed out that when others deride their Portuguese accent, they are discouraged from using their heritage language. BF said, "Because I have the accent," and BM also pointed to "people making fun of [his] language.”

Analyses of the qualitative data revealed certain differences between the male and female from Brazil. For example, BF indicated a difficulty level in learning English as a second language: "Some words were very difficult. Everything was difficult because I didn't understand.” BF considered friends to be a stronger motivator than family to learn Portuguese as a heritage language. She also recommended studying the language. Contrastingly, BM indicated that English was not difficult to learn, saying that confrontation with English was “So, so! Not that bad! It was easy.” He added that family was a motivator to learn Portuguese as a heritage language, simply citing "speaking with my family." He also recommended studying the culture, not the language in isolation, to learn the heritage language, stating "interest in culture!"

Males and females from Haiti. Analyses of the qualitative data revealed certain similitude between the male and female from Haiti. Both students recommend studying the language and continuing speaking with the parents to maintain the heritage language, preferring in such instances Haitian-Creole over English. Both students also recommended studying the language and the culture as a way to bilingualism. They also preferred using English with friends, parents, and extended family, considering Haitian- 
Creole and English to be equally important. Family was considered to be a major motivator in maintaining their heritage language. Nevertheless, there was a concern about losing Haitian-Creole as a heritage language. Finally, both students stated that when other people disrespected and derided their heritage language, such discouraged the use of Haitian-Creole. Both students expressed a concern that people in general may have a negative perception of the languages as they may relate it to the country's political situation. HF said, "I like the language, but it is really bad in Haiti."

Analyses of the qualitative data also revealed certain differences between the Haitian male and female. For example, HF indicated that English was not difficult learn, and considered culture a major motivator to learn Haitian-Creole: "I like their food, and how they speak.” For her, bilingualism was important as a way to obtain employment in the near future; hence, she considered bilingualism more important than monolingualism, "Yes, I am forgetting. I think it is important if you are applying for jobs." She also recommended speaking with family and watching movies in Haitian-Creole to become bilingual.

On the other hand, HM indicated that he had significant difficulty learning English as a second language and that listening to music was a motivator for learning Haitian-Creole: "English was hard" and "I think listening to the music is good.” For HM, bilingualism is important as a way "to help others."

Males and females from Jamaica. Analyses of the qualitative data revealed certain similitude between the male and female from Jamaica. For example, both students recommended visiting Jamaica each year to maintain Patois as the heritage language. They also preferred Patois over English, studying the language and the culture as a way 
to bilingualism, heritage language with friends, but English at school. JF was assertive, "I like Patois better than English.” Both JF and JM considered Patois and English to be equally important and were not concerned about losing Patois as a heritage language. JF suggested affirmed, “They are the same.” For these two students, when people’s disposition toward the native accent and interest in music were positive, such were major motivators for them to maintain their heritage language. On the other hand, when others disrespected their heritage language, they felt discouragement from using Patois.

Analysis of the qualitative data also revealed certain differences between the male and female from Jamaica. JF indicated that learning Patois was not difficult and that the own accent is a major motivator to learn heritage language: "Patois is important to me because that is where I come from and that is what I know—my language and I love speaking my language.” She uses Patois to communicate with friends and family and considers bilingualism to be more important than monolingualism. On the other hand, JM said that Patois was a difficult language to learn, stating, "I didn’t know it at all” and "It was hard.” For him, Jamaican culture is a major motivator to learn his heritage language, even preferring to use Patois, asserting that he "would probably go to the Patois friends."

Gender conclusion. After segregating and comparing the students' responses by gender, place of birth, and language, I found that males from Brazil, Haiti, and Jamaica were not concerned about losing their heritage language. For example, BM confirmed his use of heritage language at home, "Yeah, because you are going to need to speak with your grandma because your grandma it not going to learn English because they are a little bit old, so you have to learn the language to talk to them." He continued, "Speaking with 
family, I speak Portuguese all the time.” HM similarly considered family to be a motivator to learn the language.

The boys generally agreed that bilingualism is beneficial, stating such in terms of their own abilities to speak both languages. For example, JM bragged, "I do both really good though.” However, they disagreed about the reasons of the perceived benefits. BM touted universal English for his reason, “The whole world speaks English,” while JM referred to his personal experience, "I know what everybody is saying, so I can speak to different people.” On the other hand, HM referred directly to being helpful to others: "Because I can help people, and I can help myself if I am in a situation where I need it. I definitely need to speak it.” The students were also comfortable using English as a second language. In addition, they revealed that they did not have a language preference for their native language or English though they acknowledged they were discouraged from learning the heritage language by numerous factors.

The females from Brazil, Haiti, and Jamaica were not concerned with losing their heritage language, considered bilingualism to be beneficial and were also comfortable using English as a second language. Data also indicated that females did not have a language preference for their native language or English and differed as to the motivation to learn their heritage language. The female students agreed that bilingualism was beneficial, but were not clear about the reasons of the perceived benefits

\section{Rural and Urban Comparison}

I also compared the responses of the male and female students from Brazil, Haiti, and Jamaica based on if they were born in the city or in a rural area. The data revealed 
that two students from rural areas and three students from the city agreed that learning English as a second language was not difficult. Only one student from the city found difficulty in learning English as a second language. Overall, five students out of the six found learning English as a second language not difficult. In addition, four students from the city and from the rural area found learning no difficulty in learning their heritage language. On the other hand, the one student from the rural area found that learning their heritage language was difficult. Overall, five students of the six did not consider it difficult to learn their heritage language.

A comparison between rural and urban students found that all six students considered family to be a motivator to learn their heritage language. In addition, four students from the city preferred their heritage language over English, one student from the city and one student from the rural area preferring both their heritage language and English. Overall, four of six students preferred their heritage language, and two preferred their heritage language and English; in other words, they insisted on bilingualism.

I also found that female and male students from urban and rural areas differed in their perceptions toward bilingualism. Data revealed that two students from the city found bilingualism to be more important than monolingualism, one student concluding that bilingualism was important to help others and another considering bilingualism important for employment. On the other hand, one student from a rural area indicated that bilingualism was positive as it allows mixing both languages, while another concluded that bilingualism was more important than monolingualism.

Students' responses varied in their recommendations about become bilingual. For example, two students from the city recommended studying the language, while one 
student did not make any recommendation, and two recommended speaking with the family. Students from the rural areas also varied in their responses. For example, one student recommended visiting their native country, and one student suggested speaking with the family. Overall, two students recommended speaking with the family, two students suggested studying the language, one student recommended visiting the country, and one student had no recommendation.

\section{Further Analysis}

The study presumed that students possess an understanding of their heritage language and bilingualism. The rationale for an additional inquiry was prompted because the answers from the interview were superficial. The responses uncovered during the interviews seemed to reveal comparatively less than that what I had expected when I considered the literature promoting this research. As a result, I wanted to conduct further analysis. In essence, I believed there was a post-collaborative construct between the students and the reference from the research—a meta-conversation employed as an objective approach to retrace the elements expected from the research but not present in the dialogue with the students; thus, I opted to analyze the students' responses in light of an inquiry with the literature. In other words, I found the answers from the students were revealing; however, I wondered if what they were not stating was similarly revealing.

After considering students' answers, I asked myself to what extent their answers reflected, or didn’t reflect, current literature regarding bilingualism and heritage language. To answer this, I developed a subset of 22 questions and engaged in a conversation with the literature in light of students' responses (Table 4 showcases the 
actual 22 questions with references to the specific authors in the literature). The 22 questions developed served as a dynamic approach to reflect upon the students' answers within an academic context, thus complementing my original analysis by broadening the scope-not only accepting the students' responses as a reflection of their in-depth knowledge regarding the value of their bilingualism, but also extending the description to what students' responses lacked — that is, answers in light of the literature review I had come to expect or hope for but did not obtain.

\section{Did students express any sense of how critical their age is with respect to deciding how much they will learn and use their heritage language?}

There seems to be a trend among students who are born outside the United States. Heritage language proficiency of heritage language students gradually decreases due to a lack of exposure of their own language. Similarly, limiting the exposure to their own heritage language seems to prevent a natural advancement as the students become older. In the studies conducted by Lucas (1993), Norrid-Lacey and Spencer (2000) to first generation immigrants it was found that heritage language decrease as age increases, despite where students were born. However, it is important to note that such decrease in their heritage language in more like to occur in terms of academic language as compared to informal language. For example, the daily language employed at home with relatives or friends who speak the heritage language. These studies, however, do not mention whether the students are aware of this phenomenon. 
Table 4

Questions regarding students' answers with respect to corresponding literature

Question

Literature prompting the question

1. Do students express any sense of how critical their age is with respect to deciding how much they will learn and use their heritage language or not?

Lucas (1993), Norrid-Lacey and Spencer (2000)

2. Do students know that they may be part of an Peal and Lambert (1962), overall contribution to their maintenance or attrition of Collier (1992) their heritage language? Do they feel any responsibility?

3. Do students express any sense of metacognitive knowledge that heritage language maintenance-i.e., the means to bilingualism - could be an asset to their own cognitive growth? Do they show any examples of cognitive flexibility or abstract reasoning?

Anderson (1982), Gibbons et al., 2002); Bialystock (2010), Peal and Lambert (1962), Diaz (1983) and Landry (1974), Mouw and Xie (1999)

4. Do students employ a narrative regarding their appreciation for culture?

Bourdieu (1997) and Hooghe (2007)

5. Do students employ language regarding economic opportunity?

Arriagada (2005), Reyner (1999)

6. Do students employ language regarding social connections?

Clyne (2004), Roca and Marcos (1999)

Cummins (1994), SkutnabbKangas (1995), and TokuhamaEspinoza (2003) 
8. Do students express excitement regarding a prospect of their own full bilingualism?

9. Do students express sadness or regrets regarding a prospect of no bilingualism?

10. With respect to standards, are there any references to the following questions:

(a) Do students worry that their heritage language might not meet kinds of pressure from nonnuclear family members?

(b) Do students worry that their heritage language might not achieve academic standards?

(c) To what degree do students engage in any of those standards or benchmarks regarding their own language?

(d) What aspects of additive bilingualism are required in these standards?

11. Do students suggest that their own bilingualism could be an asset toward learning a third or fourth language?

12. Do students note that their heritage language could help them learn to read English more easily?

13. Do students convey any overt myth or misinformation about bilingualism? For example, did any student suggest that bilingualism might not be a good idea because children might find the two languages confusing?

14. Do students refer to language policy issues?
Siegel (2004), Lee (2002)

Lewis (1980)

Arriagada (2005); Cystal (2000), Crawford (2006), Brown and Cocking (2000), Brown (2005)
Bronwyn (2003), Birch(1993), Gort (2006), Crawford (1995), Thomas and Collier (1997)

Diaz (1983), Landry (1974), Mouw and Xie (1999)

Clyne (2004)

Crawford (1992),Cummins (2005) 
15. Did students refer to their school's level of commitment to bilingualism?

16. Do students report taking heritage language classes? If so, what do they say about them?

17. Did students discuss the political situations in their home countries?

18. Do students feel peer pressure either to keep or to lose their heritage language?

19. What family members are in the students' homes? Do they mention such?

20. Do students refer to their own socio-economic status?

21. Do students overtly discuss curriculum?

22. Are students able to converse metacognitively or linguistically about their heritage language?
Campbell (1998), Bransford, Brown and Coking (2000), Valdés (1995)

Delgado-Gaitan (1994), Fishman (1991)

Crawford (2006), Reyhner (1999)

Hinton (1999), Norrid-Lacey and Spencer (1999)

Ishizawa (2004), Kondo-Brown (2005), Gonzalez (2001), Guardado (2002); Hinton, Wiley and Valdés (2001)

Peal and Lambert (1962)

Chevalier (2004), Douglas (2005), Lasagabaster (2005), Wiley and Valdés (2001), Douglas (2005), Wiley and Valdés (2001),

Cummin (2005), Krashen (1996), Thomas and Collier (1997), Beaudrie and Ducar (2005) 
In the present study, students did not refer to either their ages or their length of time living in the Unites States as a deciding learning factor. The only age reference was made in terms of HF's present age and the age of arrival to the United States, "I am 16," and "[I] have been here for 7 years.” Furthermore, students did not make references to teachers, other students, or family members who speak about the importance of heritage language learning or bilingualism or why adolescents should be developing these skills.

\section{Do students know that they may be part of an overall contribution to their maintenance or attrition of their heritage language? Do they feel any responsibility?}

Peal and Lambert (1962), as well as Collier (1992), suggest that students know they are part of an overall contribution in learning their own heritage language, meaning that students are aware that if they themselves do not study their heritage language, the number of users of that language could deplete. However, there is no evidence from statements by students in this study with respect to understanding their possible contribution to the maintenance or attrition of their heritage language. The students only indicated their desire to learn their heritage language; however, their comments did not reflect that they are aware of how their own actions contribute to heritage language maintenance or attrition. In terms of the responsibility, the students simply stated that they were not concerned about losing their heritage language. For example, JM concluded: "I am not going to forget my language because I already speak it." Similarly, BM stated: "I will always speak Portuguese; I am not going to forget it.” Also, HM overtly stated: “I don’t think I am going to lose it.” 


\section{Do students express a sense of metacognitive knowledge that heritage language}

maintenance, i.e., the means to bilingualism, could be an asset to their cognitive growth? Did they show any examples of cognitive flexibility or abstract reasoning? Anderson (1982), Gibbons et al. (2002), Bialystock (2010), Peal and Lambert (1962), Diaz (1983) and Landry (1974), Mouw and Xie (1999) have all concluded that bilingualism is a cognitive asset to students—-that is, cognitive flexibility, elasticity, abstract reasoning can all be positive side effects of students' emerging bilingualism. Generally, all the cognitive assets are particular abilities that allow students to adapt their cognition to enhance their own knowledge. In this case, due to the nature of their own capabilities, the student is able to quickly adapt to particular language situations. In other words, students possess adequate cognitive tools to restructure their own knowledge and are capable of making instant linguistic combinations to meet requirements of unique situations (Spiro, 1987). However, in this study, there is no reference in the subjects' statements to the benefits of cognitive flexibility, elasticity, abstract reasoning, or literacy with respect to their own bilingualism though the students generally affirmed that bilingualism is positive for them. JM said, "I feel great actually [being bilingual].” Also, HM indicated, "Yeah, because I can help people and I can help myself if I am in a situation where I need it. I definitely need to speak it.”

\section{Do students employ a narrative regarding their appreciation for culture?}

Students demonstrated a keen interest in their own culture as concluded by Bourdieu (1997) and Hooghe (2007) —in other words, culture as an everyday experience 
signifying a way of life as experienced by the students. The students' meta-awareness and appreciation of their own culture thus may become an academic medium for promoting their own interest in learning their heritage language. To some extent, students in this study did indicate such meta-awareness. Students perceived culture as the vehicle to learn their heritage language. None of the students shared any amusing situations where one of their cultures might handle a situation differently than another, thus never really showing their overt knowledge of how a bicultural person might cleverly dance between two or more communities. At best, students referred only generally to tangible aspects of culture, notably food. For example, HF said, "Culture, because the food they eat," and BF similarly stated: "My culture...for me, I think is good to learn a little bit about the people, the food, and everything."

\section{Do students employ language regarding economic opportunity?}

Students in this study unanimously concluded that bilingualism would provide economic opportunity, just as Arriagada (2005) and Reyner (1999) had found in their own studies where students seemed to become bilingual in hopes obtaining a job in the current market. Students in this study similarly indicated that knowing two languages is essential in the present global stage as the market is in need of bilingual personnel. However, the students did not mention any aspects of proficiency levels that may be expected by any future employer. Furthermore, the students failed to recognize their personal steps in fulfilling any academic requirements in order to become fluent-i.e., the degree to which they must achieve novice, intermediate, or advanced proficiency levels. I had assumed as a language educator that students might have a sense of their heritage 
language ability in terms of strengths and weaknesses. However, the students of this study did not indicate whether the future employment might require conversational or academic language; their comments make no distinctions between heritage language use at home or at work. For example, BF said, "Yeah! Really important! I think that for you to get a job you have to speak more than one language.” HF then said, "Yes, I am forgetting. I think it is important. If you are applying for jobs. I think it is important.”

\section{Do students employ language regarding social connections?}

As Clyne (2004), as well as Roca and Marcos (1999), had observed, students in this study also found that making social connections to be an important part of student life. Students in this study stated that these connections seemed confined to using the heritage language. The heritage language seems to be a personal preference for speaking with friends in their language of comfort. BF illustrated such by saying, "No, I have my friends inviting [me] to parties and they speak Portuguese, and I have my best friend” while BM simply said, "so that I can talk to friends.”

\section{Were there any expressions or sense of cultural or linguistic flexibility, spontaneity, or imitative ability?}

Students in this study reported evidence revealing some of the phenomena named in this question, thus corroborating the studies of Cummins (1994), Skutnabb-Kangas (1995), and Tokuhama-Espinoza (2003). Students stated that they are able to code switch. For example, when I asked the interviewees if they mix English and their heritage language, BF said: "Yes! Sometimes when I want to say something but I can say it in 
English.” However, the students’ flexibility, spontaneity, and imitative abilities before, during, and after the interview were not necessarily present. Students did not code-switch during the interview nor did they imitate native English speakers, or anyone else.

\section{Did any student express excitement regarding a prospect of their own full bilingualism?}

None of the students made statements about their accomplishments in becoming bilingual, as Siegel (2004) and Lee (2002) had both seen with their subjects. However, the students showed some excitement about their bilingualism in their demonstration of their English language proficiency and their apparent extroverted personalities. For example, JF said: “I love speaking my language.” Also, HM said, just as BF had with respect to code switching, "I like both languages because I could mix [them] up, because I can say something in Creole and the same time say something in English.” Also BF said: "I think that it is important to speak both."

\section{Did students express sadness or regrets regarding a prospect of no bilingualism?}

The students did not express any sadness or regrets about their limited bilingualism, a finding similar to that of Lewis (1980). In fact, students were seemingly comfortable with their own level of English language proficiency. For example, BM said, "I can speak both languages. I can speak it with my friends and with my mom and brother.” JF also said, “I can speak Patois and English; I can speak both.” HF concluded, "It is important to speak both languages, like me. I speak Haitian and English when I want to; I can speak it.” 


\section{With respect to standards, are there any references to responses to the following questions?}

(a) Did students worry that their heritage language might not meet pressure from nonnuclear family members?

(b) Did students worry that their heritage language might not achieve academic standards?

(c) To what degree did students engage in any of those standards or benchmarks regarding their own language?

(d) What aspects of additive bilingualism are present in our current standards?

Students did not state or reveal any concerns about meeting any heritage language standard or expectation — a finding that expands on those of Arriagada (2005), Crystal (2000), Crawford (2006), Brown and Cocking (2000), Brown (2005). Students not only mentioned an interest in learning their heritage language but repeatedly stated their genuine interest in learning the heritage language through their culture. For example, HM said, "Probably culture, because it is different down there than it is here." That is probably the only reason I want to learn it.” JM concurred, “The culture, because you are colorful like your backgrounds.”

Students did not make direct statements that reflect the standards adopted in the course design by the Florida Department of Education (based on the National Standards for Foreign Language Education that were adopted by ACTFL). The development of the standards adopted nationwide is based on the five standards: communications, communities, culture, comparisons and communities. Most of the standards reflect an apparent approach toward bilingualism, except the standard referring to connections, 
where there is a reference to a foreign language and not necessarily a heritage language. In other words, students are encouraged to learn their heritage language as a foreign language, not as a heritage language. Neither the students from Brazil nor Haiti made references to Florida standards concerning their respective heritage languages.

\section{Did any student suggest that their own bilingualism could be an asset toward learning a third or fourth language?}

Students did not reference the possibility of using their heritage language as a trampoline toward the learning of other languages. Studies by Bronwyn (2003), Birch (1993), Gort (2006), Crawford (1995), and Thomas and Collier (1997) had also come to a similar conclusion. The students in this study only made references in terms of learning their heritage language as an asset for employment purposes. For example, BM said: “[It] is important to know other languages for work.” Similarly, BF also indicated that "speaking Portuguese and English is good for me because I will get a good job."

Additionally, HF stated: "I think that it is important if you are getting a job...It is good to help others at work.” Finally, JM said: “The whole world speaks English” while JF concluded: "You need to speak another language if you want a good job."

\section{Did students note that their heritage language could help them learn to read English more easily?}

Diaz (1983), Landry (1974), and Mouw and Xie (1999) found that reading and writing could help in learning English as their target language. However, the heritage language students in the current study did not mention how their heritage language could assist in the learning of English as a second language. It may be safe to conclude that 
these students do not realize how their heritage language helps with them with reading skills or other cognitive capabilities including code switching. The responses of the students only mentioned that heritage language is positive but did not elaborate further. However, when the students were confronted with providing a reason for their response about their heritage language, they only mentioned they could read in both languages. For example, JM said: "I read in newspapers and books from home and watch movies.” He also stated, "I like to read at school.” HF concluded: "I can read in English and Creole, [...] but Creole is hard sometimes." Similarly, BF stated: "Sometimes I read the internet from home” while HM overtly stated: "My dad sometimes brings the newspaper, and I read it.”

\section{Did students convey any overt myth or misinformation about bilingualism? For example, did students suggest that bilingualism might not be a good idea because children might find the two languages confusing?}

Clyne (2004) implies that students did not convey any myths or misinformation about bilingualism. For example, students did not mention if learning two languages is confusing, if mixing two languages is detrimental to academic language or reading two languages limits your English comprehension. The students in the present study only made a positive but general reference to bilingualism in terms of difficulty. While students did not refer to specific proficiency levels, several students suggested that both languages may be difficult to acquire yet did not indicate whether their reference was made in terms of learning English and their heritage language at the same time. In fact, the students did not explain what they mean by difficult. It seems that students use a 
general and common parameter to evaluate the two languages. These parameters measuring of difficulty may be internalized as degree of difficulty in a particular area, such as literacy, that is challenging for the students in their own heritage language. For example, HM said: "English is hard [and] Haitian [Creole] is difficult sometimes to read.” Meanwhile, JF said: “English was easy; it was not hard.” HF similarly concluded: "English was not that hard.” In other words, if the students perceived their own language as easy to acquire, then English was also simple to learn. Nevertheless, students never mentioned mixing up the two languages.

\section{Did students refer to language policy issues?}

Heritage language policies can be strategic links between students and curriculum, allowing students to understand and determine their role in any process of becoming bilingual. Crawford (1992) and Cummins (2005) claim that heritage language policies are important when considering bilingualism. Thus, this question asks the degree to which the subjects understand language concerning heritage language support in their community. One may posit, particularly from an additive perspective, that the role of the student is fundamentally important in defining the direction in attending the maintenance of their heritage language. ${ }^{20}$ Presently, existing language policies seemed to have superficially addressed the issue of offering courses and contributing to a more pluralistic society. In the case of these students, courses in Palm Beach County are offered in Haitian Creole and Portuguese. However, the research has yet to define how immigrant

\footnotetext{
${ }^{20}$ This issue of curriculum will be further discussed in question 21.
} 
students themselves are directly contributing to improving to existing heritage language programs (Chevalier, (2004) and Douglas (2005). The basic structures of a heritage language program should require the validation of its participants by favoring specific measures that are provided by its students or it may become counterproductive (Lewis, 1980), Omaggio-Hadley, 1993, and Carrasquillo and Rodriguez (2002). In other words, the policies must include a process from within to allow an inclusive and supportive approach that will encourage the heritage language to consistently maintain the language and not necessarily to take a course for limited purpose or time (Crawford, 1992)

During the interviews, the students stated that schools did not offer their heritage language in their school. For the Brazilian and Haitian students, this claim was actually inaccurate in that the School District of Palm Beach County offered two of the heritage languages—Haitian Creole and Portuguese — to fulfill the two-year foreign language requirement mandated by the Florida Department of Education in order to graduate from high school. Thus, these students expressed a sense that a policy should exist, at least in terms of offering courses pertinent to their heritage language learning needs. However, they showed no awareness of the actual existence of the courses or their connection to fulfilling secondary school language requirements. Additionally, students did not mention if they were previously asked about what to include in their heritage language curriculum or what that they would like to have been asked, 


\section{Did students refer to their school's level of commitment to bilingualism?}

Campbell (1998); Bransford, Brown and Coking (2000); and Valdés (1995) concluded that schools have become assertive in their commitment to bilingualism as they become more integrating in terms of valuing diverse heritage languages from the student population. Paradoxically, as the schools are striving to offer heritage language courses on their campuses, the students of this study do not seem aware that such heritage language opportunities exist in their own school. In addition, students overemphasize the importance of English over their heritage language thus minimizing any heritage language related effort by the state, the school district, or the school. In fact, the students in the present study were not aware that heritage language classes existed at Dwyer High School. For example, HF stated, “My school does not teach Creole.” JF took this notion one step further in terms of importance, referring to the high stakes exams she would be taking later: "I feel that English is more important because they score my work in school in English.”

\section{Did students report taking heritage language classes? If so, what did they say about them?}

Delgado-Gaitan (1994) and Fishman (1991) both found that students have an innate interest in studying their heritage language. However, none of the students of this

study are taking the existing opportunity to study their heritage language; despite the fact that Dwyer High School offers various heritage language courses. It was evident that students were not aware that heritage language classes were offered in Haitian Creole and Portuguese within the School District of Palm Beach County, albeit elsewhere within 
their school system. On the one hand, students are provided with the opportunity to further maintain their language. But on the other hand, the same students were not even aware of the classes. The students responses may suggest that students are simply not aware of the programs, that students are not intrinsically motivated enough to search for their own heritage language opportunities, or that the emphasis on English-based high stakes tests depletes these students’ enthusiasm for pursuing their heritage language more. In any event, students are not receiving the heritage language support. For example, one student indicated that Jamaican Patois was not offered as a heritage language in the State of Florida. HM said: “No, I am not studying Creole.” HF said: “No, I don’t.” Also, BM said: “They do not have any [Portuguese] classes here.”

\section{Did students discuss the political situations in their home countries?}

According to Crawford (2006) and Reyhner (1999), politics are an important aspect of heritage language and bilingualism; thus, one might wonder about the extent to which heritage language students themselves consider any political situations in their home countries to matters concerning their home languages. The two students from Haiti freely expressed such concern, making strong references about the politics and social occurrences taking place in Haiti. Furthermore, they connected their heritage language with these political issues due to feedback they received from peers. The two students both said that they did not want to be associated with Haitian-Creole because they felt many people may have a negative perception of the present social and political events in their country. HF indicated such by saying, "Like, when they say that in Haiti they are going to do bad stuff.” HM agreed: "Sometimes you feel like...[pause]...the 
government...because a couple of years ago, they had a lot of kidnapping...killing a lot of stuff! But it is a little bit different now. [pause]...And probably sometimes it is boring "cause sometime they asked you a bunch of questions."

\section{Did students feel peer pressure either to keep or to lose their heritage language?}

My findings contradict the findings of Hinton (1999), as well as Norrid-Lacey and Spencer (1999), who concluded that students do experience some peer pressure dissuading them from using their heritage language. Often, heritage language speakers are pressured by other classmates and even other immigrant students to use the majority language in school. As a result, it is common to see heritage language students at school being quickly assimilated by the language of the majority. To this end, one might surmise that a student's idea of belonging may be a factor that influences that student to abandon any interest in using and maintaining their heritage language. In the present study, however, students didn’t feel direct peer pressure, in fact even receiving some support from the peers supporting their own heritage language use. Still, there was a hint of peer reaction in light of political ramifications, as detailed from the previous question. One principal example lay with HM, who described the politics as a reason not to study heritage language but simultaneously had support from close friends who might be in the same situation. In other words, HM has a chance to use Haitian Creole with another HMs: "I used to with my friend. He is a senior, so he left now...Yeah, because I can help people....and I can help myself if I am in a situation where I need it. I definitely need to speak it." 


\section{What family members are in the students' homes? Did they mention such?}

Ishizawa (2004), Kondo-Brown (2005), and Gonzalez (2001) all observed that heritage language learners valued their extended family as an important and determining factor toward their learning their heritage language. Students in this study similarly mentioned uncles, brothers, sisters, parents, and grandparents. JF said that she talks with "the whole entire family.” HM added, "Yeah, because you are going to need to speak with your grandma, because your grandma it not going to learn English because they are a little bit old, so you have to learn the language to talk to them."

\section{Did students refer to their own socio-economic status?}

Peal and Lambert (1962) concluded that intellectual capabilities of the bilingual students were superior as compared to monolingual students, regardless of the socioeconomic status. In this study, the students made no reference to their own socioeconomic status nor any relationship to their own intellectual capacity. In fact, I could only infer from the data in my study that students came from a low to a middle class. My inference is based on facts the students mentioned with respect to their departure from their own country principally due to their parents' seeking employment. BM said: "I came here because my mom and dad moved to the U.S.” JM conveyed a similar message: "I came here a few years ago with my dad and my brother to live with my grandma.” HM also indicated after the interview that he was being picked up by his parents, who worked at a local supermarket. However, none of the students specifically described their 
families' income; thus, they likewise did not attach any relationship between their abilities (or lack thereof) to perform in school with respect to their socio-economic status.

\section{Did students overtly discuss curriculum?}

The findings of this study are parallel with the findings from Chevalier (2004), Douglas (2005), Lasagabaster (2005), Wiley and Valdés (2001), Douglas (2005), and Wiley and Valdés (2001). These studies concluded that students need productive involvement in the development of curricula that affect them, thus providing opportunities to the students to satisfy their interest in their own learning. In other words, these studies suggest that students should be working with teachers and administrators to create and refine the curriculum (i.e., lessons plans, syllabi). The students of this study revealed that they wanted to learn language through culture—not necessarily via the curriculum as currently presented at school. JF said: "I like to study the culture." When confronted with learning their language, JM exclaimed: “Culture!” BF elaborated: “My culture for me [...] I think is good to learn a little bit about the people, the food, and everything." In other words, students definitely had suggestions for the way they were being taught. However, there might exist a slight discrepancy in that while students in the aforementioned studies named life skills or abilities to carry on street conversations akin to those they have in English every day as their recommendations; the students of this study jumped almost exclusively to a theme of culture. In other words, they alluded everyday language, but they described such in terms of the rules and customs of their heritage language country. 


\section{Were any of the students able to converse metacognitively or linguistically about their heritage language?}

Cummin (2005), Krashen (1996), Thomas and Collier (1997), Beaudrie and Ducar (2005) suggests that students are able to converse metacognitively about their heritage language. However, students in my study did not indicate that they were metacognitively able to discuss their own heritage language, nor were the students able to

discuss their linguistic skills. The students generally affirmed that bilingualism is positive for them. JM said: "I feel great actually [being bilingual]” while HM indicated: "Yeah, because I can help people, and I can help myself. I am in a situation where I need it. I definitely needed to speak it.” However, they did not mention any linguistic nuts and bolts within these heritage languages.

\section{Summary}

Overall, these findings revealed that students valued their heritage language and bilingualism. The students’ responses revealed an interest in maintaining their heritage language to communicate with family and friends and considered these groups to be the most important motivators to maintain the language. The students, however, seem to lack concern for losing their heritage language. In fact, most students agreed that they expect to maintain their heritage language and even teach it to offspring. Similarly, the students were positive with respect to their heritage languages in terms of employment purposes; however, they did not indicate any in-depth understanding about other values such as cognition, bi-literacy, and academic achievement, or even how they would achieve an 
academic proficiency level in their heritage language that would assist them in any detailed job.

Students' responses clearly illustrated that students considered themselves bilingual, despite their degree of bilingualism. They emphasized their desire to study their heritage language through their culture; however, outside of BF's comment regarding "the people, the food, everything," no student spontaneously elaborated on what aspects of culture would have actually satisfied this desire. 


\section{CHAPTER V}

\section{CONCLUSIONS AND DISCUSSION}

The purpose of this study was to explore high school students' in-depth understanding of the value of heritage language, as such, may pertain to their own bilingualism. More specifically, the study addresses experiences of first generation students who immigrated to the United States. To investigate the students' understanding of heritage language and bilingualism, all emergent themes were analyzed and organized from a list of pre-determined semi-structured questions. A qualitative inquiry provided an opportunity to work toward in-depth understanding of the meaningful life experiences of

participants. Student answers allowed a thematic analysis, including the identification and examination of the answers in light of the literature regarding the advantages of bilingualism that surfaced during the interview.

This chapter presents a holistic analysis entailing an examination of the responses from the interviews. The chapter further explains implications of the findings, policy, conclusions and recommendations for future research, extension of the present study and further implications.

The study analyzed the responses from the students based on the theoretical framework discussed in Chapter 1. The issue at hand is that students' heritage language maintenance is a vehicle toward bilingualism, but its study continues to decline despite the apparent benefits (such as cognitive development and literacy) for students. This decline seems to be exacerbated by the English-only polices, existing curricula, and lack 
of understanding by close agents that could potentially help students internalize the benefits of bilingualism through their heritage language.

\section{Findings}

The findings suggest that students value their heritage language and feel positively toward bilingualism but differ in their preference regarding uses of their heritage language and English in a variety of contexts. These results support conclusions made by Anderson (1981) and Gibbons et al. (2002). These studies suggest that students are flexible in using their heritage language based on any immediate circumstance. For example, students may use their heritage language when speaking with other students but are also able to switch languages if needed (Diaz, 1983; Landry, 1974).

There are other findings reported by the students. Most prominently, students reported interest in studying their culture. One student, JM, overtly said so, stating, "I would study the culture because you are colorful like your backgrounds.” Meanwhile, BF agreed that he would like to study culture, albeit only superficial aspects thereof: "My culture, for me I think is good to learn a little bit about the people, the food, and everything.” In this case, culture may be a vehicle to heritage language and promote an additive approach toward bilingualism, as reported by Lambert (1985) and Lewis (1980). Again, the students repeatedly reported their interest in learning the culture as a way to learn the language with the purpose being to continue communicating with family and friends. For example HM stated: “I speak Haitian with my family and my friends too.” In addition, BM indicated the times he speaks Portuguese: "When I am home [... and when] my friends speak Portuguese [at] school.” 
Equally revealing, students' responses did not refer to or reveal any evidence about their own knowledge of cognitive advantages of bilingualism. For example, students did not mention that bilingual children have the potential to outperform monolingual children in cognitive tests (Pearls and Lambert, 1962). They did not mention bilingual students' facility to use one language or another to solve a particular problem (Diaz, 1993; Landry, 1974), nor did they mention any recognition of their own ability to decode concepts in both languages. Furthermore, students did not mention how bilingualism helps with their academic achievement (Mouw and Xie, 1999) or how their own cognition provides cultural and social opportunities, beyond employment (Bourdieu, 1997; Hooghe, 2007). It is important to note that students seemed unable to recognize how they would gain economic status through heritage language development (Arriagada, 2005; and Reyner, 1999). In this case, students did not articulate the connection between their present heritage language knowledge and the degree to which they could formally use their heritage language as a vehicle toward bilingualism.

The research did not expose any evidence of the differences between females and males regarding whether or not they remain heritage language speakers, as originally reported in a study by Portes and Hao (2002). Furthermore, there was no evidence that age may be an affecting variable toward heritage language maintenance (Alvarez, 2002; Hinton, 1999; Veltman, 1990). In other words, despite the various ages of the subjects in this study, these students did not reveal a stronger or weaker interest in learning their own heritage language. There is also no evidence in these data suggesting that being from an urban or a rural area is a contributing factor in maintaining the heritage language or a contributing factor in becoming bilingual or accelerating bilingualism. All in all, as was 
found in similar reports made by Cummins (1994), Skutnabb-Kangas, (1995), and Tokuhama-Espinoza (1993), this research did not find any evidence that students from various countries have different understandings of their heritage language or that the degree of those differences is unique to their experiences with their family, culture, language, and environment.

In sum, this study showed the following findings amid the comments of the students, confirming similar results from previous studies:

- Students have an interest and a positive attitude toward heritage language (Lee, 2002; Rivera-Mills, 2002);

- Students have a lack of understanding of bilingualism's cognitive and biliteracy benefits (Diaz, 1983; Peal and Lambert, 1962);

- Employment is perceived as the main benefit of bilingualism, though students offer no means for obtaining such employment or the bilingualism that would yield it (Guardado, 2002);

- Age may not be an affecting variable toward heritage language maintenance (Alvarez, 2002; Hinton, 1999; Veltman, 1990); and

- Students report, at least superficially, their need to add culture to curriculum to maintain heritage language (Siegel, 2004).

- $\quad$ Students were able to express narrative about their culture as a vehicle to learn their heritage language (Siegel, 2004);

- Students were able to express their excitement about learning their heritage language (Lee, 2002; Siegel, 2004); 
- Students view bilingualism to be positive but only for the purpose of employment (Guardado, 2002).

The points students failed to make spontaneously are just as illustrative of students’ lack of in-depth knowledge regarding their heritage language. The literature provided specific findings that were not supported by the students. For example, students were not able to establish their own level of heritage language proficiency and the steps to further explain their proficiency, a finding concurrent with that reported by Lucas (1993) and Norrid-Lacey and Spencer (2000). In other words, the students did not mention their current level or delineate how they were able or not able to develop their own heritage language further. The students in the present study did not make any suggestions in terms of any steps necessary to maintain their heritage language, nor did they express any metacognitive issues related to their heritage language. Beaudrie and Ducar (2005), Cummin (2005), Krashen (1996), and Thomas and Collier (1997) showed that students may have talked about their own language learning but not necessarily in terms of linguistic progress or proficiency levels - that is, in the ways teachers and professors discuss student progress. In this research project, students likewise did not discuss their abilities in terms of linguistic puzzle pieces, their progress through proficiency levels, or other related skills often found as concentration of language educators and researchers. In other words, the students did not make any reference about how they learn their own heritage language.

Similarly, the students did not provide any evidence about any possible factors that may affect them in relation to heritage language attrition, thus supporting findings reported by Agbo (2004) and Lewis (1980). In fact, the students in the present study did 
not make any reference to attrition, even though literature makes reference to attrition as a recurrent and unavoidable phenomenon among immigrant students.

In addition, studies by Chevalier (2004), Douglas (2005), Lasagabaster, (2005), and Wiley and Valdes (2001) unanimously support the idea that heritage language students must be provided with the opportunity to further maintain their heritage language. However, the students were not aware nor did they make reference to the fact that heritage language classes such as Portuguese and Haitian-Creole are available in the School District of Palm Beach County or even their own school. In fact, they overt claimed that such were not available.

Finally, the students did not express the benefits of bilingualism and how it relates to their own cognitive flexibility, self-esteem, self-identity, self-confidence and academic achievement. The students did not mention any concrete advantage of becoming bilingual, despite the array of advantages pointed out by Bialystock (2001), Diaz (1983), and Peal and Lambert, (1962). Similarly, the students were not able to associate bilingualism and bi-literacy as reported by Bronwyn (2003), Birch (1993), Crawford, (1995), Gort (2006), and Thomas and Collier (1997) with academic development. Simply, the students did not make any reference of their ability to use their existing knowledge to read and write in both languages. All in all, the students had a limited indepth understanding of heritage language and bilingualism. The utterances and comments students made during the study are equally as important as those they did not make. As an example, there was a lack of students' understanding in the various elements established by the ACTFL standards (connection, communities, culture, comparisons, and communication). 
In a sense, students did not touch on, even inadvertently, any of the ACTFL standards, despite the fact that all descriptions within the standards are broad.

Theoretically, there is a notion that a rotation between the aforementioned standards enables students to recognize the importance of their heritage language and become a successful member of the bilingual community. Such a lack of in-depth understanding on the part of these students is perhaps due to my own premature expectation since I asked students to reflect, at least superficially, as trained language professionals. In this sense, the students do not seem to follow ways of thinking of a trained language instructor. They failed to identify important ACTFL (1983) elements of their knowledge regarding their own heritage language development including their own level of proficiency, steps toward maintaining their heritage language, attrition, cognition, or any guidelines established by the standards to become equally proficient in both their heritage language and English, their second language.

\section{A Reconsideration of the Meaning of Heritage Language Learner}

Overall, this study revealed the complexity of understanding perspectives. The basic assumption that students had an in-depth understanding of heritage language and bilingualism presented a challenge because of the nature of the questions. Though the questions employed language that was understandable to the students, some students had a difficult time answering the questions because they were confronted with unusual, selfreflective questions that were perhaps never previously considered. Students also seemed perplexed by the more in-depth questions. The qualitative approach to investigate the students' "in-depth" understanding revealed, in a subtle way, that there is a variation in the degree of “in-depth” understanding of heritage language and bilingualism. A 
quantitative research approach would have been limited in attempting to interpret the reactions and utterances of the students. Specifically, the lack of students' in-depth responses yielded unexpected results. In light of these findings, we can adopt new approaches and a new direction for future research.

It is impossible to conclude, with only six research subjects, that all students have similar experiences; thus, these results cannot be generalized. However, this research presents dynamic examples of students verbally describing their personal experiences. Although their understanding is seemingly limited, it is a valued reality that provides insight to their perception. Thus, if we are serious in appropriately promoting heritage language development and bilingualism, then teachers and teacher educators need to understand the position of the student, assess where the student is in their heritage language development, and provide the best means for the student to fluctuate harmoniously between the two languages.

In addition, it is important to consider a more dynamic view of the heritage language learner. Students cannot just be heritage language learners. This study implies that there are three types of heritage language learners: the monolingual heritage language learner, the transitional bilingual-heritage language learner, and the fully bilingual heritage language learner.

$\underset{1}{\stackrel{\text { Monolingual HLL }}{\longleftrightarrow} \text { Transitional-Bilingual HLL }} \begin{gathered}\longrightarrow \\ 1.5\end{gathered}$


Currently, I find a shortcoming with respect to the current use of the term heritage language learner, which makes reference only to a monolingual heritage language student interested in studying a second language—in this case, English. Therefore, I present an alternative skill-based reference of a heritage language learner as one who has no proficiency in their heritage language or English but is making an effort to learn both languages. In this context the monolingual heritage language learner is not proficient in either language as they are still developing linguistically with respect to listening, speaking, reading, and writing. Transitional heritage language learners, at this stage of language development, are continuing to learn both their own heritage language and English but have only some proficiency in both languages. The fully bilingual heritage language learner is one who has developed advanced, superior, or native-like ${ }^{21}$ language proficiency skills in both their heritage language and the majority language—in our case, English (ACTFL, 1983). In making a distinction between the various heritage language learners, it is possible to refine short term and long-term research based on concrete evidence that there are degrees of heritage language speakers in relation to becoming bilingual. This distinction may provide more insight and specifics about the heritage language learner, and their desire to use their linguistic and cultural resources to become bilingual.

\footnotetext{
${ }^{21}$ The description of the different proficiency levels of language are based on the definitions established by the American Association for the Teaching of Foreign Languages (ACTFL).
} 


\section{Implications of the Findings}

\section{Implications for Teachers}

The students seemed intrinsically motivated to learn the heritage language, as they expressed a solid interest in doing so in their classes by including a stronger tie to culture. They did not, however, elaborate on what this notion of culture implies. ${ }^{22}$ Nevertheless, from the perspective of the heritage language student, a teacher's ignoring this interest could deter and repress possibilities of developing bilingual students (Cummins, 1994; Skutnabb-Kangas, 1995; Tokuhama-Espinoza, 2003). Such may also suggest that teachers of foreign language courses can tap into the experiences of heritage language learners as they participate in foreign language classrooms. In turn, the students are validated in terms of their heritage language.

Teachers can also help students understand numerous advantages to bilingualism. As a general response in this study, students solely referred to employment as the only direct non-family or friend-related advantage of bilingualism. In other words, students may simply be expressing a social condition that has been instilled in them and are only mirroring the economic conditions that provoked their families to immigrate to the United States in the first place.

Another implication is the employability of the heritage language student. From a socio-economic angle, students are focusing their academic and social efforts on becoming employable. As a result, students mention the economic rewards of future

\footnotetext{
${ }^{22}$ Though students did not overtly say so, one may suspect that students' heritage language, as presented in foreign language classes to non-heritage learners may be presented in a traditionally grammar-based way. Such course formats often linking linguistics to exercises in four skills-listening, speaking, reading, and writing (Siegel, 2004) — may especially bore heritage language students already familiar with such language constructs.
} 
employment, but they do not discuss how to learn or use sophisticated language - the kind of academic language that should help them obtain the economic reward. By the same token, they mention neither family nor teachers as contributors to the development of a connection between bilingualism and employment (Arriagada, 2005; Guardado, 2002; Reyner, 1999). Put simply, apart from talking with a few people close to them, students seem to want to become bilingual to obtain a position in the job market, nothing more (Guardado, 2002). Learning the heritage language and becoming bilingual may be affecting students' understanding as they seem to have limited understanding of more complex benefits, such as mental flexibility and bi-literacy (Bronwyn, 2003; Birch, 1993; Crawford, 1995; Gort, 2006; Thomas and Collier, 1997). Thus, teachers may wish to unfurl these advantages regularly for heritage language students.

This lack of recognition by teachers may embolden a subtractive approach by the students toward bilingualism as they submerge in one language to increase their probabilities of employment, but not necessarily to expand their cognitive capabilities (Portes and Hao, 2002). This effect may not reflect Slaving and Cheun’s (2005) idea of advocating the promotion of bilingualism with controlled support and active cognitive tasks - which students are probably not experiencing. Perhaps if teachers provide the basis for understanding such cognitive advantages, students would be more likely to learn that bilingual students can exercise more areas in their brain than monolingual students.

Moreover, Crystal (2000) reports that as age increases, heritage language decreases; perhaps because the students are young, they are limited by a lack of understanding of their own cognitive flexibility, ability, and performance. In other words, the basic concept of bilingualism, as presently perceived by students, seems to 
only serve as an enhancement to employment opportunities, and is not sufficient to satisfy an additive approach. At this stage, students may need more direction from agents who can provide guidance in terms of making clear of all the benefits of an additive approach toward bilingualism.

Age may partially be responsible for the decrease in heritage language maintenance and bilingualism. For example, Magiste (1986) found that elementary children age 10 are at the pinnacle in maximizing their willingness to equally achieve proficiency in both languages due to their "spontaneity, flexibility and imitative ability" (p. 117). Thus, heritage language maintenance may be more natural to younger students, who do not require further explanation. Older students may need teachers’ reaffirmation and clear convictions about the rationale for maintaining their heritage language and using it as a vehicle toward bilingualism. Perhaps as age increases, so does the need for teachers to reaffirm the benefits of bilingualism, beyond employment opportunities; for example, cognitive abilities, cognitive elasticity, academic achievement, self-esteem, and self-identity. Bilingualism, as a result of an additive approach, must be validated by teachers and valued by the students, in a way that closely reflects the same principles that are applied to English language speakers in the United States as they learn their heritage language for communication and literacy, while refining their opportunities for social and academic success (Bourdieu, 1997; Hooghe, 2007; Pearl and Lambert, 1962).

\section{Implications for Students}

Students continue to have a positive attitude toward the heritage language. Consequently, students’ own dispositions may provide convictions that are needed to be future promoters, advocates, and supporters of their heritage language and bilingualism. 
In other words, their positive attitude may provide a foundation upon which further emphasis or coaching might be helpful to maintain the heritage language (Lee, 2005; Imbens-Bailey, 1996). This sentiment may also provide an opportunity for students to explore their own language interests, which can be for beneficial for intellectual growth as it allows them to enrich their mental capabilities. The students' motivation (i.e., future employment) continues to be an important variable in considering heritage language maintenance as students report basic levels of intrinsic motivation to study the heritage language (Guardado, 2002).

\section{Heritage Language and Future Considerations}

The results of this study, particularly when put into the context of the existing literature and modern day policy, evoke several key trains of thought. I offer the following considerations regarding curriculum, parents, identity, and policy as sparks for future consideration and foundations for inquiry, discussion, and research.

\section{Curriculum}

Students in this study stated an interest in adding culture to foreign language classroom curriculum as a way for them to study their heritage language. They provided insight into their attitudes and positive dispositions, which can be used as a trampoline to curriculum design. When asked about why it is important to learn the heritage language, HM replied: "Probably culture, because it is different down there than it is here. That is probably the only reason I want to learn it...and the music." In other words, culture is 
valued as a vehicle toward heritage language. This quote confirms an interest in students' maintenance of their heritage language.

The students expressed an interest and an affinity toward heritage language and, to a certain degree, bilingualism. However, the students are not referring to their attitude or their lack of understanding of possible positive effects on cognition due to bilingualism. Example phenomena demonstrating such are showcased as students suggest adding culture, as a general term, to the existing heritage language curriculum (Chevalier, 2004; Douglas, 2005; Lasagabaster, 2005; Kanan and Dillon; Wiley and Valdes, 2001).

Though not overtly stated, students' perception of their heritage language study is most likely part of a foreign language curriculum, not necessarily designed for them but rather for non heritage language learning students. Heritage language students, in fact, may wish to refrain from grammar-based approaches in favor of a more personalized approach to learning the heritage language — through culture, though their explanations regarding what specific real-life aspects of culture, at least in this research, are currently without specific detail. Such legitimatization of the students’ heritage in a foreign language classroom may provide a more realistic value to learners by making the language more personal and more meaningful (Douglas, 2005; Kagan and Dillon, 2001; Lasagabaster, 2005; and Valdes 1995). Current curricularists could direct their attention to heritage language high school students who have been thus far neglected, perhaps gathering and developing lessons directly upon students’ own experiences. In that students in this study name employment as a motivator for maintaining heritage language, curricularists could then revisit the notion of English for Special Purposes (ESP) type elements (e.g., Business English, English for medical and legal purposes) for 
developing specific contextualized materials and extending such content for heritage language classes. Lesson plan addenda might include role plays—-for example, classes for nursing, creating and registering a business in Florida, and a basic introduction to US rights and obligations to new US citizen) conducted in Haitian-Creole, Portuguese, and Jamaican-Patois.

\section{Parents}

The results of this research suggest that parents should be encouraged to explore the capabilities and the possibilities of helping develop a bilingual-heritage language student. Parents can be important in any heritage language maintenance process as they are in constant contact with the student (Ochs \& Shieffelin, 1984). Indeed, parents, as agents, may not have the tools, experience, training, or basic knowledge that allow for a clear discussion of heritage language and bilingualism as they relate to cognition (Diaz, 1983; Peal and Lambert, 1962). This lack of understanding may be quickly absorbed by the student, who internalizes the ambiguity of learning a language and only sees the economic advantages. In this case, the students are only stating the implications of bilingualism based on early and constant mental conditioning to accept bilingualism as means to increased marketability. Thus, just as with teachers, parents' understanding of the intricate advantages of bilingualism could be assets in students' advancement toward more academic study of their heritage language.

An important dimension is the need for community language centers to stimulate parents and grandparents with the same ethnolinguistic roots to encourage heritage language learning. It is clear from the students' perspectives that speaking with family members is important. Students are confirming their own orientation to their language 
learning. They desire a meaningful connection between their lives and their heritage language. However, the school community is not mentioned as an intricate link between the generations and as a means of transmission of heritage language, a condition that is intertwined in bilingualism (Reyhner, 1999).

\section{Identity}

Another important aspect to consider is that students have their own narrative about their identity, but not necessarily about their language. According to Tapani (2009), identity is culturally-based perception of self as determined with respect to how we think other people view us. In other words, students laud and value their culture and the language they represent. The students from Haiti, Brazil, and Jamaica expressed a genuine interest in their own foods, music, and identity. For example, the students from Jamaica were proud of their own accent. The students from Haiti and Brazil stated their pride for their food and festivals (e.g., griots, samba) though examples were never specifically named. However, students also exhibited a degree of ambivalence in terms of learning and practicing their own language (Norton, 1997). The students in this study were bilingual and maintained their heritage language. However, within their narratives, the students raised suspicions about language loss because they have yet to lose their own language (Veltman, 1990). Only the previous generations of immigrants have lost their native language. To that end, students seem to have the mentorship to keep their cultural identity but not their intricate language pieces.

The students' lack of self-perception is perhaps not their own creation but rather a result of their parents and teachers. There is no evidence that the viewpoints of the mentors would hold more weight than the viewpoints of the students but I suspect that 
students' responses are likely a reflection of how they are instructed. Perhaps, if the student is mentored in having a positive outlook toward their heritage language and bilingualism, they may be more likely to adopt the positive outlook of their mentor. This kind of mentorship, I imagine, may need to be consistent through time and strong enough to inculcate an innate desire in the students to maintain their heritage language.

The findings of this study were congruent with Hinton's (1999) findings in that the students from Haiti, Brazil, and Jamaica developed a sense of shame toward their heritage language and culture for fear of being criticized, labeled, and ridiculed. Perhaps this sense of shame adds to the attitudes that children may develop in relation to the status of their heritage language. This could create a burden and a sense of resentment, especially when students are forced into English classes despite the available resources to implement bilingual programs that would foster heritage language development and bilingualism (Norrid-Lacey and Spencer, 1999).

It was not clear if the students simply wanted to submerge in the dominant language and reject their heritage language while becoming bilingual. The important point is that students seemed not to recognize the boundaries that define what is necessary to maintain their heritage language and become bilingual. It is also crucial to consider that students' lack of language competence and interest in both languages is perhaps a direct mismatch between their intent and the intent of the teachers (Fishman, 1964; Cho, Shin, \& Krashen, 2004; Valdes, 2000). Speaking positively and concretely with students about the advantages of heritage language development must continue because it might encourage students to practice and maintain their heritage language. More importantly, students must be provided with information regarding the cognitive 
value of bilingualism if we desire bilingual students. Students seem to have an innate desire to learn the heritage language for the purpose of continuing communication with family and friends instead of learning the heritage language to properly and formally communicate with other audiences (i.e., school).

\section{Policy}

Heritage language students, as mentioned in Chapter 2, can be ambivalent in defining the boundaries that may label them as “immigrants.” Such ambivalence, along with the desire to submerge in the dominant language, creates a challenge to the existing policies and current curricular programs that attend to the existing perceptions and needs. While considering pre-existing legislation, regulations, practices, and guidelines in the development of new policies, policy-makers might bear in mind that their decisions could restrict students’ learning of their own heritage language.

The heritage language speakers in this study, who attend schools in the United States, with high levels of proficiency in their heritage language may experience heritage language attrition as they are enrolled in programs that focus on English as the language to communicate with all audiences. For example, students did not mention the implementation of bilingual programs at the district level or any heritage language programs in the schools designed to maintain their heritage language, despite evidence that heritage language speakers are able to excel in their development of their heritage language while also mastering English.

It is prudent to indicate that existing school policies_e.g., English for the Children Propositions passed in California, Arizona - may further be in conflict with students' desire to become bilingual through studying their heritage culture rather than 
through studying the heritage language, particularly as modern language is often taught in high school classrooms (Crawford, 2006). This study suggests that parents, teachers, family members, and friends of heritage language students could reconsider policies by recognizing lifelong consequences of their mentorship in the realm of heritage language and bilingualism, which may result in students proportionally learning both languages. Equally important, foreign language teaching policymakers must find a practical approach and employ innovative strategies to write the heritage language curriculumnot in isolation, but in cooperation—with the heritage language students. In other words, curriculum development should include the students in the elements that are crucial for the students in order to maintain their heritage language. For example, students should be able to provide fundamental information in the narrative of the curriculum, including, lessons and authentic resource materials. Perhaps the orientation of the curriculum should be inclined to explore the various careers and its fields since the students seem to have a positive disposition to learn their heritage language for the purpose of employment. Such a venture might close any gap between the heritage language maintenance and its parallelism with bilingualism, thus creating a model that establishes and solidifies heritage language as a base for and as a mechanism toward bilingualism.

Students indicated that they are placed in foreign language classes to fulfill the language requirements mandated by the State of Florida, relegating their study of their heritage language to a matter of convenience because these languages classes are already in place. No student, however, indicated knowledge of existing heritage languages courses in Portuguese and Haitian Creole in schools in the State of Florida (see 
appendices $\mathrm{H}$ and I). It is possible-in fact, probable- that they do not know these classes are a possibility.

Policy is formed based on principles not fully understood by the decision makers, such as the needs and perspectives of the students. To this end, teachers encourage the heritage language learners in their classroom and superimpose their educational philosophies and policies on the students. Furthermore, state public policy may actually advocate for anti-bilingual programs (e.g., California, Arizona, and Massachusetts), thus presenting a challenge to heritage language learners because they are subtly forced to follow policies. As a result, these obstacles may impede any positive disposition heritage language speakers possess toward their heritage language or bilingualism.

In addition, specific funding also has a direct effect in creating a wider gap in heritage language learning and bilingualism. For example, the Foreign Language Assistance Program (FLAP), which is a federal grant, provides funds to states that will provide specific programs that will only teach so-called critical languages (i.e., Mandarin, Arabic), thus creating a greater hierarchical disparity between students who speak these languages and students who speak other common, and equally valuable languages. In this specific case, the educational institutions are faced with a dilemma where they will fulfill the needs of the government, but only benefit a few students, and even fewer heritage language students.

It is time for policy makers to recognize the diverse benefits of maintaining the heritage language as a vehicle toward bilingualism as these students are vital to our current educational system (Greymorning, 1997; Reyner, 1999). Heritage language students are potentially able to become bilingual and biliterate; they are able to co-exist 
linguistically and culturally in their schools, homes, and places of employment.

Legislators, administrators, teachers, parents, and educational policy makers should be encouraged to recognize the need to implement a policy that creates a curriculum for heritage language learners that will promote bilingualism (Crystal, 2000). This first step is to shift the perception of students who move to the United States toward parity with other countries that facilitate and encourage students communicating in more than one language.

Presently, heritage language students are located in the pendulum of a disjointed government that does not recognize heritage language as a benefit, but as a hindrance (Bransford, Brown, \& Cocking, 2000; Cummins, 2005). The federal government provides limited funds for studying critical languages and sends scarce resources to states for specific foreign language programs. ${ }^{23}$ These are primarily monetary transactions with expectations that the government obtains some benefits in exchange for their funding. Heritage language is an effective vehicle toward bilingualism, but the policies are created at the expense of research in this field. In other words, policies are overly simplified while sound research is undervalued by the decision makers (Bransford et al., 2000; Cummins, 2005; Evans \& Hornberger, 2005). As a result, only a few of the policies regarding heritage language and bilingualism are valuable and cohesive. The political climate for lobbying for and against heritage language and bilingual education is charged with distorted convictions, rather than serious studies of language and learning (e.g., Proposition 227 in California). As a result, policy makers, whose interests are often subordinated by personal ideological concerns, create pedagogical decisions on behalf of

\footnotetext{
${ }^{23}$ For additional information please visit http://www2.ed.gov/programs/flapsea/index.html
} 
the students, parents, administrators, and teachers. While policies are evolving, the heritage language students themselves are their sole advocates since teachers and families are not relaying the information. The students will have to combat the political stance with strong personal convictions guided by sound reasoning that heritage language and bilingualism are beneficial for the students and for the United States (Cummins, 2005).

\section{Recommendation for Future Researchers}

Conducting research on heritage language and bilingualism requires an in-depth exploration of additional variables. Specifically, topics such as intergenerational immigrants, culture, cognition, curriculum and policy are based on issues that were identified by the literature and recognized by the present study.

A longitudinal research of first, second and third generation immigrants from various regions of the world would provide more answers to questions related to the value of heritage language and bilingualism. The students' responses can be subsequently followed through a period of time and checked for possible variations. Although there is a substantial body of quantitative research that has investigated the decrease of heritage language, the focus of a longitudinal study may examine possible related variables associated with heritage language attrition and bilingualism—i.e., social contexts, gender, and place of birth. Perhaps the maintenance of the heritage language phenomenon described in the present study only relates to the American Continent and Caribbean, rather than other parts of the world. It must be noted that this research only analyzed data from students from three different countries and students from other regions of the world may yield different results. 
Furthermore, a study of culture may also offer fundamental questions regarding current heritage language learning in order to foster bilingualism: To what extent does culture promote heritage language and bilingualism? Is any decline of heritage language and subsequently bilingualism related to the imposition of studying about language rather than incorporating culture? Are family mentors and school mentors consequential in the perception of heritage language maintenance? What are some specific ramifications of heritage language maintenance when mentors influence the perceptions of the student? If so, to what degree do mentors influence the student?

A second set of fundamental questions is also worth considering in regards to cognition. For example, does an in-depth understanding of the benefits of bilingualism on cognition increase the learning of both languages? Would the understanding of cognition propel the study of heritage language among first, second, and third generations of heritage language students? Are the cognitive benefits more valued by the students than the benefits for future employment?

In addition, further research in curriculum seems necessary to answer important questions if students were able to participate in curriculum design. For example, would their participation increase the number of heritage language learners in heritage language programs? Would the programs become more successful? Should the heritage language curriculum be developed by monolinguals?

Finally, further research is needed to explore the effects of specific language policies on heritage language and bilingualism. Specifically, to what extent does specific language policy create an imposition on any student? How are teachers, parents, and administrators able to evade current English-only policies? Should the United States 
adopt a national policy for heritage language learning and bilingualism? Should the federal government allow individual states to decide language policies? Is there an ideal position regarding heritage language programs in the school districts, the states, and the federal government? And, should the federal government superimpose dual language education on the United States?

\section{Conclusion}

The present research found that students from Brazil, Haiti, and Jamaica have similarities and differences in their understanding of the value of heritage language and bilingualism. The findings revealed some specific references that can be utilized in the development of current heritage language programs, policies, and curricula.

The results obtained through this study shed light on a population that is seldom addressed, yet their insight was exceptionally revealing and provides guidance for future analyses. The heritage language speaker possesses the language bases to be bilingual, but the school curriculum, policies, and mentors may hinder their ability to become bilingual. The students' desire to study their own language is also an important factor toward bilingualism because students who are interested in maintaining the language consider studying culture a more meaningful way to learn their heritage language. One must then wonder if there is a disjuncture between the content of typical foreign languages classes and the goals and desires of heritage language learners who attend them.

For example, a close analysis of the heritage language courses in Haitian Creole and Portuguese (Appendices H and I) adopted by the Florida Department of Education were originally developed for the instruction of foreign language, not heritage language. 
The general framework shows that students are to be assessed in four skills (listening, speaking, reading and writing) and subsequently within three modes of communication (interpersonal, interpretive, and presentational). This approach leaves out important existing resources that heritage language students already possess, such as the knowledge of their own culture. The current approach is simply assessing students in discrete skills, and leaves behind the knowledge base that can continue to excite students' language development. The American Council for Teachers of Foreign Languages (ACTFL) standards, ${ }^{24}$ which guides current heritage language teaching, promotes pedagogy based solely on the concepts of communication, cultures, connections, comparisons, and communities, also known as the " 5 C's." However, the success of the heritage language students in becoming bilingual may depend on a sixth standard—a sixth C—-that may inculcate aspects of cognition. That is, the students may find cognition a stronger reason for learning a heritage language and become bilingual as compared to simply learning the language for future employment. In other words, bilingual students’ academic experiences—-perhaps through the comparison of their heritage language with their target language—could spark students’ realizations of their cognitive abilities regarding academic scholarship (O’Malley \& Chamot, 1994). ${ }^{25}$

Society must continue to invest in providing opportunities for students to maintain their heritage language. Guardado (2002) makes a strong argument for teachers and parents to speak positively with children about heritage language in order to encourage

\footnotetext{
${ }^{24}$ Pleas see the entire document at http://www.actfl.org/files/public/StandardsforFLLexecsumm_rev.pdf

${ }^{25}$ Please note that learning strategies such as planning, organizing, evaluating, and predicting (all separate language skills) are used as detailed in the Cognitive Academic Language Learning Approach by

J. Michael O’Malley and Ann Uhl-Chamot (1994).
} 
them to use it and maintain it. However, this approach must be guided by other important rationales for maintaining the language and becoming bilingual. For example, the research-based conclusion clearly indicates that such an approach to bilingualism “ultimately pay[s] cognitive and academic dividends” (Crawford, 1998) and a welldesigned program is able to enhance school achievement without risking English acquisition. Developing fluent bilingual students that are validated must remain a goal. Supporters of heritage language maintenance and bilingualism should continue to demand that the curriculum and policy duplicate effective language and culture programs that adapt to the oscillating conditions of the heritage language student.

Politically speaking, the conclusion of this study supports an educational rationale for heritage language as a vehicle toward bilingualism, despite the limited in-depth understanding of heritage language students about its benefits. Current policy endorses English-only practices, but the legitimatization of heritage language students in their desire to maintain their heritage language, and become bilingual, belongs to the students, and is an insuperable condition that has the potential to continue supporting students as self-advocates for their cause. 


\section{REFERENCES}

Ada, F., \& Campoy, C. (2004). Authors in the classroom: A transformative education process. New York, NY: Pearson.

ACTFL (1983). Proficiency Guidelines. New York, NY: Hastings-on-Hudson.

Agbo, S. (2004). First nations perspectives in transforming the status of culture and language in schooling. Journal of American Indian Education, 43(1), 1-31.

Alcoff, L. (1991). The problems of speaking for others. Cultural Critique, 2, 5-32.

Alleyne, Mervin. (1989). The Roots of Jamaican Culture. London: Pluto Press

Alsop, C. K. (2002). Home and away: Self-reflexive auto/ethnography. Forum: Qualitative Social Research, 3, 3-18.

Anderson, N. M. (1981). Foundations of information integration theory. New York, NY: Academic Press.

Anstrom, K. (1996). Defining the limited-English proficient students population. National Clearinghouse of Bilingual Education, 1(9), 1-8.

Anthias, F. (2001). The material and the symbolic in theorizing social stratification: Issues of gender, ethnicity and class. British Journal of Sociology, 52(3), 367-390.

Arriagada, P. A. (2005). Family context and Spanish-language use: A study of Latino children in the United States. Social Science Quarterly, 86(3), 599-619.

Arrieta, E., \& Dwyer, E. (2003, November). Heritage learners and language maintainers: A survey of attitudes in South Florida. Poster session presented at the annual meeting of American Council of Teachers of Foreign Languages. Philadelphia, PA.

August, D., \& Hakuta, K. (Eds.). (1997). Improving schooling for language-minority children. A Research Agenda. Washington, DC: National Academy Press.

Baker, C. (2001). Foundations of bilingual education and bilingualism.

Clevedon, England: Mutilingual Matters Ltd.

Banks, J., \& McGee, C. (2006). Multicultural education: Issues and perspectives. Hoboken, NJ: John Wiley \& Sons. 
Bartholomew, K., Henderson, \& Marcia, J. (2000). Coded semistructured interviews in social psychological research. In H.T. Reis \& C. Judd. (Eds.), Handbook of research: Methods in social and personally psychology (pp. 286-312). Cambridge, UK: Cambridge University Press.

Beaudrie, S., \& Ducar, C. (2005). Beginning level University heritage language programs: Creating a space for all heritage language learners. Heritage Language Journal, 3, 1-17.

Bialystock, E. (2001). Bilingualism in development: Language, literacy \& cognition. New York, NY: Cambridge University Press.

Birch, Gary (1998). Concept development through content instruction in the mother tongue of NESB secondary students with little or inadequate previous formal instruction. Washington, DC: Clearinghouse on Language and Linguistics. (ERIC Document Reproduction Service No. ED 401716)

Blaikie, N. (2000). Designing social research: The logic of anticipation. Cambridge, UK: Polity.

Bogdan, C., \& Biklen, S. (1998). Qualitative research in education: An introduction to theory and methods ( $3^{\text {rd }}$ ed.). Needham Heights, MA: Allyn \& Bacon.

Bordieu, P. (1977). Reproduction in education. SAGE studies in social education change. Beverly Hills, CA: Sage.

Brandt, E., \& Youngman, V. (1989). Language renewal and language maintenance: A practical guide. Canadian Journal of Native Education, 2(16), 42-77.

Bransford, J. D., Brown, A., \& Cocking, R. (2000). How people learn: Brain, mind, experience, and school. Washington, DC: National Academy Press.

Briñol, P., \& Petty, R. (2005). Individual differences in attitude change. In D. Abarracin, B. Johnson, \& M. P. Zanna (Eds.), The handbook of attitudes (pp. 575-616). Mahwah, NJ: Lawrence.

Bronwyn, C. (2003). Working with young English language learners: Some considerations. Washington, DC: Clearinghouse on Languages and Linguistics. (ERIC Document Reproduction Services No. 481690)

Bryant, L., \& Hoon, E. (2006). How can the intersections between gander, class, and sexuality be translated to an empirical agenda? International Journal of Qualitative Methods. 5(1), 1-12. 
Brilliant, J. J. (2000). Issues in counseling immigrant college students. Community College Journal of Research and Practice, 24, 577-586.

Butler, J. (1990). Gender trouble: Feminism and the subversion of identity. New York, NY: Routledge.

Campbell, R. (1998). Conserving National language resources: How we can build on he bilingual skills of heritage language students. In M. Met (Ed.). Critical issues in early second language learning: Building for our children's future (pp, 84-88). Glenview, IL: Scott Foresman-Addison Wesley.

Carrasquillo, A., \& Rodriguez, V. (2002). Language minority students in the mainstream Classroom $\left(2^{\text {nd }}\right.$ ed.). Tonawanda, NY: Multilingual Matters.

Carrigo, D. (2000). Just how much English are they using? Teacher and students Language distribution patterns between Spanish and English, in upper-grade, two- way immersion Spanish classes. Unpublished doctoral dissertation, Harvard University, Cambridge, MA.

Cassell, C., \& Symon, G. (2004). Essential guide to qualitative methods in organizational research. Thousand Oaks, CA: Sage

Chevalier, J. F. (2004). Heritage language literacy: Theory and practice. Heritage Language Journal, 2(1), 1-19.

Cho, G., Shin, F., \& Krashen, S. (2004). What do we need to know about heritage languages? What do we need to know about them? Multicultural Education, 11(4), 23-26.

Clyne, M. (2004). Toward an agenda for developing multilingual communication with a community base. In J. House and J. Rehbein, Multilingual communication (pp. 19-39). Philadelphia, PA: John Benjamin Publishing.

Collier, V.P. (1992). A synthesis of studies examining long-term language-minority student data on academic achievement. Bilingual Research Journal, 16, 187-212.

Collison, M. (1994). Spanish for native speakers. The Chronicles of Higher Education, 40(22) 15-16.

Crawford, J. (1992). Hold your Tongue: Bilingualism and the Politics of English Only. Reading, Massachusetts: Addison Wesley Publishing Company.

Crawford, J. (1995). Bilingual Education: History, Politics, Theory and Practice (3 ${ }^{\text {rd }}$ ed.). Los Angeles, CA: Bilingual Educational Services. 
Crawford, J. (1996). Revising the Lau decision: 20 years after. Retrieved February 14, 2008 from James Crawford's Web site: http//www.outworld.compuserve.com/homepages/JWCrawford/summing.htm

Crawford, J. (1998). The political paradox of bilingual education. Retrieved April 21, 2010from James Crawford's Web site: http://www.languagepolicy.net/excerpts/paradox.html

Crawford, J. (2006). Loose Ends in a Tattered Fabric: The Inconsistency of Language Rights in the United States. Retrieved from http://users.rcn.com/crawj/langpol/Crawford_U.S._Language_Rights.pdf

Crystal, D. (2000). Language death. New York, NY: Cambridge University

Cummins, J. (1994). The Acquisition of English as a Second Language, In SpangenbergUrbschat, K. \& Pritchard, R. (Eds.), Reading instruction for ESL students. Newark. DE: International Reading Association.

Cummins, J. (2005). A proposal for action: Strategies for recognizing heritage language competence as a learning resource within the mainstream classroom. The Modern Language Journal, 89, 585- 592.

Davies, D., \& Dodd, J. (2002). Qualitative research and the question of rigor. Qualitative Health Research, 12(2), 279-289.

Delgado, G. (1994). Socializing young children in Mexican-American families; An intergenerational perspective. In P. Greenfield \& R. Cocking (Eds.), Cross cultural roots of minority child development (pp. 394-409). Hillsdale, NJ: Lawrence Erlbaum.

Denzin, N. K. (1997). Interpretative ethnography: Ethnographic practice in the $21^{\text {st }}$ century. Thousand Oaks, CA: Sage

Dewaele, J-B. (2005). Sociodemographic, psychological and politicultural correlates in Flemish students' attitudes toward French and English. Journal of Multilingual and Multicultural Development, 26, 118-138.

Diaz, R. (1983). Thought and two languages: The impact of bilingualism on cognitive development. Review of Research in Education, 10, 23-54.

Douglas, M. (2005). Pedagogical theories and approaches to teach young learners of Japanese as a heritage language. Heritage Language Journal, 3(1), 1-19. 
Dressler, W. (1991). The sociolinguistic and patholinguistic attrition of phonology, morphology and morphophology. In E. Herber, W. Seliger, \& R. Vago (Eds.), First language attrition (pp. 99-112). Cambridge, MA: University Press.

Eisner, E.W. (1981). On the differences between scientific and artistic to qualitative research. Educational Researcher, 10(4), 5-9.

Epstein, J. (2001). School, Family and Community Partnership: Preparing Educators and Improving Schools. Boulder, CO: Westview Press.

Evans. B., \& Hornberger, N. (2005). No child left behind and unfeeling federal language education policy in the United States. Language Policy, 4, 87-106.

Fabrigar, L., MacDonald, T., \& Wegener, D. (2005).The structure of attitudes. In D. Abarracin, B. Johnson, \& M. P. Zanna (Eds.), The handbook of attitudes (pp. 79-124). Mahwah, NJ: Lawrence Erlbaum.

Farber, N. (2006). Conducting qualitative research: A practical guide for school counselors. Professional School Counseling, 9(5), 367-75.

Fishman, J.A. (1964). Language maintenance and shift as a field of inquiry. Linguistics, 9, 32-70.

Fishman, J.A. (1991). Reversing language shift: Theoretical and empirical foundations of assistance to threatened languages. Clevedon, England: Multilingual matters.

Fishman, J.A. (2001). 300 plus years of heritage language education in the United States. In J.K. Peyton, D.A Rananrd, \& S. McGinnis (eds.), Heritage languages in America: Blueprint for the future (pp. 81-98) Washington, DC \& McHenry, IL: Center for Applied Linguistics \& Delta Systems.

Fortune, T. (2001). Understanding immersion students' oral language use as a mediator of social interaction in the classroom. Doctoral dissertation, University of Minnesota, Minneapolis.

Furman, R., Lietz, C., \& Langer., C. (2006). The research poem in international social work: Innovations in qualitative methodology. International Journal of Qualitative Methods, 5(3), 1-8.

Gibbons, F.; Lane, D. J.;Gerrard, M.; Pomery, E.; \& Lautrup, C. (2002). Drinking and driving: A prospective assessment of the relation between risk cognitions and risk behavior. Risk Decision and Policy 7, 267-283. 
Glaser, B. G., \& Strauss, A.L. (1967). The discovery of grounded theory: Strategies For qualitative research. Chicago, IL: Aldine.

Gluck, S. B., \& Patai, D. (Eds.). (1991). Women's words: The feminist practice of oral history. New York, NY: Routledge.

Golafshani, N. (2003). A Comparative discussion of the notion of validity in qualitative and quantitative research. The Qualitative Report, 4(3). Retrieved March 5, 2008. from http://www.nova.edu/sss/QR/QR4-3/winter.html

Gonzalez, V. (2001a). The role of socioeconomic and sociocultural factors in language minority children's development: An ecological research view. Bilingual Research Journal, 25, 1-28.

Gonzalez, V. (2001b).Immigration: Education's story past, present and future. College Board Review, 25, 24-31.

Graymorning, S. (1997). Going beyond words: The Arapaho immersion program. In J. Reyhner (Ed.), Teaching indegenous languages (pp. 22-30). Flagstaff, AZ: Northern Arizona University.

Griffee, D. (2005). Research tips: Interview data collection. Journal of Developmental Education, 28(3), 36-37.

Guardado, M. (2002). Loss and maintenance of first language skills: Case studies of Hispanic families in Vancouver.Canadian Modern Language Review, 58(3), 341363.

Hae-Young, K. (2003).Profiles and perspectives of heritage language Korean learners. Paper presented at the AALL and APSI pedagogy group presentation conference. Retrieved October 16, 2007, from http://www.duke.edu/web/aal/presentation.pdf

Hakuta, K., Butler, Y., \& Witt, D. (2000). How long does it take English learners to attain proficiency? Policy Report 2000-1.University of California Linguistic Minority Research Institute. Retrieved August 22, 2005 from http://lmri.ucsb.edu/resdiss/2/pdf_files/hakuta.pdf

Hayes, S (1991). A century of curricular perspectives: which curricularist has been the most influential? Education Resources Information Center. (ERIC Document Reproduction Service No. ED3662350)

Hinton, L. (1999). Involuntary language loss among immigrants: Asian-American linguistic autobiographies. Retrieved February 23, 2008, from http://www.cal.org/resources/digest/involuntary.html 
Hoepft. M. (1997). Choosing qualitative research: A primer for technology education Researchers. Journal of Technology Education, 9(1) 1-17.

Hooghe, M. (2007). Social capital and diversity generalized trust, social cohesion and regimes of diversity. Canadian Journal of Political Science, 40(3), 709-32.

Imbens-Bailey, A. (1996). Ancestral language acquisition: Implications for aspects of ethnic identity among Armenian-American Children. Journal of language and social psychology, 15(4), 422-443.

Ishizawa, H. (2004). Minority language use among grandchildren in multigenerational homes. Sociological Perspectives, 47(4), 465-483.

Jackson, S. (1996). Heterosexuality as a problem for feminist theory. In L. Adkins \& V. Merchant (Eds.), Sexualizing the social: Power and the organization of sexuality (pp. 15-34). London: McMillan.

James, D. (1997). Psychosocial risks of immigrant students. The Education Digest, 63, 51-53.

Johnson, B. R. (1997). Examining the validity structure of qualitative research. Education, 3, 282-292.

Kagan, O., \& Dillon, K. (2001). A new perspective on teaching Russian: Focus on the heritage learner. Slavic and East European Journal, 45(3), 507-518.

Kirk, J., \& Miller, M. L. (1986). Reliability and validity in qualitative research. Newbury Park, CA: Sage.

Kloss, H. (1998). The American bilingual tradition. Washington, D.C; Center for Applied Linguistics.

Kondo-Brown, K. (2005). Differences in language skills: Heritage language learner subgroups and foreign language learners. The Modern Language Journal, 84(4), 563-581.

Krashen, S. (1996).Under attack; A case against bilingual education. Culver City, CA: Language Education.

Krosnick, J., Judd, C., \& Wittenbrink, B. (2005). The measurement of attitudes. In D. Abarracin, B. Johnson, \& M.P. Zanna (Eds.), The handbook of attitudes (pp. 21-78). Mahwah, NJ: Lawrence Erlbaum.

Kvale, S. (1996). Interviews: An introduction to qualitative research interviewing. Thousand Oaks, CA: Sage. 
Lai, M. (2005). Language attitudes of the first postcolonial generation in Hong Kong secondary schools. Language in Society, 34(1), 363-388.

Laird, J., \& Thompson, N. (1992). Psychology. Boston, MA: Houghton Miffling.

Lambert, W. E. (1985). Some cognitive and sociocultural consequences of being bilingual. In J. Alatisand \& J. Staczek (Eds.), Perspectives on bilingualism and bilingual education, (pp. 116-131). Washington, DC: Georgetown University Press.

Lambert, W. E., \& Klineberg, O. (1967). Children's views of foreign people. NY: Appleton-Century-Crofts.

Landry, R. (1974). A comparison of second language learners and monolinguals on divergent thinking tasks at the elementary school level. Modern Language Journal, 58, 10-15.

Lane, S. (2003). Developing novice teachers as change agents: Student teacher placements “against the grain.” Teacher Education Quarterly, 30(2) 55-68.

Lantolf, J., \& Sunderman, G. (2001). The struggle for a place in the sun.rationalizing foreign language study in the twentieth century. Modern Language Journal, 85, 525.

Lasagabaster, D. (2005). Attitudes toward Basque, Spanish and English: An analysis of the most influential variables. Journal of Multilingual and Multicultural Development, 26, 296-314.

Lau v. Nichols 1973, 414 U.S. 563, 94 S. Ct. 786 (1974).

Lee, J. S. (2005). Through the learners' eyes: Reconceptualizing the heritage and nonheritage language learners of the less commonly taught languages. Foreign Language Annals, 38(4), 554-567.

Lee, S. K. (2002). The significance of language and cultural education on secondary achievement: A survey of Chinese-American and Korean-American students. Bilingual Research Journal 26(2), 327- 337.

Leech, B. (2002). Asking questions: Technique for semistructured interviews. Political Science \& Politics, 34(4), 665-668

Leweling, V., \& Peyton., K. (1999). Spanish for native speakers: Developing dual language proficiency. ERIC Digest. Retrieved from www.cal.org/ericcll 
Lewis, G. (1980). Bilingualism and bilingual education. Albuquerque, NM: University of New Mexico Press.

Lewis, M. (1995). Focus group in qualitative research: A review of the literature. Action Research Electronic Reader. Sydney, Australia: University of Sydney. Retrieved from http://www.scu.edu.au/schools/gcm/ar/arr/arow/rlewis.html

Lofland, J., \& Lofland L. (1984). Analyzing social settings. Belmont, CA: Wadsworth Publishing.

Lucas, T. (1993). Secondary schooling for students becoming bilingual: Issues and practices. In M, Arias \& U. Casanova (Eds.), Bilingual education: Politics, Research, and Practice (pp. 113 -143). New York: The National Society for the Study of Education.

Luo, S. H., \& Wiseman, R.L. (2000). Ethnic language maintenance among Chinese immigrant children in the United States. International Journal of Intercultural Relations, 24(3), 307.

MacQuillan, J. (1996). How should heritage languages be taught?: The effects of a free voluntary reading program.Foreign Language Annals, 29, 56-72.

Magiste, E. (1986). Selected issue in second and third language learning. In J. Vaid, Language Processing in Bilinguals: Psycholinguistic and Neuropsychological perspectives (pp. 97-122). Hillsdale, NJ: Lawrence Erlbaum.

McCarty, T. L. (2002).A place to the Navajo: Rough Rock and the Struggle for selfdetermination in indigenous schooling. Mahwah, NJ: Lawrence Erlbaum.

Merriam, S. B. (1998).Qualitative research and case study application in education. San Francisco, CA: Jossey-Bass.

Merriam, S. B. (2002).Qualitative research in practice: Examples for discussion and analysis. San Francisco, CA: Jossey-Bass.

Miles, M. B., \& Huberman, M.A. (1994). Qualitative data analysis (2 ${ }^{\text {nd }}$ ed.). Thousand Oaks, CA: Sage

Morse, J., \& Field, P. (1995). Qualitative research methods for health professionals. Thousand Oaks, CA: Sage.

Mouw, T., \& Xie, Y. (1999). Bilingualism and the academic achievement of first-and second generation Asian-Americans: Accomodation with or without assimilation? American Sociological Review, 64(2), 232-252. 
No Child Left Behind Act of 2001. Public Law 107-110 (January 8, 2002). United States Congress.

Norrid-Lacey, B., \& Spencer, D. (1999, April).Dreams I wanted to be Reality: Experiences of Hispanic Immigrant Students at an Urban High School. Paper presented at the Annual Meeting of the American Educational Research Association, Montreal, Canada.

Norton, B. (1997). Language, identity and the ownership of English. TESOL Quarterly. 31(3) 409-429.

Ochs, E., \& Schiefellin, B. (1984). Language acquisition and socialization: Three developmental stories. In R. Shweder \& R. LeVine (Eds.), Culture theory: Essays on mind, self, and emotion (pp. 276-320). Cambridge, MA: Cambridge University Press.

Ogbu, J. (1982). Cultural discontinuity and schooling. Anthropology and Education Quarterly, 13(4), 290-307.

Omaggio-Hadley, A. (1993).Teaching language in context. Boston, MA: Heinle \& Heinle Publishers.

O’Malley, J., \& Chamot, A.U. (1994). Implementing the cognitive academic language learning approach. White Planes, NY: Addison-Wesley Publishing.

Ovando, C., \& Collier, V. (1998). Bilingual and ESL classrooms: Teaching in multicultural contexts. Boston, MA: Mc-Graw Hill.

Palm Beach County. (2006). Introduction. Retrieved February 9, 2007, from http://www.wikipedia.org/wiki/Palm_Beach\%2C_Florida

Pappamihiel, E. (2003). Effective practices and principles to support English language Learners in the early childhood classroom. Childhood Education, 4, 200-204.

Patton, M. (1989). Qualitative evaluation methods. Beverly Hills, CA: Sage.

Patton, M. (1990). Qualitative evaluation and research methods ( $2^{\text {nd }}$ ed.). Newbury Park, CA: Sage.

Peal, E., \& Lambert, W. E. (1962).Relation of Bilingualism to intelligence. Psychological Monographs, 76, 1-23. 
Pease-Alvarez, L. (2002). Moving beyond linear trajectories of language shift and bilingual language socialization. Conversations within Mexican-descent families: Diverse contexts for language socialization and learning. Hispanic Journal of Behavioral Sciences, 24(2), 114-137.

Perkins, L. M. (2000). The new immigrants and education: Challenges and issues. Educational Horizons, 78(2), 67-71.

Plyler v. Doe, 457 U.S. 202 (1982).

Portes, A., \& Hao, L. (2002). The price of uniformity: language, family and personality adjustment in the immigrant second generation. Ethnic and Racial Studies, 25(6), 889-912.

Portes, A., \& Schauffler, R. (1994). Language and the second generation: Bilingualism yesterday and today. The International Migration Review, 28(4), 640-661.

Potowski, K. (2004). Student Spanish use and investment in a dual immersion classroom: Implications for second language acquisition in heritage language maintenance. The Modern Language Journal, 88(1), 75-101.

Pryce, T (1997). Similarities between the debates on Ebonics and Jamaican. Journal of Black Psychology, 23(1), 238-241.

Ramirez, A. (2000). Linguistic notions of Spanish among youths from different Hispanic groups. In A. Roca (Ed.), Research on Spanish in the U.S. (pp.284-295) Somerville, MA: Cascadilla Press.

Reay, D. (1997). Feminist theory, habitus, and social class: Disrupting notions of classlessness. Women's Studies International Forum, 20(2), 225-233.

Reis, H. T., \& Judd, C.M.(Eds.). (2000). Handbook or research: Methodology in social and personality psychology. New York, NY: Cambridge University Press.

Reyhner, J. (1999, June). Maintaining and developing indigenous languages. Paper presented at the Annual Stabilizing Indigenous Language Symposium. Albuquerque, New Mexico.

Rivera-Mills, S. (2001). Acculturation and communicative need: Language shift in an ethnically diverse Hispanic community. Southwest Journal of Linguistics, 20(2), 211-221.

Roca, A., \& Marcos, K. (1999). Teaching Spanish to Spanish speakers. ERIC. Retrieved from http://www.cal.org/ericcll/faqs/rgos/sns/html 
Rong, X. L., \& Preissle, J. (1998). Educating immigrant students: What we need to know to meet the challenges. Thousand Oaks, CA: Corwin.

Rubin, H., \& Rubin, I. (1995). Qualitative interviewing: The art of hearing data. Thousand Oaks, CA: Sage.

Rummel, R.J. (1976). The conflict helix. Beverly Hill, CA: Sage.

Schecter, S., \& Bayley, R. (2004).Language Socialization in Theory and Practice. International Journal of Qualitative Studies in Education, 17(5), 605-625.

Scholte, J. (2000), Globalization: A critical introduction. New York: St. Martin Press.

School District of Palm Beach County (2008).Facts at a glance. Retrieved from http://www.palmbeach.k12.fl.us/publicaffairs

School District of Palm Beach County. (2008, August 8). LY report for High Schools. Retrieved from https://edw.palmbeach.k12.fl.us/edw/cgi-bin/upfcgi.exe

Schram, T. (2003). Conceptualizing qualitative inquiry: Mindwork for fieldwork in education. Upper Saddle River, NJ: Merril-Prentice Hall.

Schultz, A. (1967). The phenomenology of the social world (G. Walsh \& F. Lenhert, Trans.). Chicago, IL: Northwestern University Press.

Seidman, I. (2006). Interviewing as qualitative research: A guide for researchers in Educational the social sciences ( $3^{\text {rd }}$ ed.). New York, NY: Teachers College.

Shatz, M. (1991). Using cross-cultural research to inform us about the role of language in development: Comparison of Japanese, Korean, and English, and of German, American English, and American English. In M.H. Bornstein (Ed.), Cultural approaches to parenting (pp. 139-153). Hillsdale, NJ: Lawrence Erlbaum.

Sherman, R. R., \& Webb, R.B. (Eds.). (1988). Qualitative research in education: Focus and methods. Philadelphia, PA: The Farmer Press.

Shields, (1989). Standard English in Jamaica; A case for competing models. English Worldwide, 10(1), 41-53.

Siegel, S. (2004).A case study of one Japanese heritage language program in Arizona. Bilingual Research Journal, 28(1), 122 -133.

Skutnabb-Kangas, T. (Ed.). (1995). Multilingualism for all. Lisse, Netherlands: Swets \& Zeitlnger B.V. 
Slavin, R., \& Cheung, A. (2005). A synthesis of research of reading instruction for English language learners. Review of Educational Research, 75(2), 247-284.

Snyder, K, (2008). Living on the edge of chaos: Leading schools into the global age $\left(2^{\text {nd }}\right.$ ed). Milwaukee, WI: Quality Press.

Spiro, R., Vispoel, W., \& Schmitz, J (1987). Knowledge acquisition for application: Cognitive flexibility and transfer in complex content domains. Hillsdale, NJ: Lawrence Erlbaum Press.

Strauss, A., \& Corbin, J. (1990). Basic of qualitative research: Grounded theory procedures and techniques. Newbury Park, CA: Sage.

Suarez-Orozco, M. (1989).Central American refugees and US high School: A psychological study of motivation and achievement. Stanford, CA: Stanford University Press.

Tapani (2009). Is becoming a researcher some o kind of role-playing: Roles of the researcher in the process of forming identities,Reflexivity 7(3), 71-87.

Taylor, C. (1994). Multiculturalism: The politics of recognition. Princeton, NJ: Princeton University Press.

Thomas, W., \& Collier, V. (1997).School Effectiveness for Language Minority Students. Washington, DC: National Clearinghouse for Bilingual Education.

Tokuhama-Espinosa, T. (Ed.). (2003). The multicultural mind. Wesport, CT: Praeger.

Trochim, W. (2006). The research methods knowledge (3 ed.). Mason, OH: Atomic Dog Publishing.

Tse, L. (2000). The effects of ethnic identity formation on bilingual maintenance and development: An analysis of Asian American narratives. International Journal of Bilingual Education and Bilingualism, 3, 185-200.

Turner, B. A. (1981). Some practical aspects of qualitative data analysis: One way of Organizing the cognitive processes associated with the generation of grounded theory. Quality and Quantity, 15(3), 225-247.

United States Census Bureau. (n.d.). 2003 language use and English-speaking ability. Retrieved from http://www.census.gov/prod/2003pubs/c2kbr29.pdf

United States Census Bureau. (n.d.). 2006 quick facts. Retrieved From http://www.quickfacts.census.gov/qfd/states/12/12099.html 
Valdés, G. (1995). The teaching of minority as academic subjects: Pedagogical and theoretical challenges. Modern Language Journal.79(1), 299-328.

Valdés, G. (2000). The teaching of heritage languages: An introduction for SlavicTeaching professionals. In O. Kagan\& B. Rifkin (Eds.), The learning and teaching of Slavic languages and cultures (pp. 375-403). Blomington, IN: Slavica.

Valdés, G. (2001). Heritage language students: Profiles and possibilities. In J.K. Peyton, D.A. Ranard\& S. Mc Ginnis (Eds), Heritage languages in America: Preserving a national resource (pp. 37-77). Washington, DC: Center for Applied Linguistics.

Vaddes, G., \& Figueroa, R. (1994). Bilingualism and testing: A special case of bias. Norwood, N.J: Ablex.

Van Dijk, T. (1985). Handbook of discourse analysis: Dimensions of discourse. London United Kingdom: Academic Press.

Van Hook, J., Bean, F., \& Passel, J. (2005, September 1).Unauthorized migrants living in the United States: A mid-decade portrait. Washington, DC: Migration Information Source. Retrieved from http://www.migrationinformation.org/Feature/display.cfm?id=329

Van Manen, M. (1990). Researching lived experience: Human science for an action sensitive pedagogy. London, Canada: The University of Western Ontario.

Veltman, C. (1983). Language shift in the US. Amsterdam, Netherlands: Mouton.

Veltman, C. (1990). The status of the Spanish language in the United States at the beginning of the $21^{\text {st }}$ century. International Migration Review, 24(1), 108-123.

Veltman, C. (2000). The American linguistic mosaic: Understanding language shift in the United States. In S.L. McKay \& S.C. Wong (Eds.), New immigrants in the United States (pp. 58-93). Cambridge, United Kingdom: Cambridge University Press.

Visser, P., \&Krosnick, J. (1998). The development of attitude strength over the life cycle: Surge and decline. Journal of Personality and Social Psychology, 75, 1388-1409.

Weinberg, S. (1996). The reporter's handbook: A investigator's guide to documents and Techniques ( $3^{\text {rd }}$ ed.). New York, NY: St. Martin’s.

Wiley, T. (1998). The imposition of World War I era English-Only policies and the fate of German in North America. In T. Ricento \& B. Burnaby (Eds.), Language and politics in the United States and Canada, myth and realities (pp. 211-241). 
Wiley, T., \& Valdes, G. (2001). Heritage language instruction in the United States: A time for renewal. Bilingual Research Journal, 24(4), 1-5.

Witz, A., Halford, S., \& Savage, M. (1996). Organized bodies: Gender, sexuality and embodiment in contemporary organizations. In L. Adkins \& V. Merchant (Eds.), Sexualizing the social: Power and the organization of sexuality (pp.173-190). London, McMillan.

Wong-Fillmore, L.W. (1991). When learning a second language means losing the first. Early Childhood Research Quarterly, 6(3), 323-47.

Zaller, J., \& Feldman, S. (1992). A simple theory of the survey response: Answering questions versus revealing preferences. American Journal of Political Science, 36, 579-616.

Zhang, D. (2004). Home language maintenance among second generation Chinese American children. Working Papers in Educational Linguistics, 19(2), 1-10. 
APPENDIX A

CONSENT TO PARTICIPATE IN RESEARCH STUDY 


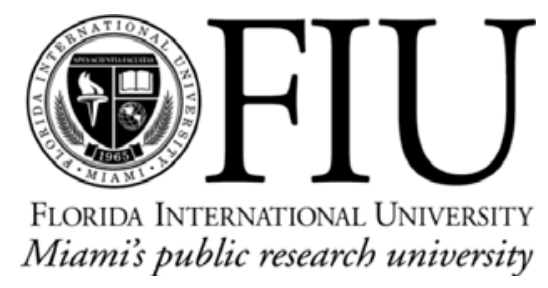

Title: Variation of in-depth understanding toward heritage language: Bilingualism among immigrant high school students.

We would like your child to be part in a research study. The investigator of this study is Edwin D. Arrieta, a doctoral student at Florida International University. The study will explore the attitudes of male adolescents and female adolescents toward maintaining their heritage language. This research will give the researcher insightful information about the attitude of young adolescents toward their heritage language, thus assisting language education professionals in many schools.

The study will include two interviews of approximately one hour and thirty minutes. The interviews will include questions about how your child feels about his or her native language.

There are no known risks related to the interview. Furthermore, your child is permitted not to respond any question should they so choose. In addition, you or you child may request to stop participating in the study at any time. Doing so will not place your child at any risk with respect to any penalty or judgment at the school or elsewhere.

In addition, there is no cost related to your child or to you. Please note that your child may not gain any direct benefit from being in the study. As a compensation for allowing your child to help, we will give a gift card as a token of appreciation.

You and your child must sign a form consenting to be part of the study. This form also explains the study. Your child will be asked to be part of the interviews if you grant your child permission and your child wants to be part of the study. Additionally, you and your child may ask questions about the study at any time.

Please note that all the data will be identified by random numbers. All data in the research is private and will not be shared with school officials or anyone directly related to the study unless required by law. The results of the study will be presented without any reference to individuals 
If you would like to know more about this research, your can contact Edwin Arrieta at (561) 798-7898. If you feel that your child was mistreated or have a questions about being in the study, you may also contact Dr. Patrice Price, the chairperson of the F.I.U Institutional Review Board at (305) 348- 2618.

If you agree for (name of your child) to be part of the study sign below

Signature of Parent

Date

I have explained the research procedures, subject rights and answered questions asked by the participants. I have offered him/her a copy of this informed consent form.

Signature of Witness

Date

Thank you in advance for your assistance in this research. Your assistance is appreciated.

Sincerely,

Edwin D. Arrieta 


\section{APPENDIX B}

ASSENT TO PARTICIPATE IN RESEARCH STUDY 


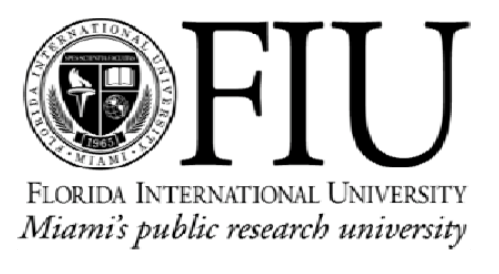

\section{ASSENT TO PARTICIPATE IN A RESEARCH STUDY}

Title: Attitudes towards heritage language among high school students.

My name is Edwin D. Arrieta and I am a doctoral student at Florida International University. You are being asked to participate in a research study. The study will look at your attitude(s) toward your native language.

We will need to obtain permission from your parent before you can help with the study. If you decide to help, you will be interviewed for one hour each time on two different occasions at your school.

1) We will ask you how you feel towards your native language.

2) The researcher will take notes, and tape record the conversation during the interview.

We expect everyone to feel different towards their native language, but the activity should take about an hour. There are not right or wrong answers. We want to know if there are certain attitudes that are helpful or not in maintaining a language.

There is no charge or payment for help. Speaking about your attitudes will not harm you in any way. If you get tired or upset you can ask for a break. We only want you to do your best. Your help with this project will not help or hurt your school grades. You or your parents may ask to stop participating at any time.

No one will know the attitudes about you, the information we learn about you is private. At the end of the study you will receive a small gift card to a fast food restaurant as a thank you for being part of the study.

If you have any questions you may ask me at any time. If you have questions about the study, you or your parent can call me, Edwin Arrieta, at 56I-644-0921. If you or your parent feel like you were not treated fairly during the study you may call Dr. Patricia Price at (305) 348-2618 or (305) 3482494.

If you would like to be in our study, sign your name here. You will be given a copy of this form.

Participant's Signature

Date

Investigator's Signature

Date 
APPENDIX C

\section{RESEARCH QUESTIONS}


Research Questions:

1. What in-depth understanding of the value of heritage language do students have about their own heritage language?

2. What is their in-depth understanding of the value of bilingualism?

3. Are there any differences in the answers associated with (a) gender, (b) place of birth, or (c) first language? 
APPENDIX D

SEMI-STRUCTURED INTERVIEW QUESTIONS 
Semi-structured interview questions as a conversational guide to answer the research questions:

1. How old are you? How old were you when you first came to the United States?

2. What grade are you in right now?

3. Where are you from?

4. What languages do you speak at home?

5. Are you from a city? Or a rural area?

6. How was your English when you first came to the United States?

7. Was it difficult to learn English?

8. Do you think it may be difficult to learn your language? Why?

9. When you started learning English did you spend the same amount of time studying it?

10. Do you spend time learning your native language? What do you do at home or school to maintain your language? Do you have specific examples?

11. Do you like your native language? Why? Do you like English more? 
12. What motivates you to learn your native language? What discourages you?

13. What language you rather use with friends? At home? Classes?

14. In your own life, how do you feel about equally learning English and your native language? Are both equally important? Why?

15. How do you feel or perceive about other students who learn English and their native language? What have you seen?

16. What would you recommend other students that may want to equally learn English and study and maintaining their native language?

17. Are you concerned about losing your native language?

18. Do you like to be around students that speak English or with those who speak your native language? How? Why? 
APPENDIX E

IRB CERTIFICATION 
IRB Certification

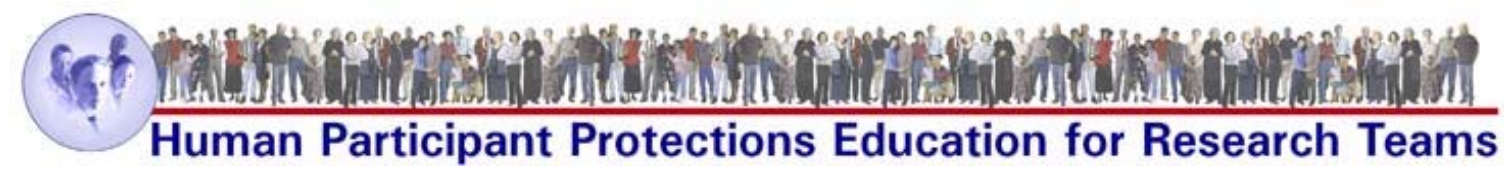

Completion Certificate

This is to certify that

Edwin Arrieta has completed the Human Participants Protection Education for

Research Teams online course, sponsored by the National Institutes of Health (NIH), on 01/27/2006.

This course included the following:

key historical events and current issues that impact guidelines and legislation on human participant protection in research.

ethical principles and guidelines that should assist in resolving the ethical issues inherent in the conduct of research with human participants. 
the use of key ethical principles and federal regulations to protect human participants at various stages in the research process.

a description of guidelines for the protection of special populations in research.

a definition of informed consent and components necessary for a valid consent. a description of the role of the IRB in the research process.

the roles, responsibilities, and interactions of federal agencies, institutions, and researchers in conducting research with human participants.

National Institutes of Health

http://www.nih.gov 
APPENDIX F

RCR TRAINING 


\section{CITI Collaborative Institutional Training Initiative}

Basic/Refresher Course - Human Subjects Research Curriculum Completion Report

$$
\text { Printed on }
$$

Learner: Edwin Arrieta (username: edwin2009)

Institution: Florida International University

Contact Information 121 Conaskonk Circle

Royal Palm Beach, Fl 33411 USA

Department: Curriculum and Instruction

Phone: 5616440921

Email: arrieta@palmbeach.k12.fl.us

Social/Behavioral Research Course:

Stage . Basic SBR Passed on 04/21/09 (Ref \# 2733957)

Required Modules Date Completed Score

Belmont Report and CITI Course Introduction $\quad$ 04/21/09 2/3 (67\%)

History and Ethical Principles - SBR $\quad$ 04/20/09 5/5 (100\%)

Defining Research with Human Subjects - SBR $\quad$ 04/20/09 3/5 (60\%)

The Regulations and The Social and Behavioral Sciences - SBR 04/20/09 5/5 $(100 \%)$ 
Assessing Risk in Social and Behavioral Sciences - SBR 04/20/09 5/5 (100\%)

Informed Consent - SBR 3/4 (75\%)

Privacy and Confidentiality - SBR 04/21/09 4/4 (100\%)

Research with Prisoners - SBR 04/21/09 4/4 (100\%)

Research with Children - SBR $\quad$ 04/21/09 4/5 (80\%)

Research in Public Elementary and Secondary Schools - SBR ～04/21/09 4/4 $(100 \%)$

$$
\begin{aligned}
& \text { International Research - SBR 04/21/09 4/4 (100\%) } \\
& \text { Internet Research - SBR 04/21/09 4/5 (80\%) }
\end{aligned}
$$

For this Completion Report to be valid, the learner listed above must be affiliated with

a CITI participating institution. Falsified information and unauthorized use of the CITI course site is unethical, and may be considered scientific misconduct by your institution.

Paul Braunschweiger Ph.D.

Professor, University of Miami

Director Office of Research Education

CITI Course Coordinator 
APPENDIX G

CODING BOX 


\section{Coding Box}

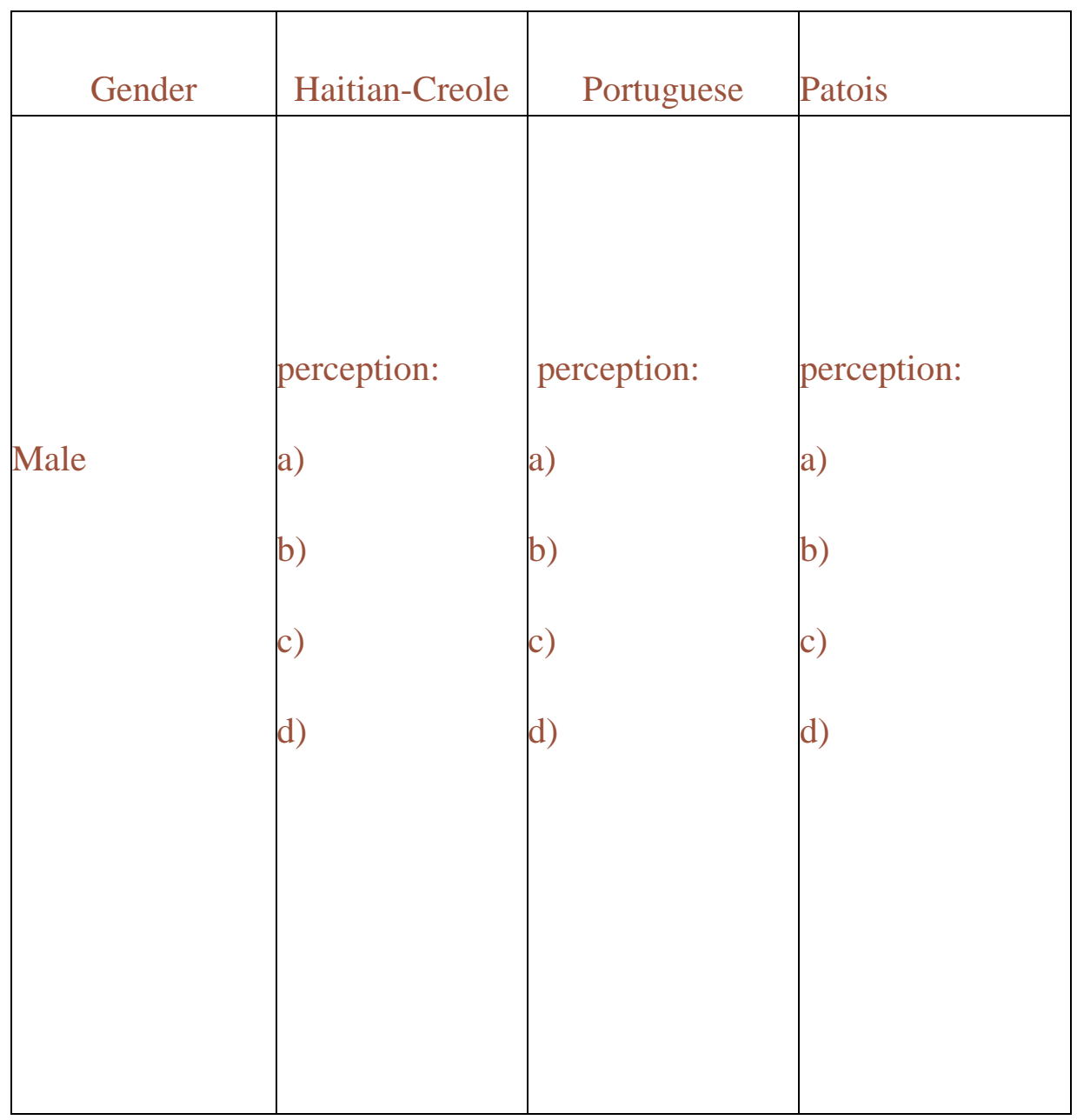




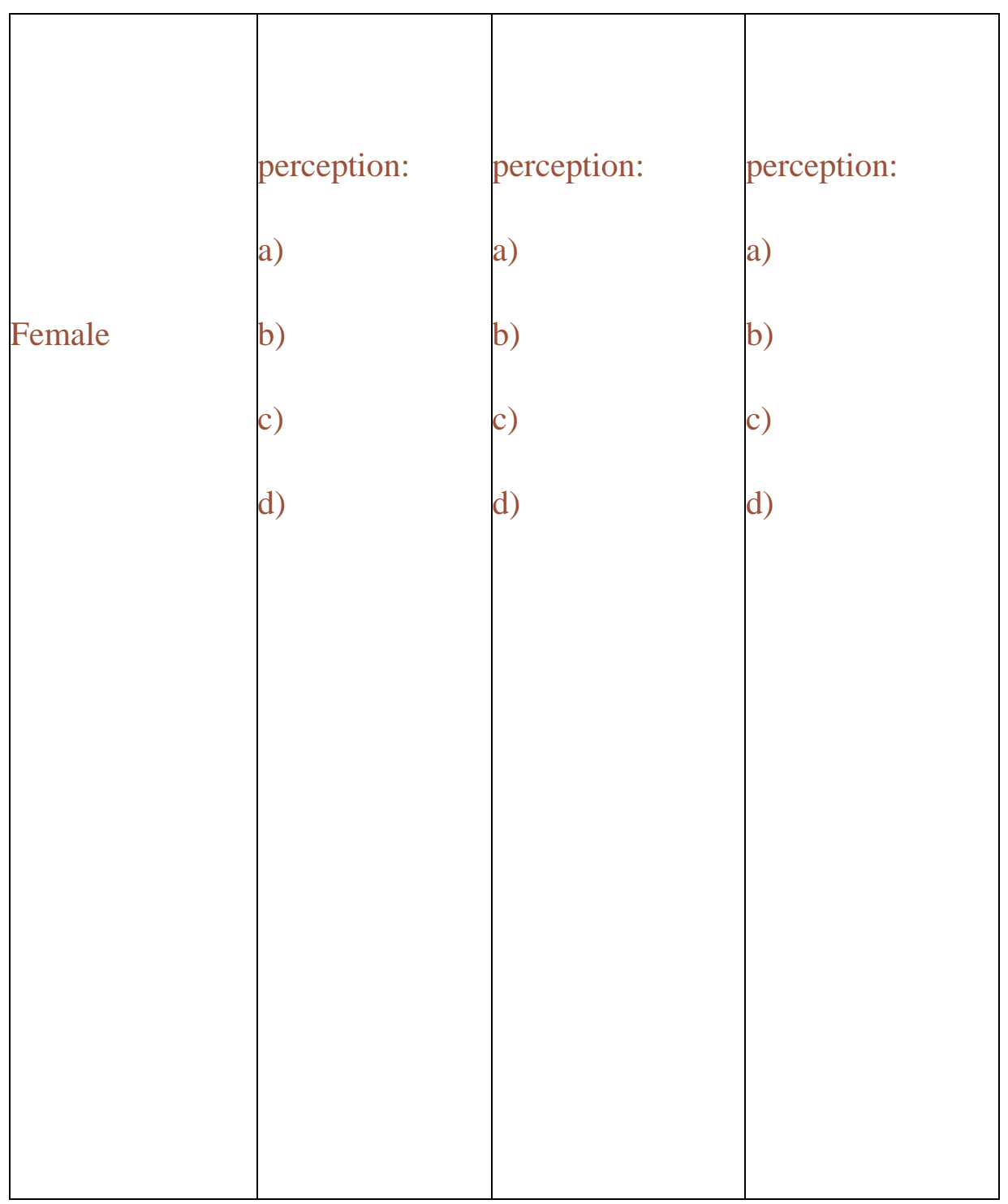




\section{APPENDIX $\mathrm{H}$}

COURSE DESCRIPTION: PORTUGUESE FOR PORTUGUESE SPEAKERS I 
Florida Department of Education

COURSE DESCRIPTION - GRADES 9-12, ADULT

Subject Area: Foreign Languages

Course Number: 0713340

Course Title: Portuguese for Portuguese Speakers I

Credit: 1.0

A. Major Concepts/Content. The purpose of this course is to enable students whose heritage language is Portuguese to develop, maintain, and enhance proficiency In their home language by reinforcing and acquiring skills in listening, speaking, reading, and writing, including the fundamentals of Portuguese grammar. The course content will reflect the cultural values of Portuguese language and societies. The course will enable students to gain a better understanding of the nature of their own language as well as other languages to be acquired.

The content should include, but not be limited to, the following:

- conversational expression of feelings, ideas, and opinions in Portuguese

- comprehension of spoken and written Portuguese

- oral and written presentation of information and ideas, in Portuguese, to an audience

- social interaction patterns within Portuguese culture

- connections between the Portuguese language and culture and other disciplines

- analysis and use of different patterns of communication an social interaction appropriate to a given setting

- critical response, in Portuguese, to a variety of literary forms

- use of a variety of strategies to construct meaning from informative, technical, and

literary texts

- use of writing processes to communicate information, ideas, and concepts, in

Portuguese, to a variety of audiences

This course shall integrate the Goal 3 Student Performance Standards of the

FloridaSystem of School Improvement and Accountability as appropriate to the content and processes of the subject matter.

Course student performance standards must be adopted by the district, and they must reflect appropriate Sunshine State Standards benchmarks.

Course Number: 0713340 - Portuguese for Portuguese Speakers I

B. Special Note. The benchmarks for this course are aligned with expected levels of language proficiency and literacy, rather than grade levels. Students should be placed in heritage language courses as appropriate to their levels of language and literacy 
proficiency.

C. Course Requirements. These requirements include, but are not limited to, the benchmarks from the Sunshine State Standards that are most relevant to this course. Benchmarks correlated with a specific course requirement may also be addressed by other course requirements as appropriate. Some course requirements in this course are not fully addressed in the Sunshine State Standards.

Both Foreign Languages and Language Arts benchmarks are included in this course. The Language Arts benchmarks should not be taught and assessed in isolation; instead they should be combined with the Foreign Languages benchmarks listed for this course.

After successfully completing this course, the student will:

1. Engage in conversation in Portuguese to express feelings, ideas, and opinions about a variety of topics (e.g., social science, humanities, the mass media, current event, etc.).

FL.A.1.2.1 express likes or dislikes regarding various objects, categories, people, and events present in the everyday environment.

FL.A.1.2.2 exchange information necessary to plan events or activities (e.g., picnics, birthday parties, science projects, and crafts).

FL.A.1.3.3 use appropriate vocabulary and cultural expressions to express the failure to understand a message and to request additional information (i.e., understand how to bridge gaps in communication in the target language).

FL.A.1.3.4 use repetition, rephrasing, and gestures effectively to assist in communicating spoken messages.

FL.A.1.4.2 rephrase and use indirect expressions to communicate a message in the target language.

FL.A.2.1.2 restate and rephrase simple information from materials presented orally, visually, and graphically in class.

LA.C.1.1.4 retell specific details of information heard, including sequence of events.

LA.C.2.1.2 recognize simple nonverbal cues, such as use of eye contact, smiles, simple hand gestures. 
Course Number: 0713340 - Portuguese for Portuguese Speakers I

2. Demonstrate understanding of spoken and written Portuguese on a variety of topics.

FL.A.2.2.2 answer or formulate questions about a variety of media experiences produced in the target language (e.g., video, radio, television, songs, or computer programs).

FL.A.2.2.3 organize information in spoken or written form about a variety of topics of academic and cultural interest (e.g., by making lists, categorizing objects, or organizing concepts).

FL.A.2.2.4 listen and read in the target language for leisure and personal enrichment (e.g., listen to, read, or view age-appropriate stories, plays, poems, films, or visual works of art).

FL.A.2.3.1 comprehend and interpret the content of authentic, written materials selected according to the familiarity of the topic and the scope of vocabulary and structure (e.g., personal letters and notes, pamphlets, newspapers and magazine articles, and advertisements). FL.A.2.3.2 comprehend and interpret the main ideas and details from television, movies, videos, radio, or live presentations produced in the target language.

FL.A.2.3.3 formulate and answer questions about the literary elements (e.g., plot, characters, main ideas, and supporting details) of authentic target-language literary selections.

LA.C.2.1.1 determine the main idea in a non-print communication.

3. Present information, concepts, and ideas to a variety of audiences through speaking and writing in Portuguese.

FL.A.3.2.1 describe important people (e.g., family members and friends) and objects present in his or her everyday environment and in school.

FL.A.3.2.3 give responses in spoken or written form (e.g., answering simple questions, formulating questions, and making simple statements) to age-appropriate stories, poems or other literature, songs, films, or visual works.

LA.C.3.1.4 use eye contact and simple gestures to enhance delivery.

LA.D.2.1.1 understand that word choice can shape ideas, feelings, and actions. 
Course Number: 0713340 - Portuguese for Portuguese Speakers I

4. Demonstrate understanding of social interaction patterns within Portuguese culture through participation in cultural activities. (Note: Benchmarks may address multiple target cultures associated with the heritage language.)

FL.B.1.1.1 participate in age-appropriate cultural activities (e.g., games, songs, birthday celebrations, storytelling, dramatizations, and role playing).

FL.B.1.2.1 recognize various activities and celebrations in which children participate in the target culture (e.g., games, songs, birthday celebrations, storytelling, dramatizations, and role playing). FL.B.1.2.2 identify patterns of behavior and the values, beliefs, or viewpoints typical of children in the target culture.

FL.B.1.2.3 experience and react to expressive and day-to-day aspects of the target culture enjoyed or produced by groups or individuals who belong to the target culture (e.g., children's songs, simple selections from authentic children's literature, artwork, typical foods, and types of dwellings).

FL.B.1.3.1 use appropriate verbal and nonverbal communication for daily activities with peers and adults.

FL.B.1.3.3 recognize simple themes, ideas, or viewpoints on social behavior or social interaction in various settings (e.g., school, family, and immediate community).

5. Apply knowledge of Portuguese language and culture to further knowledge of other disciplines.

FL.C.1.1.1 use simple vocabulary and phrases to identify familiar objects and concepts from other disciplines.

FL.C.1.1.2 participate in an activity in the target-language class that is based on a concept taught in a content class (e.g., shapes or relationships).

FL.C.2.1.1 use the target language to gain access to information that is only available through the target language or within the target culture

(listen to a story told in the target language).

FL.C.2.2.2 access information from a skit or play in the target language that is only available in the target culture.

FL.C.2.2.3 express knowledge of real objects and media intended for same-age native speakers in the target language and identify the major elements of the source material (e.g., what it is, why peers use it, and where it might be found). FL.C.2.2.4 restate and share information acquired from written texts in the context of group discussion.

Course Number: 0713340 - Portuguese for Portuguese Speakers I 
6. Analyze and use different patterns of communication appropriate to the setting. FL.D.1.1.1 know examples of word borrowing from one language to another. FL.D.1.2.2 recognize the similarities and differences between his or her native language and the target language in terms of the pronunciation, alphabet, and forms of written expression.

FL.D.1.4.1 know elements of the target language that signify time, and the similarities and differences between comparable linguistic markers in the target language and in his or her own language. (Note: In this course, students compare Portuguese and English.)

FL.D.1.4.2 understand and apply the target-language pronunciation, intonation, stress patterns, and writing conventions in a variety of contexts.

LA.D.1.1.1 recognize basic patterns in and functions of language (patterns such as characteristic sounds and rhythms and those found in written forms; functions such as asking questions, expressing oneself, describing objects or experience, and explaining).

LA.D.1.1.2 recognize the differences between language that is used at home and language that is used at school.

LA.D.2.1.3 recognize that use of more than one medium increases the power to influence how one thinks and feels.

7. Analyze and use different patterns of social interaction appropriate to the setting. FL.D.2.2.1 distinguish the similarities and differences between the patterns of behavior of the target culture related to recreation, holidays, celebrations and the patterns of behavior of the local culture. FL.D.2.2.2 recognize forms of the target language evident in the local culture (e.g., signs, symbols, advertisements, packages, displays, murals, songs, and rhymes).

FL.D.2.2.3 recognize some cultural aspects, viewpoints, and attitudes of people in both his or her own culture and the target culture relating to family, school, work, and play.

FL.D.2.3.1 understand cultural traditions and celebrations that exist in the target culture and in the native culture (e.g., holidays, birthdays, coming of age celebrations, and recreational gatherings).

FL.D.2.3.2 recognize the similarities and differences between music and songs from the target culture and those in the native culture.

FL.D.2.3.3 recognize the similarities and differences between attitudes about various topics found among teenagers in American culture and attitudes among teenagers in the target culture (e.g., surveys conducted through face-to-face contact or written exchanges). 
Course Number: 0713340 - Portuguese for Portuguese Speakers I

8. Demonstrate knowledge of wider communities of Portuguese language and culture. FL.E.1.2.1 know that many people in the United States use languages other than English on a daily basis.

FL.E.1.2.2 demonstrate an awareness of employment possibilities (and other applications) for those who are able to master the target language.

9. Respond critically to a variety of literary forms through speaking and writing in Portuguese.

LA.E.1.1.1 know the basic characteristics of fables, stories, and legends.

LA.E.1.1.2 identify the story elements of setting, plot, character, problem, and solution/resolution.

10. Use a variety of strategies to construct meaning from informative, technical, and literary texts written in Portuguese.

LA.A.1.1.2 identify words and construct meanings from text, illustrations, graphics, and charts using the strategies of phonics, word structure, and context clues.

LA.A.1.1.3 use knowledge of appropriate grade-, age-, and developmental-level vocabulary in reading.

LA.A.1.1.4 increase comprehension by rereading, retelling, and discussion.

LA.A.1.2.4 clarify understanding by rereading, self-correction, summarizing, checking other sources, and class or group discussion.

LA.A.2.1.1 determine the main idea or essential message from text and identify supporting information.

LA.A.2.1.3 read for information to use in performing a task and learning a new task.

LA.A.2.1.4 know strategies to use to discover whether information presented in a text is true, including asking others and checking another source.

LA.A.2.1.5 use simple materials of the reference system to obtain information.

LA.A.2.2.3 recognize when a text is primarily intended to persuade.

LA.A.2.2.6 recognize the difference between fact and opinion presented in a text.

LA.A.2.2.7 recognize the use of comparison and contrast in a text. 
11. Use writing processes to communicate information, ideas, and concepts, in Portuguese, to a variety of audiences.

LA.B.1.1.1 make a plan for writing that includes a central idea and related ideas.

Course Number: 0713340 - Portuguese for Portuguese Speakers I

LA.B.1.1.2 draft and revise simple sentences and passages, stories, letters, and simple explanations that

- express ideas clearly:

. show an awareness of topic and audience;

- have a beginning, middle, and ending;

- effectively use common words;

. have supporting detail; and

- are in legible printing.

(Note: Handwritten documents should be created using legible cursive or manuscript handwriting, as appropriate.)

LA.B.1.1.3 produce final simple documents that have been edited for

. correct spelling;

- appropriate end punctuation;

. correct capitalization of initial words, "I," and names ofpeople;

. correct sentence structure; and

. correct usage of age-appropriate subject/verb and noun/pronoun

agreement.

(Note: In this course, documents should be edited for correct capitalization as appropriate for Portuguese.)

LA.B.2.1.1 write questions and observations about familiar topics, stories, or new experiences.

LA.B.2.1.3 use basic computer skills for writing, such as basic wordprocessing techniques such as keying words, copying, cutting, and pasting; using e-mail; and accessing and using basic educational software for writing.

LA.B.2.1.4 compose simple sets of instructions for simple tasks using logical sequencing of steps.

LA.B.2.2.1 write notes, comments, and observations that reflect comprehension of content and experiences from a variety of media.

LA.B.2.2.2 organize information using alphabetical and numerical systems. 


\section{APPENDIX I}

COURSE DESCRIPTION: HAITIAN CREOLE FOR HAITIAN CREOLE

SPEAKERS I 


\section{APPENDIX I}

1998

Florida Department of Education

COURSE DESCRIPTION - GRADES 9-12, ADULT

Subject Area: Foreign Languages

Course Number: 0700300

Course Title: Haitian Creole for Haitian Creole Speakers I

Credit: 1.0

A. Major Concepts/Content. The purpose of this course is to enable students whose heritage language is Haitian Creole to develop, maintain, and enhance proficiency in their home language by reinforcing and acquiring skills in listening, speaking, reading, and writing, including the fundamentals of Haitian Creole grammar. The course content will reflect the cultural values of Haitian Creole language and societies. The course will enable students to gain a better understanding of the nature of their own language as well as other languages to be acquired.

The content should include, but not be limited to, the following:

- conversational expression of feelings, ideas, and opinions in Haitian Creole

- comprehension of spoken and written Haitian Creole

- oral and written presentation of information and ideas, in Haitian Creole, to an audience

- social interaction patterns within Haitian Creole culture(s)

- connections between the Haitian Creole language and culture(s) and other disciplines

- analysis and use of different patterns of communication and social interaction appropriate to a given setting

- critical response, in Haitian Creole, to a variety of literary forms

- use of a variety of strategies to construct meaning from informative, technical, and literary texts

- use of writing processes to communicate information, ideas, and concepts, in Haitian Creole, to a variety of audiences

This course shall integrate the Goal 3 Student Performance Standards of the Florida System of School Improvement and Accountability as appropriate to the content and processes of the subject matter. Course student performance standards must be adopted by the district, and they must reflect appropriate Sunshine State Standards benchmarks.

Course Number: 0700300 - Haitian Creole for Haitian Creole Speakers I

B. Special Note. Course content requirements for the two-course sequence 
M/J Haitian Creole for Haitian Creole Speakers, Beginning (0703000) and Intermediate (0703010), are equivalent to Haitian Creole for Haitian Creole Speakers I (0700300). Course content requirements for the three-course sequence that includes M/J Haitian Creole for Haitian Creole Speakers, Beginning (0703000), Intermediate (0703010), and Advanced (0703020), may be equivalent to the twocourse sequence Haitian Creole for Haitian Creole Speakers I (0700300) and Haitian Creole for Haitian Creole Speakers II (0700310). It is each district school board's responsibility to determine high school foreign language placement policies for those students who complete the M/J Haitian Creole for Haitian Creole Speakers sequences in middle school.

The benchmarks for this course are aligned with expected levels of language proficiency and literacy, rather than grade levels. Students should be placed in heritage language courses as appropriate to their levels of language and literacy proficiency.

C. Course Requirements. These requirements include, but are not limited to, the benchmarks from the Sunshine State Standards that are most relevant to this course. Benchmarks correlated with a specific course requirement may also be addressed by other course requirements as appropriate. Some course requirements in this course are not fully addressed in the Sunshine State Standards.

Both Foreign Languages and Language Arts benchmarks are included in this course. The Language Arts benchmarks should not be taught and assessed in isolation; instead they should be combined with the Foreign Languages benchmarks listed for this course.

After successfully completing this course, the student will:

1. Engage in conversation in Haitian Creole to express feelings, ideas, and opinions about a variety of topics (e.g., social science, humanities, the mass media, current events, etc.).

FL.A.1.2.1 express likes or dislikes regarding various objects, categories, people, and events present in the everyday environment.

FL.A.1.2.2 exchange information necessary to plan events or activities (e.g., picnics, birthday parties, science projects, and crafts).

FL.A.1.3.3 use appropriate vocabulary and cultural expressions to express the failure to understand a message and to request additional information (i.e., understand how to bridge gaps in communication in the target language).

Course Number: 0700300 - Haitian Creole for Haitian Creole Speakers I

FL.A.1.3.4 use repetition, rephrasing, and gestures effectively to assist in communicating spoken messages.

FL.A.1.4.2 rephrase and use indirect expressions to communicate a 
message in the target language.

FL.A.2.1.2 restate and rephrase simple information from materials presented orally, visually, and graphically in class.

LA.C.1.1.4 retell specific details of information heard, including sequence of events.

LA.C.2.1.2 recognize simple nonverbal cues, such as use of eye contact, smiles, simple hand gestures.

2. Demonstrate understanding of spoken and written Haitian Creole on a variety of topics.

FL.A.2.2.2 answer or formulate questions about a variety of media experiences produced in the target language (e.g., video, radio, television, songs, or computer programs).

FL.A.2.2.3 organize information in spoken or written form about a variety of topics of academic and cultural interest (e.g., by making lists, categorizing objects, or organizing concepts).

FL.A.2.2.4 listen and read in the target language for leisure and personal enrichment (e.g., listen to, read, or view age-appropriate stories, plays, poems, films, or visual works of art).

FL.A.2.3.1 comprehend and interpret the content of authentic, written materials selected according to the familiarity of the topic and the scope of vocabulary and structure (e.g., personal letters and notes, pamphlets, newspapers and magazine articles, and advertisements).

FL.A.2.3.2 comprehend and interpret the main ideas and details from television, movies, videos, radio, or live presentations produced in the target language.

FL.A.2.3.3 formulate and answer questions about the literary elements (e.g., plot, characters, main ideas, and supporting details) of authentic target-language literary selections.

LA.C.2.1.1 determine the main idea in a nonprint communication.

3. Present information, concepts, and ideas to a variety of audiences through speaking and writing in Haitian Creole.

FL.A.3.2.1 describe important people (e.g., family members and friends) and objects present in his or her everyday environment and in school.

Course Number: 0700300 - Haitian Creole for Haitian Creole Speakers I

FL.A.3.2.3 give responses in spoken or written form (e.g., answering simple questions, formulating questions, and making simple statements) to age-appropriate stories, poems or other literature, songs, films, or visual works. LA.C.3.1.4 use eye contact and simple gestures to enhance delivery. 
LA.D.2.1.1 understand that word choice can shape ideas, feelings, and actions.

4. Demonstrate understanding of social interaction patterns within Haitian Creole culture(s) through participation in cultural

activities. (Note: Benchmarks may address multiple target cultures associated with the heritage language.)

FL.B.1.1.1 participate in age-appropriate cultural activities (e.g., games, songs, birthday celebrations, storytelling, dramatizations, and role playing).

FL.B.1.2.1 recognize various activities and celebrations in which children participate in the target culture (e.g., games, songs, birthday celebrations, storytelling, dramatizations, and role playing). FL.B.1.2.2 identify patterns of behavior and the values, beliefs, or viewpoints typical of children in the target culture.

FL.B.1.2.3 experience and react to expressive and day-to-day aspects of the target culture enjoyed or produced by groups or individuals who belong to the target culture (e.g., children's songs, simple selections from authentic children's literature, artwork, typical foods, and types of dwellings).

FL.B.1.3.1 use appropriate verbal and nonverbal communication for daily activities with peers and adults.

FL.B.1.3.3 recognize simple themes, ideas, or viewpoints on social behavior or social interaction in various settings (e.g., school, family, and immediate community).

5. Apply knowledge of Haitian Creole language and culture(s) to further knowledge of other disciplines.

FL.C.1.1.1 use simple vocabulary and phrases to identify familiar objects and concepts from other disciplines.

FL.C.1.1.2 participate in an activity in the target-language class that is based on a concept taught in a content class (e.g., shapes or relationships).

FL.C.2.1.1 use the target language to gain access to information that is only available through the target language or within the target culture (listen to a story told in the target language).

Course Number: 0700300 - Haitian Creole for Haitian Creole Speakers I

FL.C.2.2.2 access information from a skit or play in the target language that is only available in the target culture.

FL.C.2.2.3 express knowledge of real objects and media intended for same-age native speakers in the target language and identify the major elements of the source material (e.g., what it is, why peers use it, and where it might be found). 
FL.C.2.2.4 restate and share information acquired from written texts in the context of a group discussion.

6. Analyze and use different patterns of communication appropriate to the setting.

FL.D.1.1.1 know examples of word borrowing from one language to another.

FL.D.1.2.2 recognize the similarities and differences between his or her native language and the target language in terms of the pronunciation, alphabet, and forms of written expression.

FL.D.1.4.1 know elements of the target language that signify time, and the similarities and differences between comparable linguistic markers in the target language and in his or her own language.

(Note: In this course, students compare Haitian Creole and English.)

FL.D.1.4.2 understand and apply the target-language pronunciation, intonation, stress patterns, and writing conventions in a variety of contexts.

LA.D.1.1.1 recognize basic patterns in and functions of language (patterns such as characteristic sounds and rhythms and those found in written forms; functions such as asking questions, expressing oneself, describing objects or experience, and explaining).

LA.D.1.1.2 recognize the differences between language that is used at home and language that is used at school.

LA.D.2.1.3 recognize that use of more than one medium increases the power to influence how one thinks and feels.

7. Analyze and use different patterns of social interaction appropriate to the setting.

FL.D.2.2.1 distinguish the similarities and differences between the patterns of behavior of the target culture related to recreation, holidays, celebrations and the patterns of behavior of the local culture.

Course Number: 0700300 - Haitian Creole for Haitian Creole Speakers I

FL.D.2.2.2 recognize forms of the target language evident in the local culture (e.g., signs, symbols, advertisements, packages, displays, murals, songs, and rhymes).

FL.D.2.2.3 recognize some cultural aspects, viewpoints, and attitudes of people in both his or her own culture and the target culture relating to family, school, work, and play.

FL.D.2.3.1 understand cultural traditions and celebrations that exist in the target culture and in the native culture (e.g., holidays, birthdays, “coming of age” celebrations, and recreational 
gatherings).

FL.D.2.3.2 recognize the similarities and differences between music and songs from the target culture and those in the native culture.

FL.D.2.3.3 recognize the similarities and differences between attitudes about various topics found among teenagers in American culture and attitudes among teenagers in the target culture (e.g., surveys conducted through face-to-face contact or written exchanges).

8. Demonstrate knowledge of wider communities of Haitian Creole language and culture.

FL.E.1.2.1 know that many people in the United States use languages other than English on a daily basis.

FL.E.1.2.2 demonstrate an awareness of employment possibilities (and other applications) for those who are able to master the target language.

9. Respond critically to a variety of literary forms through speaking and writing in Haitian Creole.

LA.E.1.1.1 know the basic characteristics of fables, stories, and legends.

LA.E.1.1.2 identify the story elements of setting, plot, character, problem, and solution/resolution.

10. Use a variety of strategies to construct meaning from informative, technical, and literary texts written in Haitian Creole.

LA.A.1.1.2 identify words and construct meanings from text, illustrations, graphics, and charts using the strategies of phonics, word structure, and context clues.

LA.A.1.1.3 use knowledge of appropriate grade-, age-, and developmental-level vocabulary in reading.

Course Number: 0700300 - Haitian Creole for Haitian Creole Speakers I

LA.A.1.1.4 increase comprehension by rereading, retelling, and discussion.

LA.A.1.2.4 clarify understanding by rereading, self-correction, summarizing, checking other sources, and class or group discussion.

LA.A.2.1.1 determine the main idea or essential message from text and identify supporting information.

LA.A.2.1.3 read for information to use in performing a task and learning a new task.

LA.A.2.1.4 know strategies to use to discover whether information presented in a text is true, including asking others and checking another source. 
LA.A.2.1.5 use simple materials of the reference system to obtain information.

LA.A.2.2.3 recognize when a text is primarily intended to persuade.

LA.A.2.2.6 recognize the difference between fact and opinion presented in a text.

LA.A.2.2.7 recognize the use of comparison and contrast in a text.

11. Use writing processes to communicate information, ideas, and concepts, in Haitian Creole, to a variety of audiences.

LA.B.1.1.1 make a plan for writing that includes a central idea and related ideas.

LA.B.1.1.2 draft and revise simple sentences and passages, stories, letters, and simple explanations that

- express ideas clearly;

- show an awareness of topic and audience;

- have a beginning, middle, and ending;

- effectively use common words;

- have supporting detail; and

- are in legible printing.

(Note: Handwritten documents should be created using legible cursive or manuscript handwriting, as appropriate.)

LA.B.1.1.3 produce final simple documents that have been edited for

- correct spelling;

- appropriate end punctuation;

- correct capitalization of initial words, "I," and names of people;

• correct sentence structure; and

Course Number: 0700300 - Haitian Creole for Haitian Creole Speakers I

- correct usage of age-appropriate subject/verb and noun/pronoun agreement.

(Note: In this course, documents should be edited for correct capitalization as appropriate for Haitian Creole.)

LA.B.2.1.1 write questions and observations about familiar topics, stories, or new experiences.

LA.B.2.1.3 use basic computer skills for writing, such as basic word-processing techniques such as keying words, copying, cutting, and pasting; using e-mail; and accessing and using basic educational software for writing.

LA.B.2.1.4 compose simple sets of instructions for simple tasks using logical sequencing of steps.

LA.B.2.2.1 write notes, comments, and observations that reflect comprehension of content and experiences from a variety of media.

LA.B.2.2.2 organize information using alphabetical and numerical systems. 
VITA

EDWIN DAVID ARRIETA

January 21, 1972

1990

1998

1998- 2000

2001

2001-2006

2003-2007

2006-2009

2009-2010
Costa Rica

A.A., American Sign Language

Mount Aloysius College

Cresson, Pennsylvania

B.S., Secondary Education

Clarion University of Pennsylvania

Clarion, Pennsylvania

American Sign Language Instructor

Jupiter High School

Jupiter, Florida

M.S., Modern Languages

Florida International University

Miami, Florida

Foreign Language Instructor and Department Chair Boynton Beach High School

Boynton Beach, Florida

Adjunct Professor, Curriculum and Instruction

Florida International University

Miami, Florida

District Administrator and World Languages Supervisor

School District of Palm Beach County

Palm Beach, Florida

General Director

Falcon International School

Puntarenas, Costa Rica 